\title{
Urinary incontinence in nursing home care
}

Citation for published version (APA):

Saxer, S. (2008). Urinary incontinence in nursing home care. [Doctoral Thesis, Maastricht University]. Maastricht University. https://doi.org/10.26481/dis.20080911ss

Document status and date:

Published: 01/01/2008

DOI:

10.26481/dis.20080911ss

Document Version:

Publisher's PDF, also known as Version of record

\section{Please check the document version of this publication:}

- A submitted manuscript is the version of the article upon submission and before peer-review. There can be important differences between the submitted version and the official published version of record.

People interested in the research are advised to contact the author for the final version of the publication, or visit the DOI to the publisher's website.

- The final author version and the galley proof are versions of the publication after peer review.

- The final published version features the final layout of the paper including the volume, issue and page numbers.

Link to publication

\footnotetext{
General rights rights.

- You may freely distribute the URL identifying the publication in the public portal. please follow below link for the End User Agreement:

www.umlib.nl/taverne-license

Take down policy

If you believe that this document breaches copyright please contact us at:

repository@maastrichtuniversity.nl

providing details and we will investigate your claim.
}

Copyright and moral rights for the publications made accessible in the public portal are retained by the authors and/or other copyright owners and it is a condition of accessing publications that users recognise and abide by the legal requirements associated with these

- Users may download and print one copy of any publication from the public portal for the purpose of private study or research.

- You may not further distribute the material or use it for any profit-making activity or commercial gain

If the publication is distributed under the terms of Article $25 \mathrm{fa}$ of the Dutch Copyright Act, indicated by the "Taverne" license above, 
Urinary Incontinence in Nursing Home Care 
ISBN 978-3-033-01675-0

CSusi Saxer, Zürich 2008

Print Druckerei AG Suhr 


\title{
Urinary Incontinence in Nursing Home Care
}

\author{
Proefschrift
}

Ter verkrijging van de graad van doctor

aan de Universiteit Maastricht,

op gezag van de Rector Magnificius,

Prof. mr. G.P.M.F. Mols

volgens het besluit van het College van Decanen,

in het openbaar te verdedigen

op donderdag 11 September 2008 om 10.00 uur

door

Susanne Saxer 


\section{Promotores}

Prof. Dr. R.A. de Bie

Prof. Dr. T. Dassen, Charité - Universitätsmedizin Berlin, Germany

\section{Co-Promotor}

Dr. R.J.G. Halfens

\section{Beoordelingscommissie}

Prof. Dr. J. Hamers (voorzitter)

Prof. C. Lohrmann, Medizinische Universität Graz, Austria

Prof. Dr. T. van Achterberg, UMC St Radboud, Nijmegen

Prof. Dr. J. Schols

Dr. E. van Rossum 


\section{CONTENTS}

CHAPTER 1

Introduction

CHAPTER 2

Prevalence and incidence of urinary incontinence of Swiss nursing home residents at admission and after six, 12 and 24 months

ChAPTER 3

Risk factors for urinary incontinence in nursing home residents

CHAPTER 4

Assessment of nurses' knowledge and practice about urinary

incontinence in nursing home care

CHAPTER 5

Nurses'attitude and beliefs about urinary incontinence in

nursing home care

CHAPTER 6

Nurses'knowledge, beliefs, attitudes and self-reported practice

regarding urinary incontinence in nursing home care: a model

CHAPTER 7

General discussion

Summary

Samenvatting

Zusammenfassung

Acknowledgements

Curriculum vitae 


\section{CHAPTER 1}

Introduction 


\section{Introduction}

This thesis focuses on urinary incontinence in elderly people. During a traineeship in a nursing home, I noticed the frequent remarks of nurses about urinary incontinent residents, and therefore directed my attention to this phenomenon. Noticeable was that the patient documentation often showed that residents wear incontinence-pads, but the diagnosis 'urinary incontinence' was not made, and other remarks about urinary incontinence were often lacking as well. Not only was this information missing in the documentation, discussions with caregivers also did not bring new information about urinary incontinence of these residents. Sometimes it remained unclear whether these residents were wearing pads because they were incontinent or for their own 'security' or for the 'convenience' of caregivers. It remained open, whether it was lack of knowledge, lack of consciousness of the problem, negative attitude and beliefs about urinary incontinence, or lack of reporting. Therefore, this dissertation focuses on urinary incontinence of elderly people living in nursing homes.

In this introduction the definition, prevalence and incidence of urinary incontinence in nursing homes, the role of nurses in care of incontinent residents will be introduced and discussed, and the conceptual framework will be presented. First of all a short introduction to nursing homes in Switzerland will be given.

\subsection{Swiss nursing homes}

Nursing homes in Switzerland are facilities which provide professional assistance in activities of daily living with medical and nursing services when required. There are communal, municipal, cantonal and private nursing homes. The size of the nursing homes varies from 15-20 to 300 residents. The small ones are private nursing homes. Most nursing homes have approximately the same organisational format with a manager, and a medical and nursing head. In Swiss nursing homes the nursing department is organized with the head of the department, head of each ward and there are nurses on different levels, nurse assistants with one-year education and without education, and volunteers. The percentage of educated and not-educated nurses differs from one nursing home to the other and from private to communal or municipal nursing homes. In recent years an increasing number of nursing homes were joined together into one institution with one board. 
The situation in Canton Zurich is introduced in brief as an example of how long-term care in Switzerland is organized and structured. In 2006 the population in Canton Zurich was 1274384 . There were 248 long-term-care institutions which provide 16353 beds ( 81 beds/1000 persons $>65$ years). There are different long-term care institutions: 4 long-term care wards in hospitals, 174 old people's homes (for caredependent and un-dependent persons), and 70 nursing homes for care-dependent people (Gesundheitsdirektion Kanton Zürich, 2007).

The situation for nursing homes in the Canton Zurich is presented as follows: On January 1st there were 4827 residents in nursing homes, 3661 residents were admitted during 2006, and 3803 left the nursing homes. According to the BESAlevels 1-4 (BESA $=$ care-dependency level, 0 means no care is necessary and 4 is the highest possible level of care-dependency) 182 of the admitted residents were in BESA-level 0, 282 in BESA-level 1, 537 in BESA -level 2, 847 in BESA-level 3, 1625 in the BESA-level 4 and the BESA-level of 188 residents was unknown. On December 31st in the nursing departments there were 1688 nurses on different levels, 1135 nurse assistants with a 1-year-education and without, and 258 caregivers whose education was unknown. These were all full time jobs (Gesundheitsdirektion Kanton Zürich, 2007).

\subsection{Definition and prevalence}

Urinary incontinence is defined by the International Continence Society (ICS) as the complaint of any involuntary leakage of urine (Abrams et al. 2002). Urinary incontinence is usually subdivided into different types:

- $\quad$ "tress urinary incontinence is the complaint of involuntary leakage on effort or exertion, or on sneezing or coughing.

- $\quad$ Urge urinary incontinence is the complaint of involuntary leakage accompanied by or immediately preceded by urgency.

- $\quad$ Mixed urinary incontinence is the complaint of involuntary leakage associated with urgency and also with exertion, effort, sneezing or coughing.

- Continuous urinary incontinence is the complaint of continuous leakage.

- Extra-urethral incontinence is the observation of urine leakage through channels other than the urethra. 
- Uncategorized incontinence is the observation of involuntary leakage that cannot be classified into one of the above categories on the basis of signs and symptoms" (Abrams et al. 2002).

In nursing, a further important type as defined by ICS is used, namely 'functional incontinence'. Functional urinary incontinence means the inability of a usually continent person to reach the toilet in time that is to avoid involuntary leakage (Resnick, 1995, Fantl et al. 1996, NANDA, 2005).

Involuntary loss of urine is becoming an increasingly prevalent problem, especially in aging adults (Ostaszkiewicz et al. 2004, Wyman et al. 2004). Urinary incontinence substantially increases the risk of hospitalization and the risk of admission to a nursing home (Thom at al. 1997). Amongst elderly residents of long-term facilities, the prevalence rate of urinary incontinence ranges between 49 and $77 \%$ (Brandeis et al. 1997, Adelmann, 2004). Prevalence rates of UI depend on the population studied, different methods of data collection and/or different definitions of urinary incontinence. A relatively new study (Boyington et al. 2007) with more than 90000 residents from 7640 nursing homes in south-eastern US shows a prevalence rate of $65 \%$ at admission and $74 \%$ post-admission (most recent annual assessment). At admission there was no gender difference, but post-admission the prevalence of women was higher compared to men (75\% vs. $72 \%)$. Except for pressure ulcers, the prevalence of all co-morbid conditions (dementia, diabetes, stroke, bed mobile etc.) was higher post-admission compared to admission (Boyington et al. 2007). According to Nelson \& Furner (2005) dementia and advancing age were consistently associated with the development of incontinence, but the strongest associations were found in impairments of activity of daily living and the use of patient restraints. In the near future, the proportion of the population 65 years and older will increase in Switzerland (Swiss Federal Statistical Office, 2006), as in other European countries. An increase in handicaps and chronic diseases, and urinary incontinence is therefore expected as well.

Urinary incontinence is a burden for both residents and staff. Compared to continent residents, significantly higher percentages of incontinent respondents ( $>40$ years) reported feelings of depression, loneliness or sadness (Fultz \& Herzog, 2001). 
Heidrich \& Wells (2004) demonstrated that older community-dwelling women with urinary incontinence have significantly lower subjective health, purpose in life, affect balance, personal growth, positive reactions with others, and self-esteem and higher scores for depression, that persisted over time, compared to women without urinary incontinence. Temml at al. (2000) reported a negative effect on quality of life in $66 \%$ of women with urinary incontinence. A study with approximately 90000 nursing home residents demonstrated that urinary incontinence was significantly associated with worse quality of life in residents with moderate and functional impairments (DuBeau et al. 2006).

The direct and indirect costs associated with incontinence are considerable (Hu et al. 2004). In the United States the annual total costs of urinary incontinence in an institutional setting were estimated at $\$ 5.3$ billion. Routine care cost estimates range from $\$ 9$ to $\$ 17$ per day with a mean of $\$ 15$ per urinary incontinent resident per day and depending on severity of urinary incontinence (Hu et al. 2004). Although these results were not only from nursing home settings, the psychological and economic consequences nevertheless show the necessity of research also in a nursing home setting.

Contrary to known prevalence rates of urinary incontinence in nursing home populations in different countries, we do not know prevalence and incidence rates in Switzerland. Therefore the first part of the thesis focuses on assessing prevalence, incidence and risk factors in urinary incontinent nursing home residents. Included in this research project were patient characteristics like gender and age, because of contradictory results, especially in gender (Adelmann 2004, Aggazzotti at al. 2000), as well as other previously-identified risk factors (Boyington et al. 2007, Nelson \& Furner, 2005, Palmer et al. 1991, Ouslander ar al. 1993).

This research project assessing prevalence, incidence and risk factors of urinary incontinence included 42 nursing homes from the German-speaking part of northwestern Switzerland. There were communal, municipal, cantonal and private nursing homes. The organisational form and the staff of these nursing homes were different, and also the size of these nursing homes was different, ranging from 20 to more than 150 residents. 


\subsection{The role of nurses}

Nurses, together with other health care professionals, have a major responsibility in caring for incontinent residents. Therefore, it is important that nurses are familiar with evidence-based knowledge. Presumed knowledge about urinary incontinence contains many misconceptions, for example, that urinary incontinence is a normal part of ageing or the belief that residents are too old for treatment (Department of Health, 2000). Nurses must also have a positive attitude and belief regarding urinary incontinence and towards incontinent residents if good care of urinary incontinent residents is to be ensured. However attitudes and beliefs of nurses about urinary incontinence tend to be negative, for example hoping the problem will improve without intervention or low expectations of the benefits of treatment (Department of Health, 2000). In order to provide fitting support for nurses in urinary incontinence care, it is important to know exactly the deficits in nurses' knowledge and practice and understand the underlying mechanisms for the beliefs and attitudes. Therefore, the second part of this thesis deals with nurses' knowledge, practice, beliefs and attitudes regarding urinary incontinence, and the associations of knowledge, beliefs and attitude with continence-related practice.

The second research project about nurses' and nurse assistants' knowledge, practice, attitude and beliefs about urinary incontinence included the nurses and nurse assistants of the ten municipal nursing homes of Zurich. These municipal nursing homes are similar with respect to the residents, staff and management. The size of the nursing homes ranges from 36 to more than 300 residents.

\subsection{The conceptual framework}

Theoretical conceptualization to explain behaviours has been proposed by a wide range of disciplines including psychology, sociology, education, and health sciences. Grol et al. (2005) distinguish three categories of theories and models: theories on factors related to individual professionals, theories on the influence of social interaction and context, and theories on organizational and economic context. Especially the theories on factors related to individual professionals are important to describe the relationship between the concepts knowledge, beliefs, attitude and behaviour (practice) of nurses in urinary incontinence care. Even restricting to these theories, it is not possible within the context of this dissertation to give an exhaustive 
overview of all relevant theories. In general there are two theoretical approaches in describing (evidence based) behaviour of health care workers: theories which describe factors relevant for an individual to change behaviour and theories which describe the process of change of (evidence based) behaviour of health care workers. In this section, an example of each theoretical approach is described to provide a good overview of these theoretical approaches. First of all, the theory of reasoned action and planned behaviour (Ajzen \& Fishbein, 1980, Ajzen, 1985, Ajzen \& Madden, 1986) together with two models adapted from this theory, namely the Attitude-Social influences-self Efficacy (ASE) model (De Vries et al. 1988, De Vries \& Mudde, 1998), and the Integrated-change model (De Vries et al. 2003). The second theoretical approach describes the process people have to go through in order to change behaviour: the Innovation-Decision Process of Rogers (2003). Finally a third model will be discussed, since this model is the only model directly related to the knowledge, attitude and practice of nurses regarding urinary incontinence: The model of Henderson and Kashka (Henderson \& Kashka, 2000).

\subsubsection{The theories of reasoned action and of planned behaviour}

First the theory of reasoned action briefly is introduced. Next, the theory of planned behaviour which is an expansion of the theory of reasoned action will be described. Fishbein \& Aizen (1980) developed a model to predict behaviour (Fig. 1). The direct determinant of behaviour is the intention of a person to carry out the action or not. Intention is influenced by the attitude towards behaviour and the subjective norm. The theory allows good prediction in different areas of human behaviour. Nevertheless, the theory is limited when behaviour is not under complete deliberate control. Deliberate control means a person is free to really carry out the behaviour, when wanted. The circumstance of complete deliberate control dedicates the theory of planned behaviour (Ajzen, 1985, Ajzen \& Madden, 1986). 


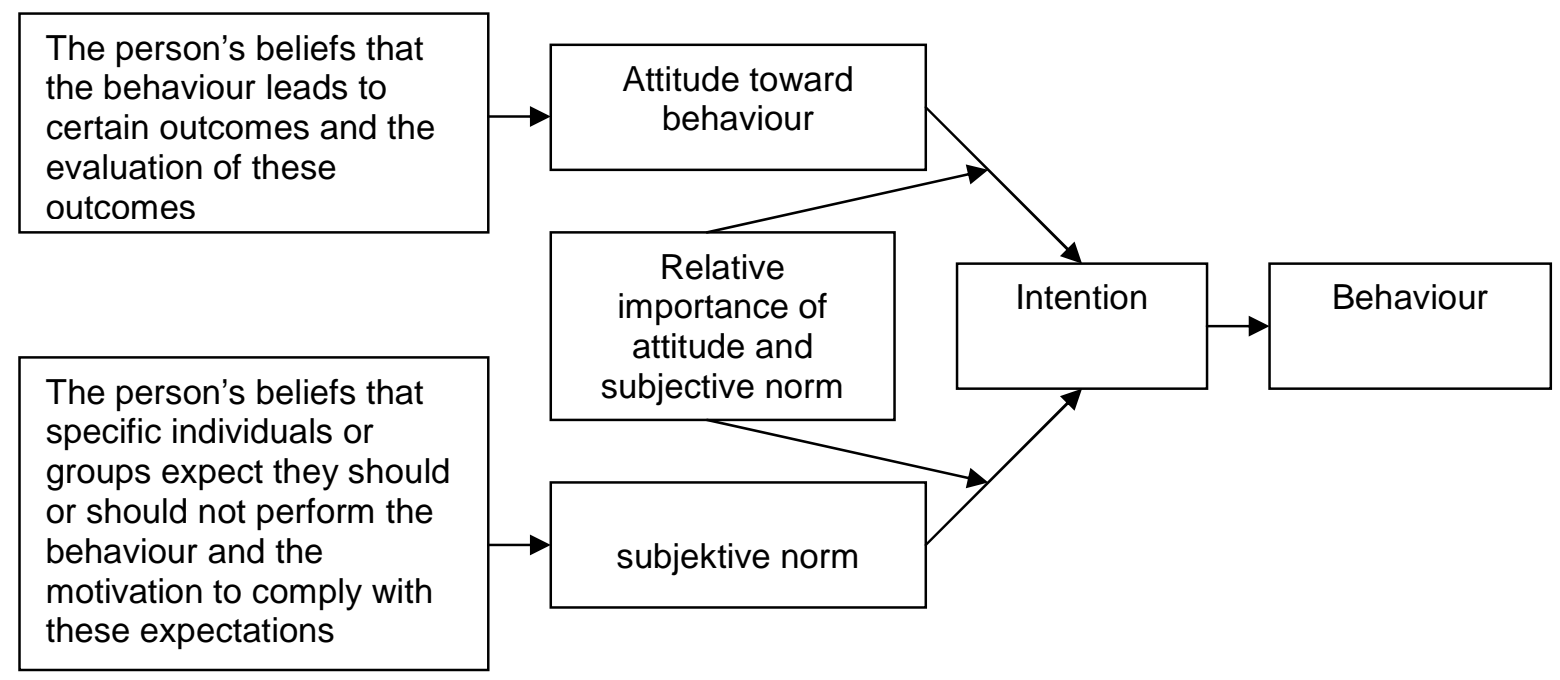

Fig. 1: Reasoned Action Model

Ajzen introduced the theory of planned behaviour by adding a new component 'perceived behavioural control', which has an influence on person's intention to perform behaviour (Ajzen, 1985, Ajzen \& Madden, 1986). Intention is the only determinant which influences behaviour in a direct way. However, intention is based on attitude toward the behaviour, subjective norm and perceived behavioural control (fig. 2). "Attitude towards behaviour is determined by the total set of accessible behavioural beliefs, while subjective norm is determined by the total set of accessible normative beliefs concerning the expectations of important referents, and perceived behavioural control is determined by the total set of accessible control beliefs" [W001]. Whether a person can carry out certain behaviours depends on the scope of actual behavioural control. According to Ajzen [W001], "actual behavioural control refers to the extent to which a person has the skills, resources, and other prerequisites needed to perform a given behaviour. Successful performance of the behaviour depends not only on a favourable intention but also on a sufficient level of behavioural control". 


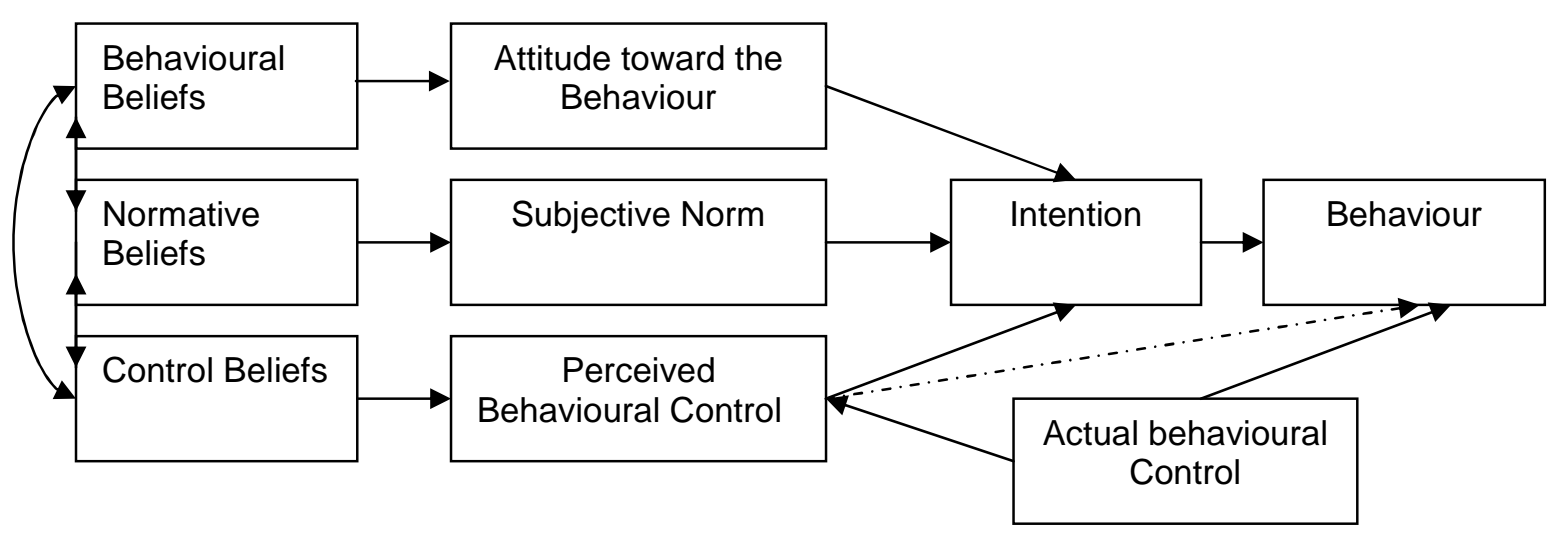

Fig. 2: Theory of planned behaviour

The concepts of the theory of planned behaviour are briefly defined:

- "Behaviour: is the manifest, observable response in a given situation with respect to a given target.

- Intention: is an indication of persons' readiness to perform a given behaviour, and it is considered to be the immediate antecedent of behaviour.

- Attitude toward the behaviour: is the degree to which performance of the behaviour is positively or negatively valued.

- Behavioural beliefs: link the behaviour of interest to expected outcomes. A behavioural belief is the subjective probability that the behaviour will produce a given outcome.

- Subjective norm: is the perceived social pressure to engage or not to engage in behaviour.

- Normative beliefs: refer to the perceived behavioural expectations of such important referent individuals or groups as the persons' family, friends, teachers or supervisors.

- Perceived behavioural control: refers to peoples' perception of their ability to perform a given behaviour.

- Control beliefs: have to do with the perceived presence of factors that may facilitate or impede performance of behaviour.

- Actual behavioural control: refers to the extent to which a person has the skills, resources, and other prerequisites needed to perform a given behaviour" [W001].

Another model derived of the theory of reasoned action is the Attitude - Social influences - self Efficacy model (ASE model). The ASE-model is one of the social cognition models commonly used in predicting and explaining health behaviour 
(Sandvik et al. 2007). The ASE-model has its origins in the theory of reasoned action (Fishbein \& Aizen, 1980) and Bandura's social cognitive theory (Bandura, 1976) and is closely related to the theory of planned behaviour (Ajzen, 1985). The ASE-model integrates two factors from Fishbein and Ajzen's theories (attitudes and subjective norms), which influence intention and behaviour with the self-efficacy concept from Bandura's social learning theory (Bandura, 1976). The concept of subjective norms in the theory of planned behaviour has been replaced with a broader definition of social influences in the ASE-model. According to the ASE-model (fig. 3), a person's attitude is a result of the expected consequences. Social influence is a result of relevant social norms, support or discouragement from important others. Self-efficacy is the result of a person's subjective assessment of his or her abilities and possibilities or can be seen as a person's belief. It is assumed that there is a direct influence of selfefficacy on behaviour. The implication of the model is that a person's behaviour can be modified by targeting attitudes, social influence and self-efficacy. External variables such as social-demographic factors do not influence behaviour directly, whereas behavioural determinants and intention do (De Vries et al. 1988, De Vries \& Mudde, 1998).

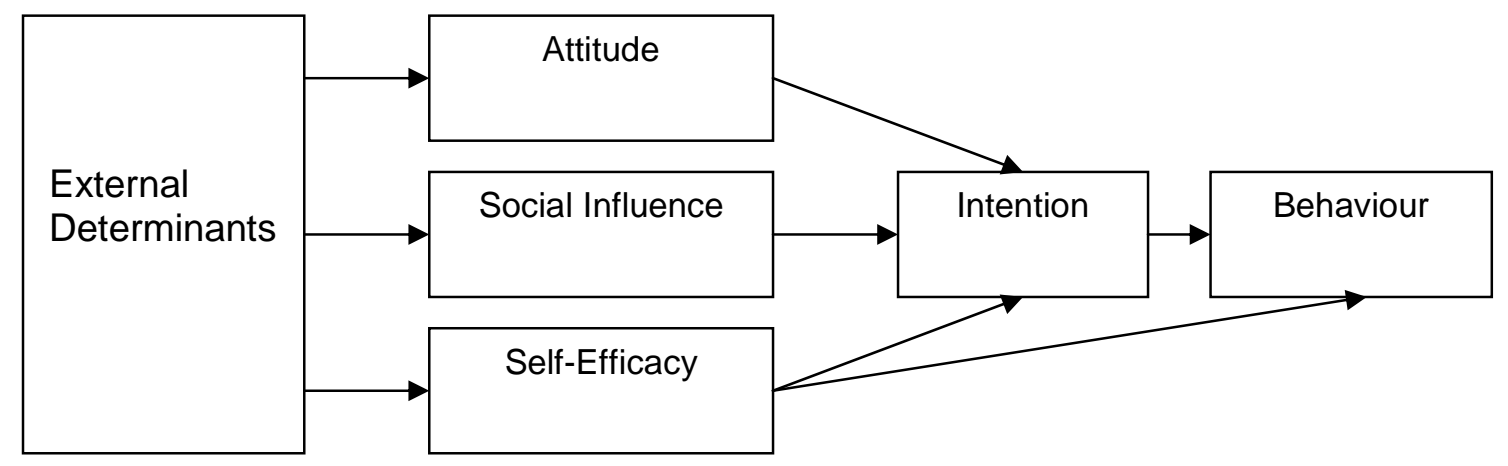

Fig. 3: Attitude-Social Influence-Self-Efficacy Model

Another model, which builds on the ASE-model, is the Integrated-Change model (Ichange model). This model differs from the ASE-model in that it also takes awareness factors (knowledge, risk perception and cues to action) and information factors (the quality, channel and source of information concerning the behaviour change) into account (Hoving et al. 2006). The l-change model distinguishes three phases in behavioural change processes, including a pre-motivation phase, motivation phase, and a post-motivation phase. According to Segaar et al. (2007) the 
model postulates that behaviour is the result of a person's intention, abilities, and barriers. Intentions are determined by attitudes, perceived social influences, and selfefficacy. Attitude is assumed to be the result of weighing the perceived advantages (pros) and disadvantages (cons) of the behaviour. The l-change model assumes that motivational factors are determined by various pre-motivational factors, namely, awareness factors (e.g. knowledge, cues to action), information factors (e.g. channel, source) and predisposing factors (e.g. behavioural factors, psychological factors).

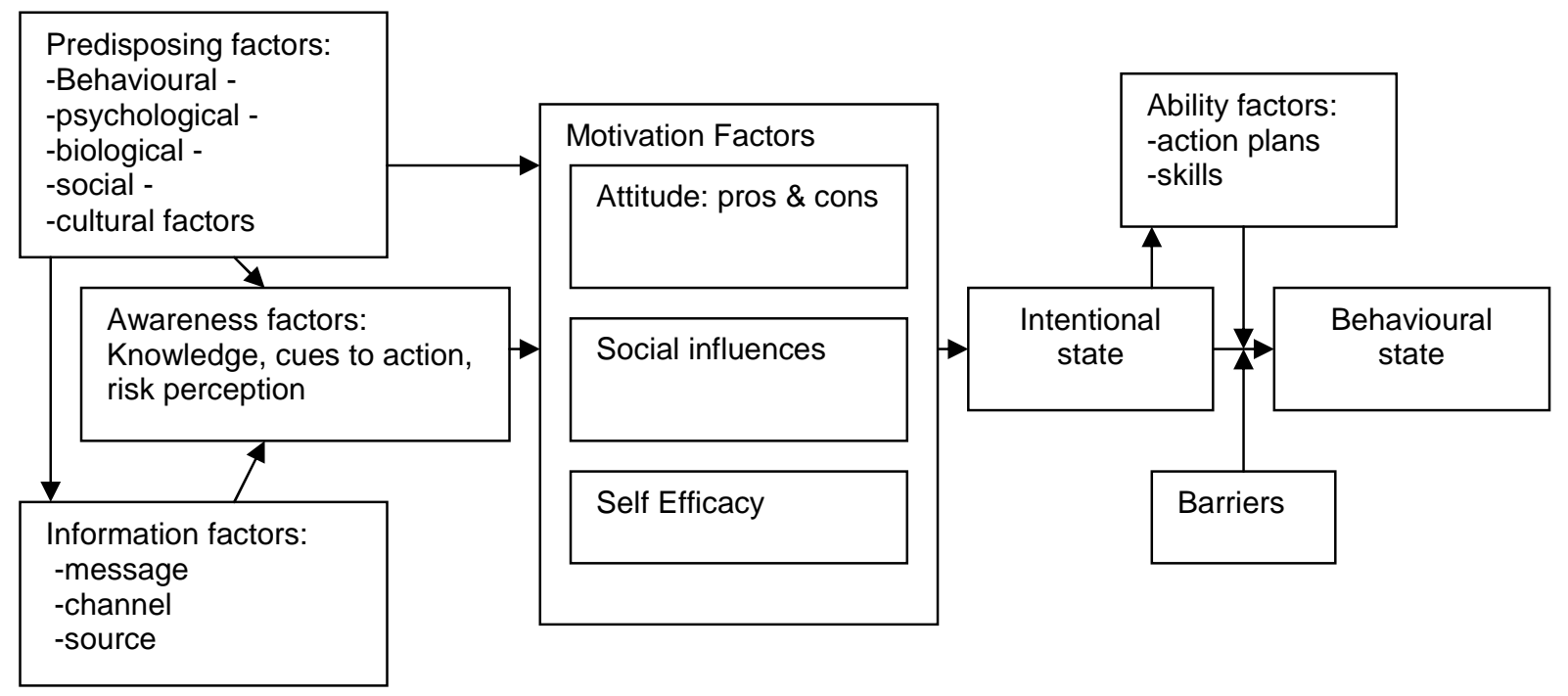

Fig. 4: Integrated Change model (De Vries et al. 2003)

\subsubsection{Innovation-decision process}

Rogers' innovation-decision process is a well-known model in nursing and other disciplines. As distinct from the previous presented theories which predict behaviour the innovation-decision process is a process through which an individual passes (1) from first knowledge of innovation, (2) to forming an attitude toward the innovation, (3) to a decision to adapt or reject, (4) to implementation of the new idea, and (5) confirmation of this decision (Rogers, 2003). The process contains different actions and choices over the time in which the individual undergoes this process. For Rogers (2003), the innovation-decision process involves five stages:

1. 'Knowledge occurs when an individual is exposed to an innovations' existence and gains some understanding of how it functions.

2. Persuasion occurs when an individual forms a favourable or unfavourable attitude towards the innovation. 
3. Decision occurs when an individual engages in activities that lead to a choice to adopt or reject the innovation.

4. Implementation occurs when an individual puts an innovation into use.

5. Confirmation occurs when an individual seeks reinforcement of an innovationdecision already made, or reverses a previous decision to adopt or reject the innovation if exposed to conflicting messages about the innovation" (Rogers, 2003, p. 171).

These stages typically follow each other in a time-ordered manner. Several comparable models are known in literature, for instance the model of Grol and Wensing (2004).

\subsubsection{Henderson and Kashkas Model}

Henderson and Kashka developed a model specific for the role of nurses with regard to urinary incontinence. In Henderson and Kashka's model (2000) knowledge and belief are related to attitude, and attitude is related to practice (fig. 5). In their research, they hypothesized that knowledge, attitude and belief would exert a direct, positive effect on practice. But they found no significant relationship between either knowledge or belief and practice, whereas there was a significant direct relationship between attitude and practice. Further analysis showed significant positive relationships between knowledge, belief and attitude. This finding led the researchers to propose a second model, which they examined. In this model, knowledge and belief were assumed to be related to attitude, and attitude related to practice (fig. 5) (Henderson \& Kashka, 2000). Henderson and Kashka was tested their model in a population of nurses who worked in different fields.

The concepts are defined as follows:

- "Knowledge is conceptualized as the comprehension and understanding of acquired facts or information about urinary incontinence in adults.

- Belief is understood as a theoretically conceptualized conviction or expectation regarding urinary incontinence in general.

- Attitude is seen as a predisposed perspective which influences nurses' thoughts, feelings, perceptions, and behaviours toward care of adults with urinary incontinence.

- Practice is defined as actions identified in the AHCPR guideline (Agency for Health Care policy and Research guideline)" (Henderson \& Kashka, 1999, 2000). 


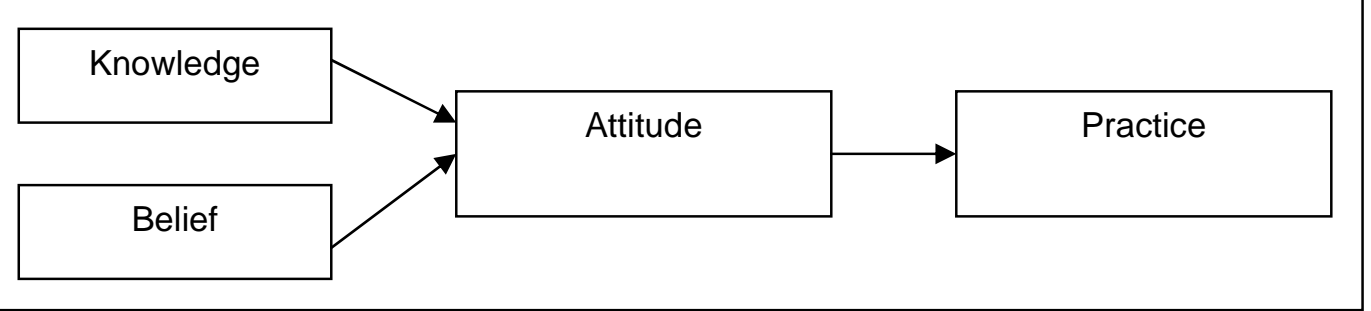

Fig. 5: Henderson's model (Henderson \& Kashka, 2000)

\subsubsection{The conceptual framework of this thesis}

The above-mentioned theories and models differ from each other in several aspects. Comparing the theory of reasoned action and planned behaviour and its successors with the model of Henderson and Kashka, the following main differences ca be distinguished:

1. The theory of reasoned action and planned behaviour describes and explains a specific behaviour, for instance giving an incontinent patient a pad or not, while the model of Henderson and Kashka explains urinary incontinence practice in general.

2. The model of Henderson and Kashka is specifically developed for practice regarding urinary incontinence, while the theory of reasoned action and planned behaviour can be used for all behaviour.

3. Knowledge is explicitly a factor in the model of Henderson and Kashka and not in the theory of reasoned action and planned behaviour.

4. Several factors in the theory of reasoned action and planned behaviour are missing in the model of Henderson and Kashka, for instance intention, subjective norms and perceived and actual behavioural control.

Rogers' innovation-decision process and Henderson's and Kashka's model differ also. The main differences are:

1. Rogers' model describes more the process a person goes through when changing behaviour, while Henderson's and Kashka's model describes the factors related to practice in urinary incontinence.

2. The model of Henderson and Kashka is specifically developed for practice regarding incontinence, while Rogers' model can be used for all behaviour.

3. Rogers' model is more elaborated. It also distinguishes a decision of the person to engage in the activity or not, which can be compared with intention 
in the theory of reasoned action and planned behaviour. Rogers' model also distinguishes the confirmation phase in which the individual seeks reinforcement for the practice.

Based on these differences, it was decided to use the model of Henderson and Kashka for the following reasons:

1. The model is specific developed for incontinence.

2. The model explicitly includes knowledge.

3. Henderson's and Kashka's model explains urinary incontinence practice in general and not a specific behaviour.

4. A questionnaire exists regarding the concepts in this model.

5. Henderson and Kashka found good results for their model, although it is a more simple model that the other ones.

\subsection{Outline of the thesis}

To achieve a better understanding of urinary incontinence in nursing home care, this thesis consists of two research projects. The first project is focused on prevalence, incidence and risk factors of incontinent nursing home residents (chapter 2-3). The second project aims at nurses' knowledge, practice, beliefs and attitudes regarding urinary incontinence (chapter 4-6).

Chapter 2 entitled "Prevalence and incidence of urinary incontinence of Swiss nursing home residents at admission and after 6, 12 and 24 months" presents secondary analyses of the data of the Minimum Data Set of the Resident Assessment Instrument 2.0. Special focus was placed on sex- and age-related differences.

Chapter 3 describes the association between the potential risk factors 'cognitive abilities and mobility' and urinary incontinence in nursing home residents older than 65 years at the time of admission and in the course of a longitudinal run.

Chapter 4 presents the development and testing of the Urinary Incontinence Practice and Knowledge Scale, designed to survey nurses' knowledge and practice. This 
article also addresses nurses' knowledge and practice concerning urinary incontinence in a nursing home setting.

Chapter 5 describes the translation, pre-test and validation of Henderson's Urinary Incontinence Attitude and Beliefs Scale and explore nurses' attitude and beliefs regarding urinary incontinence in nursing home residents.

Chapter 6 presents the association between knowledge, attitudes and beliefs regarding urinary incontinence with self-reported continence-related practice.

Chapter 7 summarizes and discusses the results of the study projects, discusses results of chapter 6 with Henderson's and Kashka's model and other models, which are described in the introduction and proposes recommendations for practice and further research.

This thesis is based on articles published in or submitted for publication to scientific journals which were written to be read independently. Some overlap between the chapters is therefore inevitable. 


\section{References}

Abrams, P., Cardozo, L., Fall, M., Griffiths, D., Rosier, P., Ulmsten, U., van Kerrebroeck, P., Victor, A., Wein, A. (2002). The standardisation of terminology of lower urinary tract function: Report from the standardisation sub-committee of the International Continence Society. Neurourology and Urodynamics, 21, 167-178.

Adelmann, PK. (2004). Prevalence and detection of urinary incontinence among older medicaid recipients. Journal of Health Care for Poor and Underserved, 15, 99-112.

Aggazzotti, G., Pesce, F., Grassi, D., Fantuzzi, G., Righi, E., De Vita, D., SantaCroce, S., Artibani, W. (2000). Prevalence of urinary incontinence among institutionalized patients: A cross-sectional epidemiological study in a midsized city in northern Italy. Urology, 56, 245249.

Ajzen, I., \& Fishbein, M. (1980). Understanding Attitudes and Predicting Social Behavior. NJ: Prentice-Hall.

Ajzen, I. (1985). From intentions to actions: a theory of planned behaviour. In Kuhl, J., \& Beckmann, J. (Eds). Action control: Form cognition to behaviour. Berlin: Springer.

Ajzen, I., \& Madden, TJ. (1986). Predicted of goal directed behaviour: attitudes, intentions, and perceived behavioral control. Journal of Experimental Social Psychology, 22, 453-474.

Bandura, A. (1976). Social Foundations of Thought and action: A Social Cognitive Theory. Eaglewood Cliffs, New York: Prentice-Hall.

Boyington, JEA., Howard, DL., Carter-Edwards, L., Gooden, KM., Erdem, N., Jallah, Y., Busby-Whitehead, J. (2007). Differences in resident characteristics and prevalence of urinary incontinence in nursing homes in Southeastern United States. Nursing Research, 56, 97107.

Brandeis, GH., Baumann, MM., Hossain, M., Norris, JN., Resnick, NM. (1997). The prevalence of potentially remediable urinary incontinence in frail older people: A study using the minimum Data set. Journal of the American Geriatrics Society, 45, 179-184.

Deparment of Health (2000). Good practice in continence services. DoH, London http://www.dh.gov.uk/en/Publicationsandstatistics/Publications/PublicationsPolicyAndGuidan $\mathrm{ce} / \mathrm{DH} 4005851$

De Vries, H., Dijkstra, M., Kuhlmann, P. (1988). Self-efficacy the third factor besides attitude and subjective norm as a predictor of behavioural intention. Health Education Research, 3, 273-282.

De Vries, H. \& Mudde, AN. (1998). Predicting stage transitions for smoking cessation applying the attitude-social influences-efficacy model. Psychosocial Health, 13, 369-385.

De Vries, H., Mudde, A., Leijs. I., Charlton, A., Vartiainen, E., Buijs, G., et al. (2003). The European Smoking Prevention Framework Approach (EFSA). An example of integral prevention. Health Education Research, 18, 611-626.

DuBeau, CE., Simon, SE., Norris, JN. (2006). The effect of urinary incontinence on quality of life in older nursing home residents. Journal of the American Geriatrics Society, 54, 13251333. 
Fantl, JA., Newman, DK., Colling, J., DeLancey, JOL., Keeys, C., Loughery, R., et al. Urinary Incontinence in Adults: Acute and chronic Management. Cinical Practice Guideline, No. 2, 1996 update. Department of Health and Human Services, Public Health Service, Agency for 367-374. Halth Care Policy and Research. AHCPR Publication No. 96-0682: Rockville.

Fultz, NH., \& Herzog, R. (2001). Self-reported social and emotional impact of urinary incontinence. Journal of the American Geriatrics Society, 49, 892-899.

Gesundheitsdirektion Kanton Zürich (2007). Langzeitversorgung Kenndaten 2006. Hrsg. Gesundheitsdirektion Kanton Zürich.

Grol, R., Wensing, M. (2004). What drives change? Barriers to and incentives for achieving evidence-based practice. MJA, 180, S57-S60.

Grol, R., Wensing, M., Eccles, M. (2005). Improving patient care: The implementation of change in clinical practice. Edinburgh: Elsevier.

Heidrich, SM., \& Wells, TJ. (2004). Effects of urinary incontinence: Psychological well-being and distress in older community-dwelling women. Journal of Gerontological Nursing, 30, 4754.

Henderson, JS., \& Kashka, MS. (1999). Development and testing of the urinary incontinence scales. Urologic Nursing, 19, 109-119.

Henderson, JS., \& Kashka, MS. (2000). Effect of knowledge, attitude, and belief on nurses' practice regards urinary incontinence in adults. Urologic Nursing, 20, 291-305.

Hoving, EF., Mudde, AN., de Vries, H. (2006). Smoking and the $\varnothing$ pattern; predictors of transitions through the stage of change. Health Education Research, 21, 305-314.

Hu, TW., Wagner, TH., Bentkover, JD., Leblanc, K., Zhou, SZ., Hunt, T. (2004). Costs of urinary incontinence and overactive bladder in the United States: a comparative study. Urology, 63, 461-465.

NANDA International (2005). NANDA-Pflegediagnosen: Definition und Klassifikation 20052006. Bern: Verlag Hans Huber.

Nelson, RL. \& Furner, SE. (2005). Risk factors for the development of fecal and urinary incontinence in Wisconsin nursing home residents. Maturitas, 52, 26-31.

Ouslander, JG., Palmer, MH., Rovner, BW., German, PS. (1993). Urinary incontinence in nursing homes: Incidence, remission and associated factors. Journal of the American Geriatrics Society, 41, 1083-9.

Ostaszkiewicz, J., Johnston, L., Roe, B. (2004). Habit retraining for the management of urinary incontinence in adults. The Cochrane Database of Systematic Reviews 2004, Issue 2. Art. No.: CD002801.pub2. DOI: 10.1002/14651858.CD002801.pub2.

Palmer, MH., German, PS., Ouslander, JG. (1991). Risk factors for urinary incontinence one year after nursing home admission. Res Nurs Health, 14, 405-12.

Resnick, NM. (1995). Urinary incontinence. Lancet, 346, 94-99.

Rogers, EM. (2003). Diffusion of Innovations. $5^{\text {th }}$ ed. New York: The Free Press. 
Sandvik, C., Gjestad, R., Brug, J., Rasmussen, M., Wind, M., Wolf, A., et al. (2007). The application of a social cognition model in explaining fruit intake in Austrian, Norwegian and Spanish schoolchildren using structural equation modelling. International Journal of Behavioral Nutrition and Physical Activity, 4:57 doi:10.1186/1479-5868-4-57.

Segaar, D., Willemsen, MC., Bolman, C., de Vries, H. (2007). Nurse adherence to a minimalcontact smoking cessation intervention on cardiac wards. Research in Nursing \& Health, 30, 429-444.

Swiss Federal Statistical Office (2006). Taschenstatistik der Schweiz. Bern: Bundesamt für Statistik, Sektion Diffusion und Amtspublikationen.

Temml, C., Haidinger, G., Schmidbauer, J., Schatzl, G., Madersbacher, S. (2000). Urinary incontinence in both sexes: Prevalence rates and impact on quality of life and sexual life. Neurourology and Urodynamics, 19, 259-271.

Thom, DH., Haan, MN., Van Den Eden, SK. (1997). Medically recognized urinary incontinence and risks of hospitalization, nursing home admission and mortality. Age and Ageing, 26, 367-374.

Wyman, JF., Bliss, DZ., Dougherty, MC., Gray, M., Kaas, M., Newman, DK., Palmer, MH., Wells, TJ. (2004). Shaping future directions for incontinence research in aging adults: Executive Summary. Nursing Research (Supplement), 53, S1-S10.

[W001]: http://www.people.umass.edu/aizen/tpb.diag.html\#null-link (7.3.08)

[W002]: http://people.umass.edu/aizen/faq.html (7.3.08) 


\section{CHAPTER 2}

Prevalence and incidence of urinary incontinence of Swiss nursing home residents at admission and after six, 12 and 24 months

Susi Saxer, Ruud J.G. Halfens, Rob A. de Bie, Theo Dassen (2008). Journal of Clinical Nursing, doi:10.1111/j.1365-2702.2007.02055.x 


\title{
Prevalence and incidence of urinary incontinence of Swiss nursing home residents at admission and after six, 12 and 24 months
}

\author{
Abstract: \\ Aims and objectives: To study the prevalence and incidence of urinary incontinence \\ in a Swiss nursing home population at admission and at six, 12, 18 and 24 months \\ after admission.
}

Background: No prevalence data for urinary incontinence in people older than 65 living in nursing homes are available in Switzerland and other German-speaking parts of Europe. Prevalence of urinary incontinence elsewhere varies between 49 $77 \%$.

Methods: This is a secondary analysis of the data of the Minimum Data Set of the Resident Assessment Instrument 2.0 in which 2719 residents were assessed. Prevalence rates and incidence were calculated at admission and at six, 12, 18 and 24 months after admission. Special focus was placed on sex- and age-related differences.

Results: Prevalence of urinary incontinence was 51.5\% (men 51.4\%, women 51.5\%) and was found to rise with increasing age. At the time of admission, $37 \%$ (men $43 \%$, women 34\%) were urinary incontinent. The prevalence increased from admission to 24 months after admission.

Conclusion: The high prevalence rates indicate the relevance of the problem for residents and caregivers alike. Early identification of individuals likely to become incontinent is crucial in the development of interventions and the prevention of urinary incontinence in this vulnerable population.

Relevance to clinical practice: The study provides valuable data about the extent of the problem of urinary incontinence in nursing homes.

\section{Key words}

Geriatric patients, incidence, nursing homes, prevalence, Switzerland, urinary incontinence 


\section{INTRODUCTION}

Urinary incontinence is a serious and costly problem of residents in nursing homes. Due to incontinence, the independence and self-esteem of older people are limited and social activities are restricted. Urinary incontinence determines to a high degree the care- dependence of older people in nursing homes (Welz-Barth et al. 1998). When care dependence increases and so does the overall cost of care.

The prevalence of urinary incontinence in people older than 65 living in nursing homes varies between 49 - 77 \% (Borrie \& Davidson 1992, Brandeis et al. 1997, Aggazzotti et al. 2000, Adelmann 2004). The variation in prevalence rates can be explained by differences in studied populations, different methods of data collection and different definitions of urinary incontinence. Highest and lowest prevalence rates are from the US and the others are from England and Italy, therefore the influence of nationality or policy does not seem likely. The studies by Palmer et al. 1991 and Ouslander et al. 1993 report the prevalence of urinary incontinence at admission to be $39 \%$.

Several patient characteristics seem related to urinary incontinence. Different studies have found a relation with age (Aggazzotti et al. 2000, Adelmann 2004). Stothers et al. (2005) also observed an increasing prevalence of urinary incontinence with increasing age, but only in men.

Aggazzotti et al. (2000) found that women suffer more often from urinary incontinence than men. On the other hand, Borrie \& Davidson (1992) and Adelman (2004) did not find significant gender-related differences. Ouslander et al. (1993) also did not find gender-related differences in the prevalence of daytime urinary incontinence at admission, however differences in urinary incontinence were observed between men and women two months and one year after admission.

It seems that prevalence of urinary incontinence increases in nursing homes after admission. Palmer et al. (1991) demonstrated a significant increase in prevalence of urinary incontinence during the time of two weeks to two months and to one year after admission. These results were confirmed by Ouslander et al. (1993).

Most studies about urinary incontinence prevalence thus far have been limited by the number of residents included and the cross-sectional design of the studies. Additionally, results of various research projects about gender-related differences are contradictory. More information based on longitudinal studies is needed about the development of urinary incontinence during the early time in a nursing home. This 
information gives more knowledge about which group of residents is most affected by urinary incontinence and during which period of their stay in a nursing home, since this knowledge enables nursing staff to focus more specifically on those that needing incontinence care.

The purpose of this study is to investigate the prevalence and incidence of urinary incontinence in elderly residents aged 65 and older, living in Swiss nursing homes. Special attention is paid to differences in gender and age.

\section{METHODS}

\section{Design}

A secondary analysis using data from the Minimum Data Set of the Resident Assessment Instrument 2.0 (RAl 2.0). The Minimum Data Set of the Resident Assessment Instrument is normally used in nursing homes for nursing planning, quality management and resource management (Garms-Homolova \& Gilgen, 2000). The Minimum Data Set consists of 16 areas including the usual problem areas of nursing home residents (e.g. cognitive abilities, activities of daily living). The following items of the Minimum Data Set are included in this research:

- Urinary incontinence: Urinary incontinence is defined as at least two episodes of involuntary loss within one week. Residents with a catheter are considered to be continent. Hardly any residents in Swiss nursing homes have a catheter, incontinent nursing home residents wear pads.

- Demographic data: Gender, age and time of admission.

The instrument was developed in the United States between 1987 - 1991 and tested in detail (Hawes et al. 1997). Currently, over $90 \%$ of the US nursing homes use the Resident

Assessment Instrument (Hawes et al. 1997). It has been translated into different languages and nursing homes in 15 different countries now use the instrument.

The reliability of the different subscales of the Minimum Data Set has been tested and established in several studies. Hawes et al. (1995) found an interrater reliability of the two items bowel and bladder incontinence of the subscale incontinence of 0.91. Crooks et al. (1995) examined the relationship between the subscale incontinence severity ratings and direct measures of incontinence frequency. There was a statistically-significant correlation $(r=0.49 ; p \leq 0.001)$ between research staff 
wetness checks and the Minimum Data Set ratings, but no significant relation to wetness checks performed by nursing staff $(r=0.003 ; p<0.914)$. There was a wide variability within and between the nursing homes in the correlation. Only two out of nine nursing homes had no significant correlation between the wet rates and the Minimum Data Set ratings.

\section{Sample}

The study sample consists of data of all residents from forty-two different geriatric and nursing homes in north western Switzerland. Thirty-five nursing homes lie in the canton Solothurn, six in the canton Aargau and one in the canton Bern. Nursing homes in Switzerland provide supervision and assistance in activities of daily living as well as medical and nursing services and are usually organised in a primary nursing system. The residents are nursed by registered nurses, nurse assistants or auxiliary nurses. The continence care in these nursing homes is variable. All residents in the sample are older than 65 years and physically and/or cognitively impaired in different grades.

The investigation period started in January 1999 in five of the geriatric and nursing homes and January 2000 in 37 of the homes and ended in June 2002 for all homes. Four different samples are available for the analyses:

- Point prevalence: On a fixed date in 2002, urinary incontinence among 2610 nursing home residents was assessed;

- Prevalence at admission: These data were available for 2719 residents entering the nursing home between 1999 to June 2002;

- Incidence for the period of 12 months: 788 residents' data are available for a period from admission to 12 months after admission. The missing 1931 residents resulted from: 1137 (42\%) residents had died, had left the nursing homes or had entered another institution (920 from admission to the $6^{\text {th }}$ month and 217 from $7^{\text {th }}$ to the $12^{\text {th }}$ month). 669 residents (25\%) were admitted to the nursing homes after July 2001 and finally $125(5 \%)$ are true missing data;

- Incidence for the period of 24 months: 282 residents' data are available for a period from admission to 24 months after admission. The missing 2437 resulted from: 1337 (49\%) residents had died, had left the nursing homes or had entered another institution (920 from admission to the sixth month, 217 from seventh to the twelfth month, 122 from thirteenth to the eighteenth month 
and 78 from nineteenth to the twenty-fourth month). 1043 residents (38\%) were admitted to the nursing homes after July 2000 ( 403 after January 2002, 266 after July 2001, 199 after January 2001, 175 after July 2000) and finally $57(2 \%)$ are true missing data.

\section{Data collection}

Nursing home residents are routinely assessed at admission and every 6 months post-admission. Assessments were carried out by nurses in collaboration with doctors and physiotherapists. All nurses had undergone at least 1.5 days of training to correctly assess urinary incontinence using the Minimum Data Set.

All retrieved data were anonymous and were provided for this research by the firm QSys AG. This firm is responsible for the introduction, education and quality management of this instrument in Switzerland. The director of each nursing home gave the researchers written consent.

To ascertain reliability, data collection only started after all nurses had been trained to assess urinary incontinence using the Minimum Data Set. Furthermore, the nursing homes included in this study had a minimum of one year experience with this instrument. The 42 included nursing homes met all these criteria.

The assessments of the residents were made at admission and then at half-year intervals, or more frequently if the conditions of the residents changed. Here we report only the assessments at admission and half-year intervals up to two years postadmission.

\section{Data analysis}

Data analysis was performed in SPSS 11.0. Analysis included calculation of the point prevalence of urinary incontinence and the prevalence of urinary incontinence at admission. The data at admission and six, 12, 18 and 24 months after admission were used to calculate the incidence.

The chi-square test was employed to evaluate the association between age and urinary incontinence and the difference between women and men (prevalence of urinary incontinence at a specific point in time and admission). A probability value of $<0.01$ was taken to denote statistical significance. Gender and age group differences were analysed with the chi-square test (prevalence in course of time during 12 and 
24 months) with a Bonferroni correction: $p<0.0025$ was used as the level of significance.

\section{RESULTS}

\section{Point prevalence of urinary incontinence}

Table 1 shows the point prevalence of urinary incontinence in the groups of all residents, men and women. It shows that $51.5 \%$ of the residents are urinary incontinent. Women and men are equally affected by incontinence $(p=0.957)$, while the prevalence rises with increasing age. The chi-square tests show a significant association between age and urinary incontinence in the total of residents $(p<$ $0.0001)$ and in women $(p=0.005)$; in men the association is not significant $(p=0.244)$.

Table 1: Point-prevalence of urinary incontinence of residents in Swiss nursing homes in 2002

\begin{tabular}{llll}
\hline Age (sample) & All residents (UI) & Men (UI) & Women (UI) \\
& Abs (\%) & Abs (\%) & Abs (\%) \\
\hline Age $65-<75(\mathrm{~N}=242$, men 100, women 142) & $110(45.5 \%)$ & $44(44 \%)$ & $66(46.5 \%)$ \\
Age $75-<85(\mathrm{~N}=882$, men 251, women 631) & $442(50.1 \%)$ & $133(53 \%)$ & $309(49 \%)$ \\
Age $85-<95(\mathrm{~N}=1258$, men 254, women 1004) & $649(51.6 \%)$ & $130(51.2 \%)$ & $519(51.7 \%)$ \\
Over $95(\mathrm{~N}=228$, men 37, women 191) & $143(62.7 \%)$ & $23(62.2 \%)$ & $120(62.8 \%)$ \\
Total (N=2610, men 642, women1968) & $1344(51.5 \%)$ & $330(51.4 \%)$ & $1014(51.5 \%)$
\end{tabular}

\section{Prevalence of urinary incontinence at admission}

In the period from 1999 or 2000 - June 2002, 2719 residents entered the nursing homes, 910 men and 1809 women.

Table 2 shows that at admission, 36.8\% of the residents were incontinent. Women were less urinary incontinent than men (43 versus 34\%; $p<0.0001$ ). No significant difference is found between the different age groups, either within the total group or among women and men ( $\mathrm{p}=0.639 ; 0.444 ; 0.553$, respectively). 
Table 2: Prevalence of urinary incontinence at admission of all residents, men and women

\begin{tabular}{llll}
\hline Age (sample) & All residents (UI) & Men (UI) & Women (UI) \\
& Abs (\%) & Abs (\%) & Abs (\%) \\
\hline Age 65 - <75 (N=288, men 140, women 148) & $98(34 \%)$ & $55(39.3 \%)$ & $43(29.1 \%)$ \\
Age $75-<85(\mathrm{~N}=991$, men 362, women 629) & $376(37.9 \%)$ & $165(45.6 \%)$ & $211(33.5 \%)$ \\
Age $85-<95(\mathrm{~N}=1213$, men 359, women 854) & $441(36.3 \%)$ & $155(43.2 \%)$ & $286(33.5 \%)$ \\
Over $95(\mathrm{~N}=227$, men 49, women 178) & $86(37.9 \%)$ & $19(38.8 \%)$ & $67(37.6 \%)$ \\
Total $(\mathrm{N}=2719$, men 910, women 1809) & $1001(36.8 \%)$ & $394(43.3 \%)$ & $607(33.6 \%)$
\end{tabular}

\section{Development of urinary incontinence: Incidence during 12 and 24 months after admission}

Data of 788 residents are available for a period of 12 months and data of 282 residents for a period of 24 months. Table 3 shows the distribution in gender and age groups.

Table 3: Distribution in gender and age groups

\begin{tabular}{lllll}
\hline & Men & Women & Age < 85 & Age 85, >85 \\
& Abs (\%) & Abs (\%) & Abs (\%) & Abs (\%) \\
\hline Time period over 12 months & $225(28.6 \%)$ & $563(71.4 \%)$ & $327(41.5 \%)$ & $461(58.5 \%)$ \\
Time period over 24 months & $81(28.7 \%)$ & $201(71.3 \%)$ & $122(43.3 \%)$ & $160(56.7 \%)$ \\
\hline
\end{tabular}

Incidence stratified for gender

Fig. 1 shows that the incidence of urinary incontinence increases by $15 \%$ from admission to the twelfth month in the group for whom data are available over the first 12 months. This holds for both women and men (17\% versus $12 \%)$. At admission, the prevalence for women was 32\%, after 6 months $42 \%$ and after 12 months $49 \%$. However for men the prevalence at admission was $45 \%$, after six months $48 \%$ and after 12 months $57 \%$. At admission there is a significant difference between urinary incontinent men and women $(p=0.001)$. In contrast to the findings at admission, no significant differences exist at six and 12 months after admission. 
Fig. 2 shows that the incidence increases by $26 \%$ during the period of 24 months in the group for whom data are available over 24 months. For men, the incidence increases by $27 \%$, for women by $29 \%$. No gender-significant differences are found between urinary incontinence at the five points in time. At admission the prevalence for women was 33\%, after six months $42 \%$, after 12 months $51 \%$, after 18 months $54 \%$ and after 24 months 62\%. However, for men the prevalence at admission was 40\%, after six months 44\%, after 12 months 47\%, after 18 months 53\% and after 24 months $57 \%$.

\section{Incidence stratified for age groups}

Fig. 3 shows the incidence of urinary incontinence split into two age groups (less than 85 or 85 and older) from admission to the twelfth month. It shows that the residents '85 and older' have less urinary incontinence than the younger residents at each point in time. However, these differences are not significant. At admission the prevalence for residents <85 years was 40\%, after six months $47 \%$ and after 12 months $53 \%$. However for residents $>85$ years the prevalence at admission was $33 \%$, after 6 months $41 \%$ and after 12 months 50\%.

Figure 4 shows the incidence from admission to the twenty-fourth month. At admission the prevalence for residents $<85$ years was $36 \%$, after six months $48 \%$ and after 12 months 49\%, after 18 months 57\% and after 24 months 63\%. However, for residents $>85$ years the prevalence at admission was 34\%, after 6 months $39 \%$, after 12 months 50\%, after 18 months $52 \%$ and after 24 months 59\%.

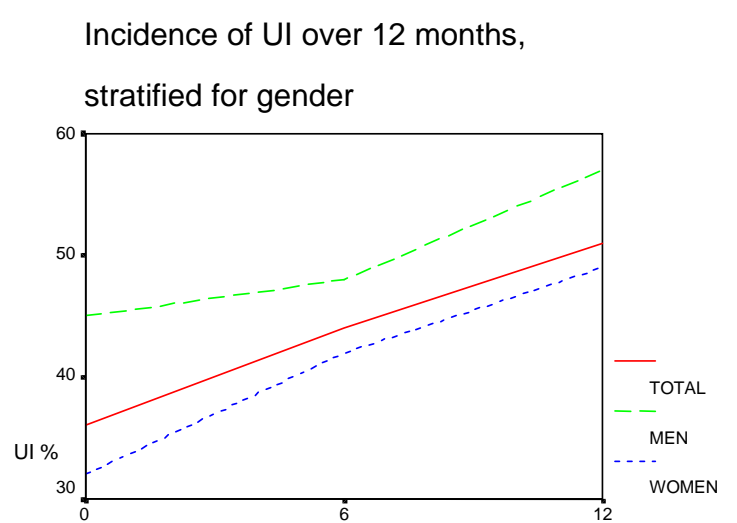

MONTHS

Figure 1: Incidence of urinary incontinence over 12 months, divided in men, women and all residents

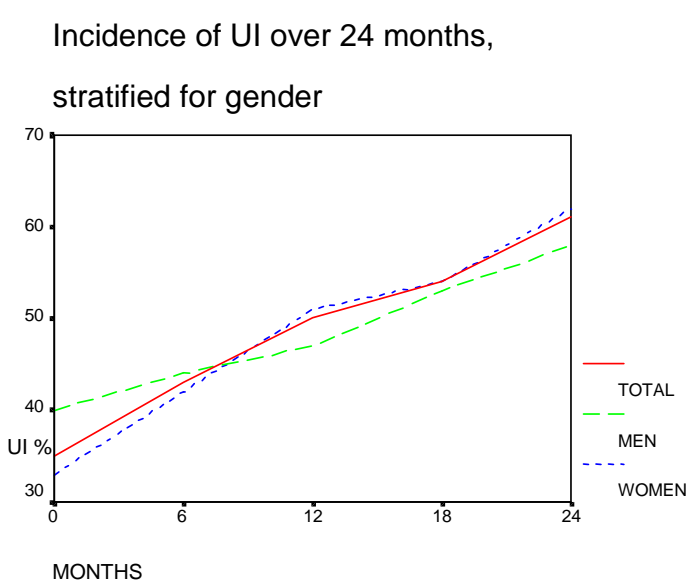

Figure 2: Incidence of urinary incontinence over 24 months, divided in men, women and all residents 


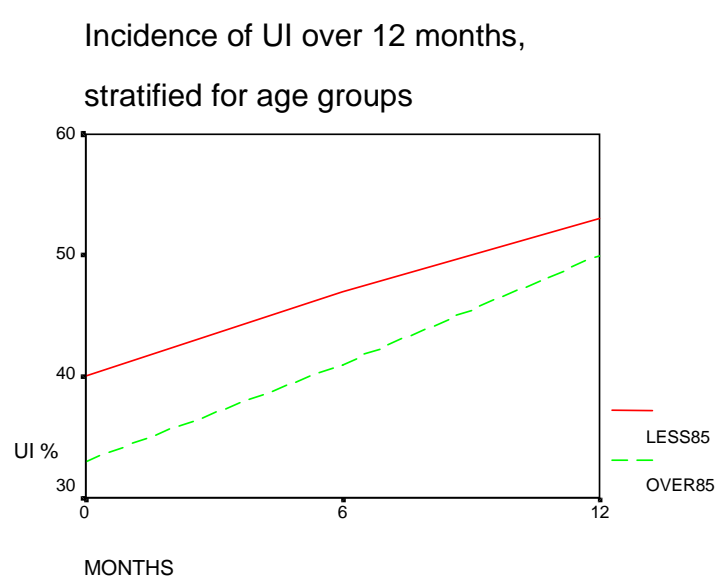

Figure 3: Incidence of urinary incontinence over 12 months, divided in age groups less or more than 85 years
Incidence of Ul over 24 months,

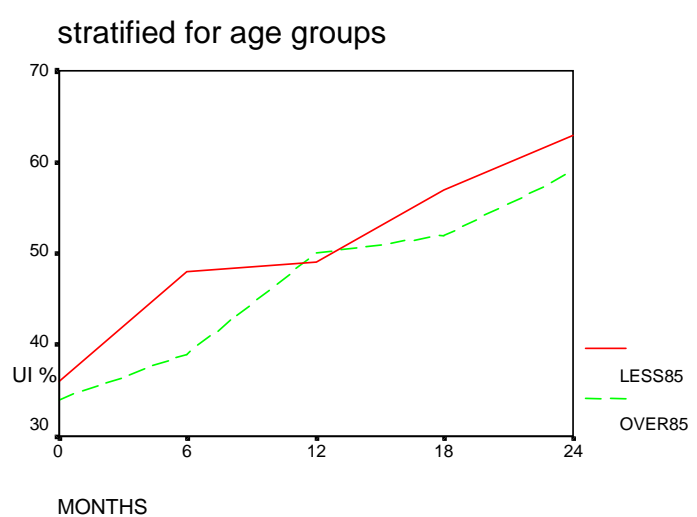

Figure 4: Incidence of urinary incontinence over 24 months, divided in age groups less or more than 85 years

\section{DISCUSSION AND CONCLUSION}

This study presents the prevalence and incidence of urinary incontinence in residents of nursing homes in northwestern Switzerland. In the population under study, the point prevalence of urinary incontinence was $51.5 \%$. This is in accordance with findings by Brandeis et al. (1997) and Aggazzotti et al. (2000). However Borrie \& Davidson (1992) found a higher prevalence of $62 \%$ in a long-term care hospital in London. Adelmann (2004) also established a higher prevalence (77\%). These differences can be explained by different characteristics of the sample. Borrie \& Davidson (1992) had a sample of long-term care hospital residents and in the present study of nursing home residents. Adelman (2004) analysed Medicaid recipients. In general, these people have low income and low-income older adults have higher rates of many medical disorders than those with higher income (Adelman, 2004), probably also including urinary incontinence. No difference was found for gender in the present study. This did not corroborate results by Aggazzotti et al. (2000) however the results by Borrie \& Davidson (1992) and Adelmann (2004) show similar findings. Aggazzotti et al. (2000) found a higher prevalence in women than in men (difference between men and women 20\%, $p>0.0001$ ), while Adelmann (2004) and Borrie \& Davidson (1992) reported no significant differences. We observed an age-specific increase of urinary incontinence, which agrees with Aggazzotti et al. (2000), Adelmann (2004) and Stothers et al. (2005). 
At admission, the prevalence of urinary incontinence is $37 \%$, which is in accordance with Ouslander et al. (1993) and Palmer et al. (1991). This result is much lower than the prevalence at a specific point in time (51.5\%). This finding may suggest that the residents enter the nursing homes in better health and are thus less care-dependent. Welz-Barth et al. (1998) established an association between urinary incontinence and multi-morbidity as well as need for care. In this study, the prevalence of urinary incontinence in the four age groups remains almost the same. Apparently, the residents enter the nursing home in a similar state of health, regardless of age differences. At admission, women have less urinary incontinence than men (34\% versus $43 \% ; p<0.0001)$. It seems that men enter the nursing home in poorer health than women. It is known that care-dependent men are looked after longer at home than women. The gender-related differences did not coincide with Ouslander at al. (1993). These differences could be explained by the different samples relating to the age and gender distribution. In Ouslander's study, the age distribution was as follows: $65-74$ years $16 \%, 75-84$ years $48 \%$ and $>85$ years $36 \%$. $77 \%$ were women. In the present study, the age distribution was $65-75$ years $10 \%, 75-85$ years $37 \%$ and $>85$ years $53 \% .66 \%$ were women.

The prevalence of urinary incontinence in the course of time over 12 and 24 months increases in both men and women. Palmer et al. (1991) and Ouslander et al. (1993) also reported an increase in the prevalence of urinary incontinence from admission to one year later. The present study shows, therefore, that depending on the duration of stay, more residents suffer from urinary incontinence. After 24 months, urinary incontinence rates are $61 \%$ versus $35 \%$ at admission (men: $57 \%$ versus $40 \%$, women: $62 \%$ versus $33 \%$ ). During the first six months in the nursing home, the increase of urinary incontinence in the group of all residents is $8 \%$ in the one-yearcohort (men: $3 \%$ and women 10\%) and $8 \%$ in the two-year-cohort (men: $4 \%$ and women $9 \%$ ). During the second six months, the increase of urinary incontinence is $7 \%$ in the one-year-cohort (men $9 \%$ and women $7 \%$ ) and $7 \%$ in the two-year-cohort (men 3\% and women $9 \%$ ). Therefore, the risk of developing urinary incontinence was almost the same in the first 6 months as in the second 6 months in all residents and women and nearly the same, whether the residents stayed only one or two years in the nursing home.

However, in men the risk of developing urinary incontinence is lower than for women. It is not easy to explain these gender-related differences. Possibly, men arrive at a 
nursing home in a worse condition than women and will temporarily improve as a result of better care. Possibly, women's health deteriorates, contributing to development of urinary incontinence. Also gender-related differences in treatment might be possible. To answer these questions in further studies it is important to include measurements of state of health, care dependency and which type of urinary incontinence care the residents can receive.

A comparison of Fig. 1 and 2 shows a lower prevalence for men in Fig. 2 than in Fig. 1. A possible explanation for this finding may be that the men who live two years or longer in a nursing home setting are in better health than men who are in this setting only one year. Better condition is also probably associated with less urinary incontinence. This difference applies to the male residents but, interestingly, not to the female residents.

Figs. 3 and 4 show that older residents have less urinary incontinence than younger ones, albeit not significantly so. Therefore, age at the different points in time did not play a role in urinary incontinence in nursing home residents.

An important result for nursing practice is the lower prevalence of urinary incontinence at admission. The prevalence increases in the time of stay in the nursing homes. For this reason, a specific urinary incontinence assessment at admission is very important to enable early initiation of specific urinary incontinence prevention and therapy.

For future studies, the inclusion of measures to ascertain the severity of urinary incontinence, the stage of the care-dependence in association with urinary incontinence and the recognition of risk factors would be advantageous. In addition, the attitudes of nurses towards patients with urinary incontinence should be explored, because the nurses play an important role in the prevention and treatment of urinary incontinence in their patients.

Some limitations must be addressed in this study. The measurements accrue from secondary data not specifically gathered for this research. However, some security precautions were taken, such as the training of nurses in using Minimum Data Set prior to data collection or the experience of at least one year with the instrument in the nursing homes. Furthermore, data collected before fulfilment of these conditions were excluded from the study.

The data were analysed retrospective, during the period 1999 to 2002 . Nevertheless they are relevant and valid, since the situation in nursing homes in Switzerland has 
not changed over the last years, nor have the demographic characteristics of their residents. Comparable populations enter the nursing homes, at the same age and in similar state of health.

This study has generated new information about prevalence regarding different points in time, different age-groups and gender. The high prevalence rates indicate the relevance of the problem for residents and caregivers alike. Early identification of individuals likely to become incontinent is crucial in the development of interventions and the prevention of urinary incontinence in this vulnerable population.

The authors thank the authorities of the nursing homes for data and Q-Sys AG for preparing the data.

\section{Contributions}

Study design: SS, RH, TD; data collection: SS; analysis: SS; manuscript preparation: SS, RH, RdB, TD. 


\section{References}

Adelmann, PK. (2004). Prevalence and detection of urinary incontinence among older medicaid recipients. Journal of health care for the poor underserved, 15, 99-112.

Aggazzotti, G., Pesce, F., Grassi, D., Fantuzzi, G., Righi, E., De Vita, D., SantaCroce, S., Artibani, W. (2000). Prevalence of urinary incontinence among institutionalized patients: A cross-sectional epidemiological study in a midsized city in northern Italy. Urology, 56, 245249.

Borrie, MJ., \& Davidson, HA. (1992). Incontinence in institutions: costs and contributing factors. Canadian Medical Association journal, 147, 322-328.

Brandeis, GH., Baumann, MM., Hossain, M., Norris, JN., Resnick, NM. (1997). The prevalence of potentially remediable urinary incontinence in frail older people: A study using the minimum Data set. Journal of the American Geriatrics Society, 45, 179-184.

Crooks, VC., Schnelle, JF., Ouslander, JP., McNees, MP. (1995). Use of the minimum data set to rate incontinence severity. Journal of the American Geriatrics Society, 43, 1363-1369.

Garms-Homolova, V., \& Gilgen, R. (2000). RAI 2.0: Resident Assessment Instrument. $2^{\text {nd }}$ ed. Verlag Hans Huber, Bern.

Hawes, C., Morris, JN., Phillips, CD., Fries, BE., Murphy, K., Mor, V. (1997). Development of the nursing home Resident Assessment Instrument in the USA. Age and Ageing, 26, 19-25.

Hawes, C., Morris, JN., Phillips, CD., Mor, V., Fries, BE., Nonemaker, S. (1995). Reliability estimates for the minimum data set for nursing home resident assessment and care screening (MDS). The Gerontologist, 35, 172-178.

Ouslander, JG., Palmer, MH., Rovner, BW., German, PS. (1993). Urinary incontinence in nursing homes, incidence, remission and associated factors. Journal of the American Geriatrics Society, 41, 1083-1089.

Palmer, MH., German, PS., Ouslander, JG. (1991). Risk factors for urinary incontinence one year after nursing home admission. Research in Nursing \& Health, 14, 405-412.

Stothers, L., Thom, D., Calhoun, E. (2005). Urologic diseases in America Project: Urinary incontinence in males -demographics and economic burden. The Journal of Urology, 173, $1302-1308$.

Welz-Barth, A., Garcia-Schürmann, C., Füsgen, I. (1998). Incontinence, dementia and comorbidity: Predictive factors for need of care and admission to nursing homes. Wiener Medizinische Wochenschrift, 13, 305-308. 


\section{CHAPTER 3}

Risk Factors for Urinary Incontinence in Nursing Home Residents

Susi Saxer, Ruud J.G. Halfens, Marianne Müller, Theo Dassen (2005). Risk Factors for Urinary Incontinence in Nursing Home Residents. Swiss Medical Weekly 135, 495-502 


\section{Risk Factors for Urinary Incontinence in Nursing Home Residents}

\section{Summary}

Question: What are potential risk factors for urinary incontinence in nursing home residents older than 65 years at the time of admission and over time?

Method: Secondary analysis of data from the Minimum Data Set of the Resident Assessment Instrument in a cross-section as well as a longitudinal section.

The sample contained data of 2722 residents from 42 different geriatric and nursing homes in the north-west Switzerland.

Results: The cross-sectional analysis showed the variable 'moving in bed' as the most important personal variable for incontinence at admission.

Longitudinal analyses: The most important risk factor was 'moving in bed' as it continued its action even at 12 months. In a further analysis (incontinence one year after admission with the risk factors at admission) the items 'long-term memory, state season and walking in room' were important factors.

Conclusion: The data suggest that mental and physical exercises could be a way to reduce urinary incontinence. However, physical exercises would be the most important, because 'moving in bed' continued its action even at 12 months.

Despite some limitations attributable to the data collection, this is the first study in Switzerland to examine the risk factors for urinary incontinence among nursing home residents.

Key words: urinary incontinence, geriatric patients, nursing home, mobility, cognitive abilities, Minimum Data Set, Switzerland 


\section{Introduction}

Urinary incontinence affects more than half of all elderly nursing home residents. In a study carried out in Switzerland with 2610 geriatric and nursing home residents of 65 years and older, the prevalence was $52 \%$ based on the Minimum Data Set of the Resident Assessment Instrument (Saxer et al.) In other studies among residents 60 years and older the prevalence was between $49 \%$ and $62 \%$ (Aggazzotti et al. 2000, Brandeis et al. 1997, Peet et al. 1995, Borrie \& Davidson, 1992).

Urinary incontinence in nursing home residents is associated with high expenses (Amt für Umweltschutz, 2002). The elderly people's independence and selfconfidence is also considerably impaired by urinary incontinence. Additionally, urinary incontinence influences old people's care dependency to a high degree (Welz-Barth et al. 1998) and increasing care dependency leads to increasing expenses.

Literature mentions various risk factors for urinary incontinence. Aggazzotti et al. (2000) showed a higher prevalence among residents older than 95 years than among those who were younger than 65 years. In contrast to this, Welz-Barth et al. (1998) did not discover any age-dependent increase in urinary incontinence. Both Aggazzotti et al. (2000) and Borrie et al. (1992) described a higher prevalence among females than males. The authors of this study (Saxer at al.) did not find any gender-specific differences, however, the prevalence at the time of admission was higher among men than women. Two studies identified dementia, impaired mobility and the male sex to be risk factors (Palmer et al. 1991, Ouslander et al. 1993). Two other studies also discovered a relationship between urinary incontinence and dementia (Welz-Barth et al. 1998, Brandeis et al. 1997) whereas the medical diagnoses of diabetes mellitus and depression revealed no association with urinary incontinence (Brandeis et al. 1997). Brandeis et al. (1997) discovered that there was a relationship between urinary incontinence and restrictions to the activities of daily life. Yu et al. (1990) stated that urinary incontinence is more frequently a problem of mental and physical impairments than a functional disorder of the bladder.

In summary, contradicting results are found by various researchers. Moreover, studies regarding urinary incontinence in Switzerland and other German speaking countries are lacking. In order to prevent urinary incontinence and to be able to provide medical treatment and care, it is essential to have differentiated knowledge of urinary incontinence and the relevant risk factors. This study therefore looks closer 
into the following question: Are 'cognitive abilities, mobility, mood, faecal incontinence and incontinence auxiliaries, age and gender' potential risk factors for urinary incontinence in geriatric and nursing home residents older than 65 years at the time of admission and over time?

\section{Design}

This is a secondary analysis of data from the Minimum Data Set (MDS) of the Resident Assessment Instrument (RAI) in a cross-section as well as a longitudinal section.

\section{Instrument}

This study was carried out using data of the MDS (RAI 2.0). It is an instrument applied in geriatric and nursing homes and is mainly for the care planning, quality management, financing and resource management (Garms-Homolova \& Gilgen, 2000). The MDS (RAI 2.0) consists of 16 areas. These are the usual problem areas of geriatric and nursing home residents (e.g. cognitive abilities, physical functions).

The following items of the MDS (RAI 2.0) were used for the investigation:

Urinary incontinence: Urinary incontinence is assessed as the response variable (yes-no). Incontinence is defined as at least two episodes of involuntary loss within one week. Residents with a bladder catheter or stoma are regarded as 'continent'. Hardly any residents in Swiss nursing homes have a catheter, incontinent nursing home residents wear pads.

- $\quad$ Cognitive abilities ( 7 items): The cognitive abilities comprise questions referring to memory ( 2 items), recollection ability (4 items) and the ability to make ordinary decisions (1 question). The four-part division of the variable 'ability to make ordinary decisions' was combined in two categories: 'no problem' for independent or partly independent residents and 'problem' for those with medium or serious impairments.

- Mood (4 total scores): This area consists of 4 total scores regarding questions about verbal expression, sleep, sadness and indifference.

- Mobility (11 items): The questions in this area refer to movement (4 items), movement auxiliaries (3 items) and accidents (4 items). The fivepart division of the variable 'movement' was combined in: 'no problems' 
for independent residents, 'minor problems' for residents requiring supervision or assistance to a certain extent, 'problems' for residents requiring increased help or being entirely dependent.

Faecal incontinence and incontinence auxiliaries (4 items): This area consists of one question regarding faecal incontinence and 3 questions regarding incontinence auxiliaries.

Demographic data (3 items): Age, gender and date of admission.

The instrument was carefully developed and thoroughly tested in the USA from 1987 to 1991 (Hawes et al. 1997). The next section describes the reliability and validity measurements of the MDS (RAI 2.0) subscales used for this research.

Hawes et al. (1997) tested the interrater reliability of the following subscales: memory, recollection ability, ADL, continence (whole subscale), continence (only bladder and faecal incontinence). They obtained good to very good results that were confirmed by further studies (Sgadari et al. 1997, Resnick et al. 1996) (Subscale Incontinence).

Additionally, the concurrence between the MDS subscales and various instruments were tested with good results:

MDS subscales with Mini-Mental State Examination, Dementia Rating Scale and Dementia Rating Scale Subset (Snowden et al. 1999).

- MDS subscales with Global Deterioration Scale and Mini-Mental State Examination (Hartmeier et al. 1994).

- $\quad$ MDS subscales with Mini-Mental State Examination (Hartmeier at al. 1995).

Hartmeier et al. (1995) showed that sensitivity and specificity of the MDS were over 0.90 .

Another study (Crooks et al. 1995) examined the concurrence between urinary incontinence (MDS) and the measured humidity of the patient's sanitary pads. It revealed that there was significant correlation when researchers examined the pads and no significant correlation when ward staff examined them.

\section{Sample}

The sample contained data of residents from 42 different geriatric and nursing homes in north-west Switzerland. 35 geriatric and nursing homes were in the canton of 
Solothurn, six in the canton of Aargau and one in the canton of Berne. All residents are older than 65 years and care dependent.

In five of the geriatric and nursing homes the investigation period started in January 1999, in 37 of the homes it started in January 2000 and finished in June 2002 for all residents. During this period, 2722 residents were admitted to the geriatric and nursing homes.

The sample of the four logistic regression models showed the following:

Logistic regression 1, at the time of admission: 2112 observations. The difference to 2722 resulted from missing variables.

Logistic regression 2, 6 months after admission: 281 observations

Logistic regression 3, 12 month after admission: 204 observations

Logistic regression 4, urinary incontinence 1 year after admission with the risk factors at admission: 446 observations.

The missing variables of the logistic regression 2,3 and 4 resulted from: missing variables, residents that had died, or entered an other institution or entered the nursing homes after December 2001 (regression model 2, 3 and 4) or June 2001 (regression model 3 and 4), because the data gathering was finished in June 2002.

Additional to this, only the residents who were continent at admission were included in the logistic regression 2 and only those who were continent six months after admission were included in the logistic regression 3.

\section{Data Gathering}

Data gathering was conducted by means of MDS (RAI 2.0). It is the usual assessment carried out by nursing staff in close cooperation with the other professional groups involved (physicians, physiotherapists, etc.) for all geriatric and nursing home residents upon admission and again in six-months intervals. In order to ensure correct performance of the assessment with MDS all nursing staff members were trained for $1 \frac{1}{2}$ days.

Following written consent from all geriatric and nursing home directors, the data were made available to the investigator of the company responsible for the introduction, training and quality development of the RAI system in Switzerland.

In order to obtain higher credibility, the data were only used for this research after all nursing staff members had completed the RAI system training and performance 
gathering had been carried out with this instrument. No previous data were included in the investigation.

Assessment was generally conducted upon admission and then again in six-month intervals. An interim assessment was required as soon as the resident's condition changes. However, analysis only included the data of the observations made upon admission and after six and twelve months.

\section{Statistical Analysis}

Cross tables show the proportion of continent and incontinent patients in subgroups defined by the levels of several risk factors. This descriptive analysis was carried out by SPSS 11.0.

Logistic regression models with incontinence (yes/no) as the binary response variable were used to identify statistically significant risk factors. A cross-sectional model was developed to describe the relationship between incontinence and the personal characteristics at the time of admission into the nursing home. Two additional models investigated the occurrence of incontinence after six months and after a year of living in the home. In the first case, only those people were included in the analysis that were continent at the time of admission, in the second case only those who were still continent after a period of six months. A further analysis listed the probability of incontinence a year after admission to a home depending on the risk factors at the beginning of the stay. All models included age group and gender as explanatory variables. The remaining risk factors, which were examined in the model building process, referred to the problems in the areas of mobility, cognitive abilities, mood, faecal incontinence and incontinence auxiliaries. Additionally, the interactions between age groups as well as gender and all other variables were tested in this model.

An automatic selection procedure was implemented on the basis of Akaike's Information Criterion (AIC). Potential models were also compared with each other regarding changes in the deviance as Goodnes-of-Fit statistics. The definite models include all variables that could not have been omitted without significantly increasing the deviance. On the other hand, none of the risk factors not included in the definite model would have significantly reduced the deviance. For the purpose of easier interpretation, the regression coefficients were transformed into odds ratio (OR). The relevant odds for incontinence were then compared with those of a reference group. 
All regression analyses were carried out by means of the $R$ statistical software package release 1.6.0 and the methods for generalised linear models of binomial data (Venables \& Ripley, 2002).

\section{Results}

\section{Characteristics of Newly Admitted Residents}

2722 residents were examined who entered the nursing homes in the period from January 1999 (2000) to June 2002. There were 910 (33\%) men and 1809 (67\%) women. 288 (11\%) residents were 65 - 75 years old, 991 (36\%) were 75 - 85 years old, 1216 (45\%) were 85 - 95 years old and 227 (8\%) were over 95 years of age.

Upon admission, $37 \%$ of the residents were urinary incontinent of whom $34 \%$ females and $43 \%$ males $(p=<0.0001)$. Division into age groups $(65-75,75-85,85-95$ and over 95 years), revealed hardly any age-related differences in the urinary incontinent residents (34\% to $38 \%$ ).

Table 1 illustrates the bivariate correlation between selected items of the two areas 'cognitive abilities and mobility' and urinary incontinence. Although cross tables were created for all items, Table 1 only shows those characteristics that proved to be important for the bivariate analyses.

It was established that in all areas the residents with problems were more frequently incontinent than those without problems. The only exception was the variable 'accidents: hip fracture in the last 6 months'.

Table 1: Characteristics of continent and incontinent residents at admission

\begin{tabular}{|c|c|c|c|c|c|c|}
\hline & $\begin{array}{l}\text { Continent } \\
\text { no problems }\end{array}$ & minor probl. & problems & $\begin{array}{l}\text { Incontinent } \\
\text { no problems }\end{array}$ & minor probl & problems \\
\hline Long-term memory ף & $1118(65.1 \%)$ & & $598(34.9 \%)$ & $412(41.2 \%)$ & & $588(58.8 \%)$ \\
\hline $\begin{array}{l}\text { Impaired recollection ability: } \\
\text { state season } \ddagger\end{array}$ & $1258(73.3 \%)$ & & $458(26.7 \%)$ & $464(46.4 \%)$ & & $537(53.6 \%)$ \\
\hline $\begin{array}{l}\text { Cognitive abilities to make } \\
\text { ordinary decisions } \ddagger\end{array}$ & $1126(65.6 \%)$ & & $590(34.4 \%)$ & $354(35.4)$ & & $64764.6 \%)$ \\
\hline Mobility: Moving in bed † & $1039(60.4 \%)$ & $368(21.4 \%)$ & $312(18.2 \%)$ & $311(31.1 \%)$ & $294(29.3 \%)$ & $396(39.6 \%)$ \\
\hline Mobility: Moving in room * & $1013(68.7 \%)$ & $301(20.4 \%)$ & $161(10.9 \%)$ & $304(40.3 \%)$ & $253(33.6 \%)$ & $197(26.1 \%)$ \\
\hline \multirow{2}{*}{$\begin{array}{l}\text { Mobility: Moving about on own } \\
\text { corridor ** }\end{array}$} & $972(58.6 \%)$ & $419(25.2 \%)$ & $269(16.2 \%)$ & $257(28.1 \%)$ & $319(34.9 \%)$ & $339(37 \%)$ \\
\hline & $\begin{array}{l}\text { No } \\
\text { Continent }\end{array}$ & & $\begin{array}{l}\text { Yes } \\
\text { Continent }\end{array}$ & $\begin{array}{l}\text { No } \\
\text { Incontinent }\end{array}$ & & $\begin{array}{l}\text { Yes } \\
\text { Incontinent }\end{array}$ \\
\hline $\begin{array}{l}\text { Mobility: Permanently } \\
\text { dependent on wheelchair }\end{array}$ & $1491(86.7 \%)$ & & $228(13.3 \%)$ & 762 (76\%) & & 241 (24\%) \\
\hline $\begin{array}{l}\text { Accidents: Hip fracture in last } 6 \\
\text { months }\end{array}$ & $1640(95.4 \%)$ & & $79(4.6 \%)$ & $961(95.8 \%)$ & & $42(4.2 \%)$ \\
\hline $\begin{array}{ll}1 & 6 \text { observations miss } \\
\ddagger & 5 \text { observations miss } \\
\dagger & 2 \text { observations miss } \\
\star & 493 \text { observations m } \\
\star * & 147 \text { observations m }\end{array}$ & $\begin{array}{l}\text { ng for this var } \\
\text { ng for this var } \\
\text { ng for this var } \\
\text { ssing for this } \\
\text { ssing for this }\end{array}$ & $\begin{array}{l}\text { able } \\
\text { able } \\
\text { able } \\
\text { ariable } \\
\text { ariable }\end{array}$ & & & & \\
\hline
\end{tabular}




\section{Correlation Between Personal Characterics, Risk Factors and Urinary Incontinence}

Apart from age groups and gender 26 personal characteristics were examined in total, out of which 8 appeared in the definite regression models. The four models (tables 2, 3 and 4) include the same variables to a great extent. These are the variables of the two areas 'cognitive abilities' and 'mobility'.

Table 2: P-values and odds ratio for urinary incontinence at admission

\begin{tabular}{|c|c|c|c|}
\hline Variables & \multicolumn{3}{|c|}{ Logistic Regression 1} \\
\hline \multicolumn{4}{|l|}{ Gender * $^{*}$} \\
\hline male & $<0.001$ & 1.69 & $1.36-2.09$ \\
\hline \multicolumn{4}{|l|}{ Age groups $†$} \\
\hline 65 to 74 & 0.84 & 3.73 & . 一。势 \\
\hline 75 to 84 & 0.16 & 76.36 & 0.17 - 㧊 \\
\hline 85 to 94 & 0.10 & 154.93 & $0.37-. \ddagger \ddagger$ \\
\hline \multicolumn{4}{|l|}{ Long-term memory $\ddagger$} \\
\hline No problem & 0.005 & 0.70 & $0.54-0.90$ \\
\hline \multicolumn{4}{|l|}{ State season $\S$} \\
\hline no & $<0.001$ & 1.59 & $1.24-2.04$ \\
\hline \multicolumn{4}{|l|}{ Cognitive abilities $\ddagger$} \\
\hline no problem & $<0.001$ & 0.64 & $0.49-0.83$ \\
\hline \multicolumn{4}{|l|}{ Walking in room $\mathbb{\|}$} \\
\hline no problem & -- & -- & -- \\
\hline minor problems & -- & -- & -- \\
\hline \multicolumn{4}{|l|}{ Moving about in own corridor $\mathbb{\Upsilon}$} \\
\hline no problem & 0.57 & 0.78 & $0.33-1.85$ \\
\hline minor problems & 0.33 & 0.64 & $0.26-1.58$ \\
\hline \multicolumn{4}{|l|}{ Moving in bed $\mathbb{\Upsilon}$} \\
\hline no problem & $<0.001$ & 0.51 & $0.36-0.73$ \\
\hline minor problems & 0.49 & 0.89 & $0.64-1.24$ \\
\hline \multicolumn{4}{|l|}{ Wheelchair ** } \\
\hline yes & -- & -- & -- \\
\hline \multicolumn{4}{|l|}{ Hip fracture $\S$} \\
\hline none & 0.10 & 141.55 & 0.36 - . 㧊 \\
\hline \multicolumn{4}{|l|}{ Age $x$ Moving about } \\
\hline 65 to $74-$ no problem & 0.17 & 0.33 & $0.07-1.57$ \\
\hline 75 to 84 - no problem & 0.01 & 0.28 & $0.11-0.75$ \\
\hline 85 to $94-$ no problem & 0.33 & 0.63 & $0.25-1.61$ \\
\hline 65 to $74-$ minor problems & 0.71 & 0.74 & $0.15-3.68$ \\
\hline 75 to $84-$ minor problems & 0.98 & 1.02 & $0.37-2.83$ \\
\hline 85 to $94-$ minor problems & 0.85 & 1.10 & $0.41-2.93$ \\
\hline \multicolumn{4}{|l|}{ Age $x$ Hip fracture } \\
\hline 65 to $74-$ none & 0.91 & 0.50 & . 一㧊 \\
\hline 75 to $84-$ none & 0.24 & 0.03 & -11.09 \\
\hline 85 to $94-$ none & 0.11 & 0.01 &.-3.04 \\
\hline
\end{tabular}

* Female patients is the reference group.

† Age group '95 and older' is the reference group.

¥ Reference level is 'problems'.

$\S$ Reference level is 'yes'.

** Reference level is 'no'.

II Reference level is 'problems'

拉 Values are missing if smaller than 0.01 or higher than 100.

Cross-sectional analysis: The first regression analysis examined the relationship between incontinence and the personal characteristics at the time of admission. The best model based on the AIC and the change of deviance comprises eight 
explanatory variables. Table 2 illustrates the P-values and the odds ratio $(\mathrm{OR})$, including $95 \%$ of confidence intervals $(\mathrm{Cl})$.

Of all non-interacting variables 'moving in bed' is the most important personal variable for incontinence, which was demonstrated by the minimal OR of 0.51 . The odds for incontinence were therefore approximately half as high for a mobile person as for somebody who needs assistance when moving in bed. The two variables 'state season' and 'cognitive abilities' were almost of the same importance. The odds for incontinence for people with problems in these areas are 1.6 times higher than for people without those problems. Male gender was a significant characteristic as well. The odds for incontinence for males are 1.7 times higher than for females.

Interpretation of the results of interacting variables was more complicated. In order to compare two groups, the relevant odds ratio of main effect and interaction had to be multiplied with each other. The odds for incontinence for a 90 -year-old person without hip fracture, for example, are $154.93 \times 0.01=1.55$ times higher than for a resident of at least 95 years of age, also without hip fracture. The confidence intervals for odds ratio comparing age groups or people with and without hip fractures were quite large, so that the subsequent results should be interpreted with due care.

Longitudinal analyses: A second regression analysis examined the relationship of risk factors with incontinence six months after admission to the home. In order to respect the chronological development, this regression model only considered those people who were still continent at the time of admission. The best model according to the AIC and the change of deviance comprised seven explanatory variables. Table 3 (logistic regression 2) illustrates the results. 'Moving in bed' was the most important rater for incontinence. The odds for incontinence were $5.88(=1 / 01.7)$ times higher for patients with difficulties in moving in bed than for patients without those problems. The second important factor concerned problems with long-term memory. The odds for incontinence were $5.26(=1 / 0.19)$ times higher for persons with long-term memory problems than for persons without such impairments. The factor 'state season' was looked at separately for females and males, because there was an interaction with gender. The odds for incontinence were $6.4(=1.51 \times 4.24)$ times higher for males with memory difficulties regarding the season than for those without. The analogue comparison of females reveals odds ratio of only 1.51 . 
In a third regression analysis, we examined the association between risk factors and incontinence 12 months after admission to the home. To enable examination of the chronological development, the regression model only took into account those people that were still continent six months after admission. The best model according to AIC and the change of deviance comprised four explanatory variables. Table 3 (logistic regression 3) contains the results. Again 'Moving in bed' was the most important rater for incontinence. The odds for incontinence were 7.69 (1/0.13) times higher for residents with problems in moving in bed than for those without any such problems. The second important factor was 'moving about in own corridor'. The odds for incontinence were 6.67 (1/0.15) times higher for residents with difficulties in moving about in own corridor than for those without.

Table 3: P-values and odds ratio for incontinence 6 months (logistic regression 2) and 12 months after admission (logistic regression 3 )

\begin{tabular}{|c|c|c|c|c|c|c|}
\hline 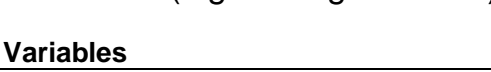 & $\begin{array}{l}\text { Logistic F } \\
\text { P-values }\end{array}$ & $\begin{array}{l}\text { ression } 2 \\
\text { Odds Ratio }\end{array}$ & $95 \% \mathrm{Cl}$ & \begin{tabular}{|l} 
Logistic F \\
P-values
\end{tabular} & $\begin{array}{l}\text { ression } 3 \\
\text { Odds Ratio }\end{array}$ & $95 \% \mathrm{Cl}$ \\
\hline $\begin{array}{l}\text { Gender * }^{*} \text { male }\end{array}$ & 0.33 & 0.56 & $0.18-1.78$ & 0.90 & 1.08 & $0.35-3.29$ \\
\hline Age groups $†$ & & & & & & \\
\hline 65 to 74 & 0.76 & 1.27 & $0.28-5.68$ & 0.54 & 0.54 & $0.07-3.96$ \\
\hline $\begin{array}{l}75 \text { to } 84 \\
85 \text { to } 94\end{array}$ & $\begin{array}{l}0.39 \\
0.94\end{array}$ & $\begin{array}{l}1.71 \\
1.04\end{array}$ & $\begin{array}{l}0.50-5.79 \\
0.33-3.30\end{array}$ & $\begin{array}{l}0.31 \\
0.62\end{array}$ & $\begin{array}{l}0.44 \\
0.70\end{array}$ & $\begin{array}{l}0.09-2.15 \\
0.17-2.92\end{array}$ \\
\hline $\begin{array}{l}\text { Long-term memory ₹ } \\
\text { No problem }\end{array}$ & $<0.001$ & 0.19 & $0.08-0.46$ & -- & -- & -- \\
\hline $\begin{array}{l}\text { State season } \S \\
\text { no }\end{array}$ & 0.35 & 1.51 & $0.63-3.62$ & -- & -- & -- \\
\hline $\begin{array}{l}\text { Cognitive abilities } \ddagger \\
\text { no problem }\end{array}$ & -- & -- & -- & -- & -- & -- \\
\hline $\begin{array}{l}\text { Walking in room } 9 \\
\text { no problem } \\
\text { minor problems }\end{array}$ & $\begin{array}{l}-- \\
--\end{array}$ & $\begin{array}{l}-- \\
--\end{array}$ & $\begin{array}{l}-- \\
--\end{array}$ & -- & -- & -- \\
\hline $\begin{array}{l}\text { Moving about in own corridor } \mathbb{} \\
\text { no problem } \\
\text { minor problems }\end{array}$ & $\begin{array}{l}-- \\
--\end{array}$ & $\begin{array}{l}-- \\
--\end{array}$ & $\begin{array}{l}-- \\
--\end{array}$ & $\begin{array}{l}0.01 \\
0.03\end{array}$ & $\begin{array}{l}0.15 \\
0.20\end{array}$ & $\begin{array}{l}0.03-0.67 \\
0.04-0.85\end{array}$ \\
\hline $\begin{array}{l}\text { Moving in bed } 9 \\
\text { no problem } \\
\text { minor problems }\end{array}$ & $\begin{array}{l}<0.001 \\
0.60\end{array}$ & $\begin{array}{l}0.17 \\
0.76\end{array}$ & $\begin{array}{l}0.06-0.48 \\
0.27-2.13\end{array}$ & $\begin{array}{l}0.005 \\
0.009\end{array}$ & $\begin{array}{l}0.13 \\
0.14\end{array}$ & $\begin{array}{l}0.03-0.55 \\
0.03-0.62\end{array}$ \\
\hline $\begin{array}{l}\text { Wheelchair ** } \\
\text { yes }\end{array}$ & 0.11 & 6.98 & $0.64-76.54$ & -- & -- & -- \\
\hline $\begin{array}{l}\text { Hip fracture } \S \\
\text { none }\end{array}$ & 0.03 & 6.38 & $1.16-34.66$ & -- & -- & -- \\
\hline $\begin{array}{l}\text { Gender } \times \text { State season } \\
\text { male }- \text { no }\end{array}$ & 0.08 & 4.24 & $0.85-21.13$ & -- & -- & -- \\
\hline
\end{tabular}

* Female patients is the reference group.

† Age group '95 and older' is the reference group.

$\ddagger$ Reference level is 'problems'.

$\S$ Reference level is 'yes'.

** Reference level is 'no'.

II Reference level is 'problems'

㧊 Values are missing if smaller than 0.01 or higher than 100. 
In the forth logistic regression, the effect of the risk factors as estimated at the time of admission was examined for incontinence after one year. According to the AIC and the change of deviance the best model comprised seven explanatory variables. The results are illustrated in Table 4 (logistic regression 4). The most important factor was 'Walking in the own room'. The effect of problems in this area was different for males than females due to existing interaction with the gender. The odds for incontinence were $1.40(=1 /(2.1 \times 0.34))$ times higher for men with walking problems than for those without. For females the effect was even stronger. The odds were now $2.94(=1 / 0.34)$ times higher for females with walking problems than for women without these difficulties. In addition, we were dealing with the risk factors of subscale 'cognitive abilities'.

Table 4: P-values and odds ratio for urinary incontinence 1 year after admission with the risk factors at admission (logistic regression 4)

\begin{tabular}{|c|c|c|c|}
\hline \multirow{2}{*}{ Variables } & \multicolumn{3}{|c|}{ Logistic Regression 4} \\
\hline & P-values & Odds Ratio & $95 \% \mathrm{Cl}$ \\
\hline \multicolumn{4}{|l|}{ Gender * } \\
\hline male & 0.29 & 0.58 & $0.21-1.60$ \\
\hline \multicolumn{4}{|l|}{ Age groups † } \\
\hline 65 to 74 & 0.04 & 0.43 & $0.19-0.95$ \\
\hline 75 to 84 & 0.16 & 0.62 & $0.32-1.21$ \\
\hline 85 to 94 & 0.18 & 0.64 & $0.34-1.23$ \\
\hline \multicolumn{4}{|l|}{ Long-term memory $\ddagger$} \\
\hline No problem & 0.001 & 0.53 & $0.36-0.78$ \\
\hline \multicolumn{4}{|l|}{ State season $\S$} \\
\hline no & $<0.001$ & 1.99 & $1.33-2.97$ \\
\hline \multicolumn{4}{|l|}{ Cognitive abilities $\ddagger$} \\
\hline no problem & 0.07 & 0.69 & $0.47-1.03$ \\
\hline \multicolumn{4}{|l|}{ Walking in room $\mathbb{q}$} \\
\hline no problem & $<0.001$ & 0.34 & $0.18-0.63$ \\
\hline minor problems & 0.82 & 0.92 & $0.44-1.91$ \\
\hline \multicolumn{4}{|c|}{ Moving about in own corridor $\mathbb{9}$} \\
\hline no problem & -- & -- & -- \\
\hline minor problems & -- & -- & -- \\
\hline \multicolumn{4}{|l|}{ Moving in bed $\uparrow$} \\
\hline no problem & -- & -- & -- \\
\hline minor problems & -- & -- & -- \\
\hline \multicolumn{4}{|l|}{ Wheelchair ** } \\
\hline yes & -- & -- & -- \\
\hline \multicolumn{4}{|l|}{ Hip fracture $\S$} \\
\hline none & 0.05 & 2.50 & $1.01-6.61$ \\
\hline \multicolumn{4}{|l|}{ Gender x Walking } \\
\hline male - no problem & 0.19 & 2.10 & $0.70-6.33$ \\
\hline male - little assistance & 0.03 & 4.65 & $1.16-18.60$ \\
\hline
\end{tabular}

* Female patients is the reference group.

† Age group '95 and older' is the reference group.

$\neq$ Reference level is 'problems'.

$\S$ Reference level is 'yes'.

** Reference level is 'no'.

II Reference level is 'problems'

㧊 Values are missing if smaller than 0.01 or higher than 100. 


\section{Discussion}

This study provided an answer to the research question: What is the association between 'cognitive abilities, mobility and demographic data' with urinary incontinence of nursing home residents older than 65 years at the time of admission, and after 6 and 12 months? The results of the cross tables (tables 1) showed that residents who had problems with 'cognitive abilities and mobility' suffered more frequently from urinary incontinence than residents without those problems.

The results of the logistical regression are discussed separately: first the crosssectional (table 2) and then the longitudinals (tables 3 and 4).

Cross-sectional analysis: The most important item was "moving in bed". In the subscale 'cognitive abilities' three items (long-term memory, state season, cognitive abilities) were important. Other researchers also found that dementia was associated with urinary incontinence at the time of admission (Welz-Barth et al, 1998, Palmer et al. 1991). Another important factor was 'hip fracture'. The interpretation of the (interacting) variable 'hip fracture' should be interpreted with due care, because the confidence intervals for odds ratio comparing age groups or people with and without hip fractures were quite large. Nevertheless, possibly residents with a hip fracture might receive better care than residents without a hip fracture. Better care might have a positive effect on urinary incontinence.

The odds for incontinence for males were 1.7 times higher than for women. Therefore, more incontinent men than incontinent women entered the nursing home. A possible reason could be that care-dependent men are cared for longer at home than women. According Welz-Barth (1998) care dependency and incontinence are in strong correlation (Welz-Barth et al, 1998).

Longitudinal analyses: Table 3 showed different risk factors for urinary incontinence. From admission to 6 month after admission (logistic regression 2), the factors 'longterm memory' and 'moving in bed' were important predictors for urinary incontinence. In both, the odds for incontinence were more then 5 times higher for persons with these problems than for persons without. In the time-period from 6-12 months after admission (logistic regression 3) the factors 'moving in bed' and 'moving about in own corridor' were risk factors. Other researchers (Brandeis et al. 1997, Palmer et al. 1991, Ouslander et al. 1993) also determined an association between urinary incontinence and impaired mobility at different points of time of the stay in a nursing 
home. The most important factor seemed to be 'moving in bed', as it continued its action even at 12 months.

Table 4 (logistic regression 4) lists the probability of incontinence one year after admission depending on the risk factors at admission. 'Walking in room' was an important predictor for urinary incontinence for women and men. But for women the effect was stronger. Variables of the subscale 'cognitive abilities' were important predictors for urinary incontinence, as well. It is quite interesting that these variables played no role in the logistic regression 3 . It can be interpreted that the risk factors 'cognitive abilities' were only important if residents had this since the beginning of the stay in a nursing home.

The items of the subscales 'mood, faecal incontinence and incontinence auxiliaries' did not reveal any association with urinary incontinence at any point of time. However, Ouslander et al. (1993) showed an association between faecal incontinence and the development of urinary incontinence, which might be due to the different designs, samples and measures.

Nevertheless, the present study also has some restrictions. The most significant restriction is probably that the measures were secondary data that were not gathered for research. Some security precautions were still made, e. g. the data for this research were not taken until all nurses had been trained in the assessment with MDS, and the nursing homes had at least one year of practice using the instrument. No previous observations were included in the research.

The association between urinary incontinence and mental and physical problems at various times was reported. It was established that different items of the subscales 'cognitive abilities and mobility' did have an influence on urinary incontinence. This led to the conclusion that residents with cognitive and / or mobility impairments were more frequently incontinent. Mental and physical exercises could therefore be a way to reduce urinary incontinence. However the most important would be physical exercises, because 'moving in bed' continued its action even 12 months.

However, in the future, it is essential to do more research with specific questionnaires regarding mobility and cognitive abilities and with a more controlled data collection. Experimental research could then determine the advantages of mental and physical exercises for the improvement of urinary continence. In addition, the attitudes of nurses towards patients with urinary incontinence should be explored, because the 
nurses play an important role in the prevention and treatment of urinary incontinence of their patients.

The reduction of urinary incontinence in elderly people remains an important topic as urinary incontinence diminishes the elderly person's independence and self-esteem.

The authors would like to thank the authorities of the nursing homes for providing the data, and Q-Sys AG for preparing the data. 


\section{References}

Saxer, S., Halfens, R., de Bie, RA., Dassen, T. Prevalence and incidence of urinary incontinence of Swiss nursing home residents at admission and after 6, 12 and 24 months. submitted.

Aggazzotti, G., Pesce, F., Grassi, D., Fantuzzi, G., Righi, E., De Vita, D., et al. (2000). Prevalence of urinary incontinence among institutionalized patients: a cross-sectional epidemiological study in a midsized city in northern Italy. UROLOGY, 56, 245-9.

Brandeis, GH., Baumann, MM., Hossain, M., Norris, JN., Resnick, NM. (1997). The prevalence of potentially remediable urinary incontinence in frail older people: a study using the minimum data set. JAGS, 45, 179-84.

Peet, SM., Castleden, CM., McGrother, CW. (1995). Prevalence of urinary incontinence and faecal incontinence in hospitals and residential and nursing homes for older people. BMJ, $311,1063-4$

Borrie, MJ., \& Davidson, HA. (1992). Incontinence in institutions: costs and contributing factors. Can Med Assoc, 147, 322-8.

Amt für Umweltschutz, Basel-Landschaft. (2002). Bericht zum Inkontinenzeinlagentest. Massnahmeplan Abfallvermeidung. Unveröffentlichter Bericht.

Welz-Barth, A., Garcia-Schürmann, C., Füsgen, I. (1998). Inkontinenz, Demenz und Multimorbidität: prädiktive Faktoren für Pflegebedürftigkeit und Heimunterbringung. WMW, 13, 305-8.

Palmer, MH., German, PS., Ouslander, JG. (1991). Risk factors for urinary incontinence one year after nursing home admission. Res Nurs Health, 14, 405-12.

Ouslander, JG., Palmer, MH., Rovner, BW., German, PS. (1993). Urinary incontinent in nursing homes: incidence, remission and associated factors. JAGS, 41, 1083-9.

Yu, LC., Rohner, TJ., Kaltreider, D., Hu, T., Igou, JF., Dennis, PJ. (1990). Profile of urinary incontinence elderly in long-term care institutions. JAGS, 38, 433-9.

Garms-Homolova, V., \& Gilgen, R. (2000). RAI 2.0: Resident Assessment Instrument. $2^{\text {nd }}$ ed. Berne: Verlag Hans Huber.

Hawes, C., Morris, JN., Phillips, CD., Fries, BE., Murphy, K., Mor, V. (1997). Development of the nursing home Resident Assessment Instrument in the USA. Age Ageing, 26, 19-25.

Hawes, C., Morris, JN., Phillips, CD., Mor, V., Fries, BE., Nonemaker, S. (1995). Reliability estimates for the Minimum Date Set for nursing home residents assessment and care screening (MDS). The Gerontologist, 35, 172-8.

Sgadari, A., Morris, JN., Fries, BE., Ljunggren, G., Jonsson, PV., DuPaquier, J., et al. (1997). Efforts to establish the reliability of the resident assessment instrument. Age Ageing, 26, 2730.

Resnick, NM., Brandeis, GH., Baumann, MM., Morris, JM. (1996). Evaluating a national assessment strategy for urinary incontinence in nursing home residents: Reliability of the minimum data set and validity of the resident assessment protocol. Neurourol Urodyn, 15, 583-98. 
Snowden, M., McCormick, W., Russo, J., Srebnik, D., Comtois, K., Bowen, J., et al. (1999). Validity and responsiveness of the minimum data set. JAGS, 47, 1000-4.

Hartmeier, SL., Sloane, PD., Guess, HA., Koch, GG. (1994). The MDS cognition scale: A valid instrument for identifying and staging nursing home residents with dementia using the minimum data set. JAGS, 42, 1173-9.

Hartmeier, SL., Sloane, PD., Guess, HA., Koch, GG., Mitchell, M., Phillips, CD. (1995). Validation of the minimum data set cognitive performance scale: agreement with the minimental state examination. J Gerontol Med Sci, 50A, M128-33.

Crooks, VC., Schnelle, JF., Ouslander, JP., McNees, MP. (1995). Use the minimum data set to rate incontinence severity. JAGS, 43, 1363-69.

Venables, WN., \& Ripley, BD. ( 2002). Modern applied statistics with S. 4th ed. New York: Springer. 


\section{CHAPTER 4}

Nurses' knowledge and practice about urinary incontinence in nursing home care

Susi Saxer, Rob A. de Bie, Theo Dassen, Ruud J.G. Halfens (2008). Nurse Education Today, doi: 10.1016/j.nedt.2008.05.009. 


\title{
Nurses' Knowledge and Practice about Urinary Incontinence in Nursing Home Care
}

\begin{abstract}
Background: An important barrier in the implementation of effective incontinence treatments is the level of knowledge of the nurses concerning assessment and treatment of urinary incontinence. Therefore, it is important to assess current nurses' knowledge and practice in urinary incontinence care so that nurses can receive adequate training and education.

Aims and objectives: This article reports on the development and testing of the Urinary Incontinence Practice and Knowledge Scale as well as the results of nurses' practice and knowledge about urinary incontinence.

Methods: A cross-sectional design with a convenience sample of nurses and nurse assistants was used.

Results: Nurses answer two-thirds of the questions correctly. The level of knowledge of the nurse assistants is lower than that of nurses. Education and experience in the field are associated with the level of knowledge. Nurses and nurse assistants perform continence-related actions only 'sometimes' or 'often' at best. Both groups have best results in the subscale 'Support' and they have most deficits in 'Documentation'.

Conclusion: Nurses and nurse assistants need more education and training in urinary incontinence care. Special focus should lie on documentation. The results give information towards adequate education and training for nurses as well as nurse assistants.
\end{abstract}

Key words: nurses' knowledge, nurses' practice, urinary incontinence, nursing home 


\section{INTRODUCTION}

About $60 \%$ of nursing home residents suffer from urinary incontinence (Brandeis et al. 1997; Aggazzotti et al. 2000; Adelmann 2004; Saxer et al. 2008). Caring for urinary incontinent people is a constant challenge for health care personnel.

Research shows effective interventions for urinary incontinence in older people (Fantl et al. 1996). For example, an important treatment is the use of prompted voiding, especially for older people without or with minor cognitive impairments (Burgio et al. 1994; Fantl et al. 1996; Ouslander at al. 2001; Schnelle et al. 2002). For the cognitively-impaired elderly, routine or scheduled toileting training also shows a positive effect (Colling et al. 1992 \& 2003). However, an important barrier in the implementation of effective incontinence treatments is the level of knowledge of the nurses concerning assessment and treatment of urinary incontinence (LekanRutledge et al. 1998; Watson et al. 2003). Therefore, it is important to assess current nurses' knowledge and practice in urinary incontinence care so that nurses can receive adequate training and education.

Only Henderson \& Kashka (2000) studied the knowledge and practice of American nurses. American nurses correctly answered $73 \%$ of the questions about knowledge and they performed continence-related practice about half the time. No data are available on the subject in Europe. Since the education and practice of nurses differs between America and Europe, transfer of US research findings is not entirely possible. Therefore it was decided to investigate the knowledge and practice of nurses' and nurse assistants in Swiss nursing homes.

The study was conducted in two phases: (1.) new questionnaires about practice and knowledge were systematically developed with content validity analysed by a panel of experts, and (2.) validation of the developed scales and exploration of nurses' and nurse assistants' knowledge and practice about urinary incontinence.

\section{METHODS}

\section{Design}

A cross sectional design with a written questionnaire was used to measure the knowledge and practice of nurses and nurse assistants from different nursing homes. 


\section{Instrument}

To measure nurses' knowledge and practice about urinary incontinence a new instrument had to be developed. In fact there is a questionnaire to measure nurses knowledge and practice, the URINARY INCONTINENCE SCALES@) (Henderson 1996). Most questions of the original scale could not be used since they did not address nursing home residents; or when activities of specifically Swiss doctors were described.

The newly-developed Knowledge and Practice Instrument (KPI) is based on the Clinical Practice Guideline (Fantl et al. 1996), clinical practice audits, literature, findings from clinical research (Saxer et al. 2005, Saxer et al. 2008) and the questionnaire used by Henderson (1996). The KPI consists of two different scales, one about knowledge and the other about practice of nurses. The dimensions of the knowledge scale are general knowledge about urinary incontinence and urinary incontinent residents, e.g. mobility and cognitive impairment and urinary incontinence in older people, and illnesses, which could result in urinary incontinence. The Practice scale covered the following dimensions: frequency and time of incontinence episodes, amount of urine, drinking habit, assessment, information and documentation, scheduled toileting, and support. The dimensions were translated into observable aspects, e.g. the dimension 'drinking habit' reflects the amount of fluid intake, time of fluid intake and kind of fluid. And the aspect 'kind of fluid' was translated into the question, e.g. 'I know whether the resident drinks beverage with caffeine or diuretic fluids'.

The differences of the newly-developed KPI and Hendersons' questionnaires (1996) are: The knowledge scale consists of 18, Hendersons' (1996) of 38 questions. 11 are the same questions as in Hendersons' questionnaire, and seven are new questions. The newly developed questions include questions about urinary incontinent nursing home residents in general and specific for mentally and physically impaired residents. 27 of Hendersons' questions do not address nursing home residents or the questions do not apply to knowledge of nurses in Swiss nursing homes.

The practice scale consists of 30, Hendersons' of 25 questions. Seven are the same questions as in Hendesons questionnaire (Henderson, (1996). and 23 were developed by our research team. 18 of Hendersons' questions do not address 
nursing home residents or questions concern more actions of Swiss doctors than nurses. The newly-developed questions cover about documentation, support and toileting schedules.

To evaluate the content validity of the KPI, the developed questions were shown to a panel of ten experts, who were chosen for their practice and/or research experience in the area of urinary incontinence and who were involved in the development of the 'Nationale Expertenstandard zur Kontinenzförderung' in Germany. Experts were asked to evaluate each item as it related to the dimension using the following fourpoint scale: $1=$ not relevant, 2 = unable to assess, 3 = needs minor revision, and 4 = very relevant. They were also asked to make suggestions for 'minor revisions' (Polit \& Beck, 2004). Items which $80 \%$ of the expert panel rated 3 or 4 were considered as items reflecting content validity.

In the knowledge scale, 18 of the 19 items were accepted and two small revisions were made. In the practice scale, 30 of the 32 items were accepted by the experts. The two 'not-accepted items' were to difficult to assess. For a few items, the expert panel made some suggestions which were incorporated into the final version.

Next, 13 nurses and seven nurse assistants judged the comprehensibility of the individual items. Only small revisions were needed, mainly simplifying language and avoiding jargon.

The final knowledge scale consists of 18 items regarding facts and statements about urinary incontinence and urinary-incontinent elderly people. Response categories are: yes, no, don't know. The final practice scale consists of 30 items regarding nurses' actions towards urinary-incontinent elderly residents. Responses are measured on a four-point Likert scale (always, often, sometimes, never). The questionnaires are in German. Appendix 1 shows the translated items of the KPI.

Besides the knowledge and practice scale, demographic characteristics of the participants, like age, education and experience in the field are also included in the questionnaires.

\section{Sample}

The sample consisted of 199 registered nurses and 116 nurse assistants who work in one of the ten municipal nursing homes of Zurich, representing approximately one- 
third of all nurses and nurse assistants employed at these nursing homes. The municipal nursing homes of Zurich are similar with respect to the residents, staff and management.

Swiss nurses and nurse assistants differ with respect to education, as well as the area of responsibility. Nurses have received an education of three years and nurse assistants only one year. However, the two groups work with residents and are involved in the care of urinary incontinent patients, e.g. they accompany residents to the toilet or change pads, and they instruct residents for scheduled toileting. Nurses have the responsibility for residents and the planning of care. Nurse assistants also care for the residents but they do more the routine care.

\section{Procedure}

Nurses and nurse assistants who work in one of the ten municipal nursing homes were invited to participate in the survey on a voluntary basis, after permission was obtained from the head of the nursing homes and the nurse managers. The clinical nurse specialists were asked to act as contact persons. In personal instruction, the clinical nurse specialists were familiarized with the aims of the research project and the data collection. They organized the measurement in a school room for all nurses and nurse assistants, who participated on a voluntary basis in the project. Each participant received the questionnaires, an envelope and an accompanying letter that explained the complete research project, the instructions for filling out the questionnaire and written assurance that participation was voluntary and anonymous. After the participants had filled out the questionnaires, they put them in an envelope, sealed the envelope, and gave them to the clinical nurse specialists. The latter sent the questionnaires to the researchers.

\section{Ethical consideration}

The Ethics Committee's president of the municipal nursing homes of Zürich approved the research.

\section{Data Analysis}

The statistical analysis was carried out in SPSS 13.0. The items of the knowledge scale were recoded so each correct answer received the score 1 , and a score 0 for 
an incorrect or uncertain answer. The answer categories in the practice scale were coded as 3 (always) to 0 (never).

An exploratory factor analysis was employed for the urinary incontinence practice scale. For better interpretability the factor analyses with rotated factors was used (principal varimax rotated component analysis). Reliability estimates were based on Cronbach's Alpha. Descriptive data were calculated.

To test the association between demographic data with knowledge and practice, an analysis of variance with transformed response variables (if necessary) was performed. The choice of the model was based on the $\mathrm{R}^{2}$. The variable 'age' was divided into three similarly large groups: < 33 years, $33-43$ years and > 43 years, the variable 'education' into two groups 'nurses with diploma and nurse assistants' and the variable 'experience in the field' into three groups < 3 years, $3-10$ years and $>10$ years'.

\section{RESULTS}

The participating registered nurses and nurse assistants were between 18 and 63 years old, with a mean of 28 years. $40 \%$ were younger than 33 years, $28 \%$ were 33 to 43 years and $32 \%$ were older than 43 years. $39 \%$ of the participants had more than 10 years experience in the care of old people, $40 \%$ between 3 and 10 years, $21 \%$ less than 3 years.

\section{Reliability and validity}

Construct validity of the urinary incontinence practice scale was examined by conducting a principal component analysis. According to the screeplot, four factors were important. The four-factor model yielded an explained variance of $39 \%$ (factor 1: $17.5 \%$, factor $2: 8.7 \%$, factor $3: 7.3 \%$ and factor $4: 5.5 \%)$. The first factor contains ten items, and is labelled 'drinking habit and excretion'. The second factor contains six items, and is labelled 'assessment and information'. The third factor contains six items, and is labelled 'documentation', and the fourth factor contains eight items, labelled 'support'.

To test the reliability, Cronbach's Alpha was calculated for each subscale. Factor three showed better reliability without the items 16 and 29. (see appendix 1). Therefore, these items were deleted. Reliability for the first factor (drinking habit and 
excretion) was 0.77 (Cronbach's Alpha), for the second factor (assessment and information) 0.81 , for the third factor (documentation) 0.74 and for the fourth factor (support) 0.69.

Factor analysis was performed a second time without the items 16 and 29 explaining $41.8 \%$ of variance (factor $1: 19.3 \%$, factor $2: 9.4 \%$, factor $3: 7.5 \%$ and factor $4: 5.6 \%$ ) The loadings of the items of these four factors are shown in table 1.

Therefore the final urinary incontinence practice scale consists of 28 items with four subscales with ten, six, four and eight items (see appendix 1)

Table 1: Loadings of the $2^{\text {nd }}$ factor analysis

\begin{tabular}{|c|c|c|c|c|}
\hline Item Numbers & Factor 1 & Factor 2 & Factor 3 & Factor 4 \\
\hline 1. & 0.53 & & & \\
\hline 2. & 0.59 & & & \\
\hline 3. & 0.65 & & & \\
\hline 7. & 0.64 & & & \\
\hline 8. & 0.66 & & & \\
\hline 9. & 0.57 & & & \\
\hline 10. & 0.47 & & & \\
\hline 12. & 0.54 & & & \\
\hline 13. & 0.54 & & & \\
\hline 26. & 0.31 & & -0.21 & \\
\hline 4. & & 0.81 & & \\
\hline 5. & & 0.79 & & \\
\hline 6. & & 0.64 & & \\
\hline 11. & & 0.69 & & \\
\hline 20. & & 0.55 & & 0.31 \\
\hline 27 & & 0.70 & & \\
\hline 14. & & 0.24 & 0.58 & \\
\hline 15. & & & 0.74 & \\
\hline 17. & & & 0.75 & \\
\hline 18. & & & 0.69 & \\
\hline 16. & & & - & \\
\hline 29. & & & - & \\
\hline 19. & & 0.25 & & 0.40 \\
\hline 21. & 0.22 & & 0.34 & 0.48 \\
\hline 22. & & & 0.40 & 0.43 \\
\hline 23. & 0.21 & & & 0.65 \\
\hline 24. & & & & 0.62 \\
\hline 25. & 0.21 & & & 0.59 \\
\hline 28. & & 0.23 & & 0.41 \\
\hline 30. & & & & 0.43 \\
\hline
\end{tabular}

\section{Nurses' and nurse assistants' knowledge about urinary incontinence}

The knowledge scale consists of 18 items with a dichotomous measurement scale. The highest possible score is 18 , which means all questions are answered correctly. 


\section{Knowledge of registered nurses}

The knowledge scores ranged from 7 to 17 with a mean of 12.0 (table 2).

96-98\% of the nurses answered correctly on the following three items: Urinary incontinence can occur more often in sneezing, coughing and walking. Having a stroke may lead to urinary incontinence. Toilet training can improve incontinence in older people requiring care.

Approximately $85 \%$ of the nurses did not know the right answer to the questions: On admission to a home, more women are incontinent than men. More than $80 \%$ of all residents in nursing homes suffer from urinary incontinence.

The knowledge of nurse assistants

The scores ranged from 5 to 15 with a mean of 10.1 (table 2).

90-94\% of the nurse assistants answered correctly on the following two items: Urinary incontinence can occur more often in sneezing, coughing and walking. Toilet training can improve incontinence in older people requiring care.

$82-85 \%$ of the nurse assistants did not know the right answer to the questions: Stress incontinence is caused by psychological problems. On admission to a home, more women are incontinent than men. More than $80 \%$ of all residents in nursing homes suffer from urinary incontinence.

The most extreme differences between the knowledge of nurses and nurse assistants are in the items 13 and 15 (Certain medications can treat urinary incontinence. Some antihypertensive or sleep medications can cause urinary incontinence). $78 \%$ of nurses knew the answer to the item 13 , but only $35 \%$ of nurse assistants, respectively $67 \%$ and $33 \%$ to the item 15 .

Table 2: Knowledge: Mean of scores

\begin{tabular}{lcc}
\hline & $\begin{array}{l}\text { Nurses with diploma: } \\
\text { Mean (n: 199) }\end{array}$ & $\begin{array}{l}\text { Nurse assistants: } \\
\text { Mean (n: 113) }\end{array}$ \\
\hline Knowledge scale (max. 18) & 12.0 & 10.1 \\
\hline
\end{tabular}

Association between demographic data and knowledge

The association between the 'knowledge' and demographic characteristics (age, education and experience in the field) was calculated with analysis of variance. It 
shows that education and experience in the field are strongly associated with knowledge $\left(F=25.5 ; p=<0.000 ; R^{2}=0.19\right)$.

\section{Nurses' and nurse assistants' practice about urinary incontinence}

The urinary incontinence practice scale consists of 28 items. It contains four subscales. Table 3 shows the possible scores of each subscale and their interpretations.

Tab. 3: Scores of the four practice subscales

\begin{tabular}{lcccc}
\hline Subscales 1-4 & $\begin{array}{c}\text { Always } \\
\text { done }\end{array}$ & Often done & $\begin{array}{c}\text { Sometimes } \\
\text { done }\end{array}$ & Never done \\
\hline $\begin{array}{l}\text { 1. Drinking habit and excretion } \\
(10 \text { items) }\end{array}$ & 30 points & $15-29$ points & $1-14$ points & 0 points \\
\hline $\begin{array}{l}\text { 2. Assessment and information (6 } \\
\text { items) }\end{array}$ & 18 points & $9-17$ points & $1-8$ points & 0 points \\
\hline 3. Documentation (4 items) & 12 points & $6-11$ points & $1-5$ points & 0 points \\
\hline 4. Support $(8$ items) & 24 points & $13-23$ points & $1-12$ points & 0 points \\
\hline
\end{tabular}

\section{Drinking habit and excretion}

Registered nurses: The scores ranged from 11 to a perfect score of 30 , with a mean of 21.5 (table 4 ). In this subscale, $91.5 \%$ of nurses reported 'always' to item 26 (I know whether the resident wears a pad or other protective device).

Nurse assistants: The scores ranged from 3 to a perfect score of 30 , with a mean of 21.0 (table 4). In this subscale, $90 \%$ of nurse assistants reported 'always' to item 26.

\section{Assessment and information}

Registered nurses: The scores ranged from 2 to 18, with a mean of 12.4 (table 4).

Nurse assistants: The scores ranged from 2 to 18, with a mean of 8.9 (table 4). Approximately $35 \%$ of nurse assistants answered the following statements with "never": On admission and if the health situation changes, I ask the resident how long he/she has been incontinent. I ask residents whether they lose urine especially on sneezing, laughing or coughing.

\section{Documentation}

Registered nurses: The scores ranged from 0 to 12, with a mean of 4.3 (table 4 ). In this subscale, $40 \%$ of the nurses reported 'never' in item 15 (I note in the documentation how much urine the resident loses in an incontinence episode). 
Nurse assistants: The scores ranged from 0 to 12 with a mean of 4.6 (table 4). In this subscale $40 \%$ of the nurse assistants reported 'never' in item 15.

\section{Support}

Registered nurses: The scores ranged from 0 to 24, with a mean of 19.8 (table 4). In this subscale, $92 \%$ of the nurses reported 'always' in the following item: If incontinent residents express a wish to go to the toilet, I help them if necessary.

Nurse assistants: The scores ranged from 0 to 24, with a mean of 20.5 (table 4). Approximately $90 \%$ of nurse assistants reported 'always' in the following items: I inform the ward if a resident becomes incontinent. If incontinent residents express a wish to go to the toilet, I help them if necessary. If incontinent, mobility-limited residents wish to go to the toilet, I help them.

Table 4: Practice: Mean of the scores

\begin{tabular}{lcc}
\hline Subscales 1-4 & $\begin{array}{l}\text { Nurses with diploma: } \\
\text { Mean (n: 199) }\end{array}$ & $\begin{array}{l}\text { Nurse assistants: } \\
\text { Mean (n: 116) }\end{array}$ \\
\hline 1. Drinking habit and excretion (max. 30) & 21.5 & 21.0 \\
\hline 2. Assessment and information (max.18) & 12.4 & 8.9 \\
\hline 3. Documentation (max. 12) & 4.3 & 4.6 \\
\hline 4. Support (max. 24) & 19.8 & 20.5 \\
\hline
\end{tabular}

Association between demographic data and practice

The association between the subscales 'drinking habit and excretion', 'assessment and information', 'documentation' and 'support' and demographic data (age, education and experience in the field) was calculated with analysis of variance. It shows that education is strongly associated with 'assessment and information ( $F=$ 63.0; $p=<0.000 ; R^{2}=0.16$.

No association was found for 'drinking habit and excretion', 'documentation' and 'support' and demographic data (age, education and experience in the field).

\section{DISCUSSION}

This article pursues two goals: the development and testing of a urinary incontinence knowledge and practice instrument as well as reporting on the results on nurses' knowledge and practice about urinary incontinence. 
This study shows that nurses' knowledge regarding urinary incontinence is satisfactory and that of nurse assistants is somewhat lower than that of nurses. This is seen also in items 13 and 15 about medication. Because nurse assistants are less educated than nurses, this result seems logical. More than $90 \%$ of nurses and nurse assistants know that 'Urinary incontinence occurs frequently when sneezing, coughing and walking' and 'Toilet training can improve incontinence in older residents requiring care'. It could be that basic knowledge about urinary incontinence and urinary-incontinent residents does exist, but specific knowledge does not. This is also seen in that more than $82 \%$ of nurses and nurse assistants do not know the right answers for the items 7 and 8 'On admission to a home, more women are incontinent than men'. 'More than $80 \%$ of all residents in nursing homes suffer from urinary incontinence'. The association between 'experience in the field' and 'knowledge' shows the importance of experience with urinary-incontinent residents.

A comparison with Henderson's study (Henderson \& Kashka, 2000) shows that the knowledge level of US nurses was higher than that of Swiss nurses. The difference could be because of the different scales and samples or because US nurses really had a higher knowledge level.

The urinary incontinence practice instrument consists of four distinct subscales. In the subscale 'drinking habit and excretion', the mean scores of the nurses and nurse assistants are nearly the same. The lack of difference in this subscale could be because these tasks are equally performed by nurses and nurse assistants.

In subscale 'assessment and information', the mean score of nurses is higher than that of nurse assistants. Because the tasks in this subscale are more in line with the responsibility of nurses than nurse assistants, it seems logical that the score of nurses is higher than that of nurse assistants. It is therefore not surprising that $35 \%$ of nurse assistants never perform the following tasks: 'On admission and if the health status changes, I ask the resident how long he/she has been incontinent' and 'I ask residents whether they lose urine especially on sneezing, laughing or coughing'.

In the subscale 'documentation', the mean of both groups is low. The low score of the nurses is remarkable because the responsibility for documentation lies mainly with the nurses, not nurse assistants. However, nurse assistants have also the task of documenting e.g. to fill out a bladder and drink diary. The lack of difference of the scores of nurses and nurse assistants and the low scores could be because 
documentation is often a problem in nurses' work, and not only in urinary incontinence care.

In the subscale 'support', the mean of nurses is lower than that of the nurse assistants. The higher score of the nurse assistants shows that nurse assistants work more in the area 'support' than nurses. This could be because of the different tasks of nurses and nurse assistants in the care of their residents.

Because the analysis of variance shows that 'education' is strongly associated with 'assessment and information', it could be important to influence actions in this subscale with better education.

The KPI has been carefully developed and the content validity evaluated by a panel of experts. The KPI consists of two scales: the urinary incontinence knowledge scale and the practice scale with four subscales. The factor analysis of the urinary incontinence practice scale showed that a four-factor model yielded an explained variance of $41.8 \%$. The assignment of the variables to the first, second and third factor is very clear. In the fourth factor, some variables load on two components, but the highest loadings are found in the fourth factor. The reliability for the four subscales of the practice scale was adequate. Nevertheless, the overall reliability and validity of the KPI is quite good.

\section{LIMITATIONS}

In this study, a convenience sample was used which may have influenced the result. Another limitation of this study is that we had to develop a new instrument, and future research is needed to show if it is reliable and valid enough. However our results are promising in this respect.

\section{CONCLUSIONS}

The results show a lack of specific knowledge about urinary incontinent residents, therefore especially nurses have to be re-educated in the specific knowledge and this knowledge has to be integrated in nursing education. Probably nurse assistants do not need the specific knowledge, but nurses do, because they are responsible for the residents and the care planning. 
There is a need for improving practice, especially in documentation. Nurses and nurse assistants should receive adequate support in documentation. Good documentation is important because this helps the nurses and nurse assistants to give each resident uniform and appropriate care. Because education and experience in the field are not associated with documentation, other supportive interventions, e.g. 'on-the-job-training' and positive role models are needed for improving practice of documentation. And the importance of documentation should be taught in nursing schools and incorporated in the curriculum.

Also improvement in 'drinking habit and excretion' and 'assessment and information' is necessary, because documentation is only possible if nurses know how much the residents drink or excrete. For care planning a serious assessment is necessary; with this information nursing care could be planned, carried out and evaluated. Introducing of evidence-based practice guidelines could also be a way to improve practice. 


\section{Appendix 1: Knowledge and Practice Instrument (KPI)}

\section{Knowledge}

1. Urinary incontinence improves in most residents with suitable treatment.

2. When awake, most people need to empty the bladder every $2-4$ hours.

3. Stress incontinence is caused by psychological problems.

4. A bladder infection can cause urinary incontinence.

5. Older men may suffer from urinary incontinence after a prostate surgery.

6. Urinary incontinence can occur more often in sneezing, coughing or walking.

7. On admission to a home, more women are incontinent than men.

8. More than $80 \%$ of all residents in nursing homes suffer from urinary incontinence.

9. Diabetes can cause urinary incontinence.

10. Having a stroke may lead to urinary incontinence.

11. More residents suffer from urinary incontinence after being in a nursing home for a year than at admission.

12. Mobility-limited residents are equally often urinary incontinent as mobile residents.

13. Certain medications can treat urinary incontinence.

14. Older people who have Parkinson are also often incontinent.

15. Some antihypertensive or sleep medications can cause urinary incontinence.

16. Urinary incontinence is a normal part of ageing (over 65 years).

17. Toilet training can improve incontinence in older people requiring care.

18. Demented residents are more often urinary incontinent than non-demented residents.

(Some questions are based on the practice segment of the Urinary Incontinence Scale by Jane Schade Henderson, 1996)

\section{Practice}

Drinking habit and excretion

1. I know how much the residents drink.

2. I know the times at which the residents drink.

3. I know whether the residents drink beverages with caffeine or other beverages with diuretic effects (e.g. coffee, cola etc.).

7. I know how much urine the residents lose in an incontinence episode (damp underpants, wet pads, etc.).

8. If the resident is demented, I control how much urine they lose in an incontinence episode (damp underpants, wet pads, etc.).

9. I know how often the incontinent residents go to the toilet (e.g. every 30 minutes, every 3 hours, etc.).

10. I know the situations (e.g. during morning coffee, taking a walk, bathing etc.), in which the residents are incontinent/lose urine.

12. I know the frequency of incontinence episodes of the residents (e.g. once a week, several times a day, etc.).

13. If the resident is demented, I check the times at which he/she loses urine.

26. I know whether the resident wears a pad or other protective device.

\section{Assessment and information}

4. On admission and if the health status changes, I ask the resident how long he/she has been incontinent.

5. I ask the residents whether they notice that they lose urine.

6. I ask incontinent residents about secondary episodes in using the toilet (such as pain on urinating, feeling of urgency, dripping).

11. I ask residents whether they lose urine especially on sneezing, laughing or coughing.

20. If a resident become incontinent, I inform the doctor.

27. If the resident was already incontinent at home, I ask what she/he did about it and whether it helped.

\section{Documentation}

14. I note in the documentation the times at which the residents are incontinent.

15. I note in the documentation how much urine the resident loses in an incontinence episode.

16. It makes no sense to write down how much the incontinent residents drink. 
17. I note in the documentation the times at which the incontinent residents drink.

18. I note in the documentation what the incontinent residents drink.

29. If demented incontinent residents express a wish to go to the toilet, I tell them they can go in the pads.

\section{Support}

19. I inform the ward if a resident becomes incontinent.

21. I set up a toilet plan for incontinent residents who have no or only slight mental incapacity.

22. I set up a toilet plan for demented, incontinent residents (if they don't already have one).

23. If incontinent residents have a toilet plan, I request that they use the toilet according to the toilet plan.

24. If demented, incontinent residents have a toilet plan, I request that they use the toilet according to the toilet plan.

25. I help mobility-limited incontinent residents to use the toilet according to the toilet plan.

28. If incontinent residents express a wish to go to the toilet, I help them if necessary.

30. If mobility-limited incontinent residents express the wish to use the toilet, I help them.

(Some questions are based on the practice segment of the Urinary Incontinence Scale by Jane Schade Henderson, 1996) 


\section{References}

Adelmann, PK. (2004). Prevalence and detection of urinary incontinence among older medicaid recipients. Journal of Health Care for the Poor and Underserved, 15, 99-112.

Aggazzotti, G., Pesce, F., Grassi, D., Fantuzzi, G., Righi, E., De Vita, D., SantaCroce, S., Artibani, W. (2000). Prevalence of urinary incontinence among institutionalized patients: A cross-sectional epidemiological study in a midsized city in northern Italy. Urology, 56, 245249.

Brandeis, GH., Baumann, MM., Hossain, M., Norris, JN., Resnick, NM. (1997). The prevalence of potentially remediable urinary incontinence in frail older people: A study using the minimum Data set. Journal of the American Geriatrics Society, 45, 179-184.

Burgio, LD., McCormick, KA., Scheve, AS., Engel, BT., Hawkins, A., Leahy, E. (1994). The effects of changing prompted voiding schedules in the treatment of incontinence in nursing home residents. Journal of the American Geriatric Society, 42, 315-320.

Colling, J., Ouslander, J., Hadley, BJ., Eisch, J., Campbell, E. (1992). The effects of patterned urge-response toileting (PURT) on urinary incontinence among nursing home residents. Journal of the American Geriatric Society, 40, 135-141.

Colling, J., Owen, TR., McCreedy, M., Newman, D. (2003). The effects of a continence program on frail community-dwelling elderly persons. Urologic Nursing, 23, 117-122, 127131.

Fantl, JA., Newman, DK., Colling, J., DeLancey, JOL., Keeys, C., Loughery, R., et al. (1996). Urinary Incontinence in Adults: Acute and chronic Management. Clinical Practice Guideline, No. 2, 1996 update. Department of Health and Human Services, Public Health Service, Agency for Health Care Policy and Research. AHCPR Publication No. 96-0682: Rockville.

Henderson, JS. (1996). Urinary Incontinence Attitude, Belief, Practice and Knowledge Scales. In Nurses' attitude, belief, practice, and knowledge regarding urinary incontinence in adults: LISREL analysis of a model. Unpublished doctoral dissertation, Texas Woman' University, Denton, TX.

Henderson, JS., Kashka, MS. (2000). Effect of knowledge, attitude, and belief on nurses' practice regards urinary incontinence in adults. Urologic Nursing, 20, 291-305.

Lekan-Rutledge, D., Palmer, M., Belyea, M. (1998). In their own words: nursing assistants perceptions barriers to implementation of prompted voiding in long-term care. Gerontologist, $38,370-378$.

Ouslander, JG., Ai-Sammarrai, N., Schnelle, JF. (2001). Prompted voiding for nighttime incontinence in nursing home: Is it effective? Journal of the American Geriatric Society, 49, 706-709.

Polit, DF., Beck, CT. (2004). Nursing research: Principles and methods. $7^{\text {th }}$ ed. Lippincott Williams \& Wilkins, Philadelphia, pp. 423.

Saxer, S., Halfens, RJG., Müller, M., Dassen, T. (2005). Risk factors for urinary incontinence in nursing home residents. Swiss Medical Weekly, 135, 495-502. 
Saxer, S., Halfens, RJG., De Bie, R., Dassen, T. (2008). Prevalence and incidence of urinary incontinence of Swiss nursing home residents at admission and after 6, 12 and 24. Journal of Clinical Nursing. doi:10.1111/j.1365-2702.2007.02055.x.

Schnelle, F., Alessi, CA., Simmons, SF., Al-Sammarrai, NR., Beck, JC., Ouslander, JG. (2002). Translating clinical research into practice: A randomized controlled trial of exercise and incontinence care with nursing home residents. Journal of the American Geriatric Society, 50, 1476-1483.

Watson, NM., Brink, CA., Zimmer, JG., Mayer, RD. (2003). Use of the agency or health care policy and research urinary incontinence guideline in nursing homes. Journal of the American Geriatric Society, 51, 1779-1786. 


\section{CHAPTER 5}

Nurses' Attitude and Beliefs about Urinary Incontinence in Nursing Home Care

Susi Saxer, Ruud JG. Halfens, Theo Dassen, Rob A. de Bie (2007) submitted for publication 


\title{
Nurses' Attitude and Beliefs about Urinary Incontinence in Nursing Home Care
}

\begin{abstract}
About $60 \%$ of nursing home residents suffer from urinary incontinence. Nurses have a major responsibility in the care of incontinent residents. Therefore nurses need adequate knowledge and a positive attitude toward incontinent patients. This article reports on nurses and nurse assistants' attitudes and beliefs regarding urinary incontinence in nursing home residents in Switzerland.

199 registered nurses and 116 nurse assistants who work in one of the ten municipal nursing homes of Zurich were questioned with the German version of Hendersons' attitude and belief scale. Findings show that nurses and nurse assistants had a negative belief regarding urinary incontinence. Nurses' behavioural and emotional attitude towards urinary incontinence residents is positive. Nurse assistants' behavioural attitude is also positive, but their emotional attitude tends to be negative. The associations between demographic data and beliefs and attitudes are presented. These results serve as a basis for re-educating, supporting, and training in incontinence care.
\end{abstract}




\section{INTRODUCTION}

About $60 \%$ of nursing home residents suffer from urinary incontinence (Adelmann, 2004, Aggazzotti et al. 2000, Brandeis et al. 1997, Saxer et al. 2008). Prevalence of urinary incontinence increases with age (Adelmann 2004, Aggazzotti et al. 2000, Saxer et al. 2008). Incontinence is also a costly problem in nursing home residents and it decreases the independence and self-esteem of older people and restricts social activities. Nurses in collaboration with other health care professionals have a major responsibility in the care of incontinent residents. Therefore nurses need adequate knowledge and a positive attitude toward incontinent patients.

Research shows the availability of effective interventions for urinary incontinence in older people (Fantl et al. 1996), e.g. habit retraining and timed voiding (Colling et al. 1992, Fantl et al. 1996, Palmer et al. 1994). This knowledge should be used in nursing practice (Roe et al. 2004).

Attitudes and beliefs and what one has learned ultimately influence professional actions (Henderson \& Kashka, 1999). Nursing staffs' attitude towards urinary incontinent residents may also influence the quality of care provided (Vinsnes et al. 2001). Nurses' feelings towards urinary incontinent patients have also been investigated. Staff has mainly positive reactions towards patients with urinary incontinence (Campbell et al. 1991, Cheater 1991, Yu et al. 1991). On the other hand, staff also report that urinary incontinence is difficult and frustrating to deal with (Vinsnes et al. 2001, Yu et al. 1991).

Henderson and Kashka (2000) studied the attitude, knowledge and practice of American nurses. These nurses showed on average positive attitudes and beliefs towards urinary incontinent patients (89 out of 120 points, respectively 70 out of 138 points). The research group of Vinsnes et al. (2001) found more negative than positive attitude toward urinary incontinent people among Norwegian nurses and nurse assistants, although nurse assistants showed more positive attitudes and feelings than registered nurses (Vinsnes et al. 2001). The interviewees in both studies worked in hospitals, home care and nursing homes, and nurses in Henderson's study also worked in different positions, as staff nurses, supervisors or managers. Because of the contradictory results and the different sample in the two studies, easy transfer of these findings to nursing home care is impossible.

Therefore, the aim of the study is to explore nurses' and nurse assistants' attitude and beliefs regarding urinary incontinence in nursing home residents in Switzerland. 
Since no German questionnaire about attitude and beliefs is available, the study was conducted in two phases: (1) translation and pre-test of Henderson's Urinary Incontinence Attitude and Beliefs Scale (1996) and (2) validation of the translated scales and exploration of nurses' and nurse assistants' attitude and beliefs.

\section{PHASE 1: TRANSLATION OF HENDERSON'S ATTITUDE AND BELIEFS SCALE Methods}

The URINARY INCONTINENCE SCALES@ (Henderson, 1996) about attitude and beliefs was translated from English to German and pre-tested.

\section{The English and German version of Hendersons' attitude and beliefs scale}

The original English version of Hendersons' attitude and beliefs scale is a part of the URINARY INCONTINENCE SCALESC) (Henderson, 1996) and consists of 43 questions. It is divided into two subscales: attitude and beliefs. The subscale attitude consists of 20 items and the beliefs scale of 23 items; all with a six-point Likert scale (ranging from strongly agree to strongly disagree). Table 1 shows an example of the attitude and beliefs scale. After receiving Henderson's written permission to translate and use her attitude and beliefs scale in Switzerland, the scale was translated from English to German and from German to English by two different professional translators. The English version and the Original version of Henderson (1996) were compared. Only small differences were observed, which could be resolved with the translators.

Table 1: Examples of questions about Henderson's attitude and beliefs

- Attitude: Nurses should ask patients if they have urinary incontinence

- Beliefs: Urinary incontinence is a heavy burden for men who have it.

\section{Pre-test}

A pre-test was performed to test the feasibility of the German version of Henderson's questionnaire with a convenience sample of twenty persons, consisting of seven 
nurse assistants and thirteen registered nurses in one nursing home. They filled out the questionnaires. After each item was discussed, the nurses and nurse assistants gave their comments about the comprehensibility of the questions. Analysis of this pre-test showed that nurses and nurse assistants had difficulties acknowledging they have to give the answer from their own point of view, and not the resident's. Therefore, all items were reformulated to emphasize that the item is about their attitude and beliefs. The content of the items stayed the same. Examples are: 'According to me, nurses should ask patients if they have urinary incontinence'. Or 'I think urinary incontinence is a heavy burden for men who have it'. One question was changed a little, because in the English version it was asked whether 'The genitourinary history should be a part of nursing assessment'. In Switzerland the genitourinary history is an unequivocal part of the medical assessment. Therefore, Swiss nurses and nurse assistants were asked about a specific urinary incontinent assessment relevant for nurses.

The scale was completed with questions about demographic data of interviewees.

\section{PHASE 2: SURVEY OF NURSES' ATTITUDE AND BELIEFS ABOUT URINARY INCONTINENCE}

\section{Design}

A cross-sectional design with a convenience sample of nurses and nurse assistants was used.

\section{Sample}

The convenience sample consisted of 199 registered nurses and 116 nurse assistants who work in one of the ten municipal nursing homes of Zurich, representing approximately one-third of the nurses and nurse assistants employed at these nursing homes. The municipal nursing homes of Zurich are similar, with respect to the residents, staff and management.

Swiss nurses and nurse assistants differ with respect to education, as well as the area of responsibility. Nurses have received an education of three years and nurse assistants only one year. However, both groups work with residents and are involved in the care of urinary incontinent patients, e.g. they accompany residents to the toilet or change pads, they instruct residents for scheduled toileting. Nurses have the 
responsibility for residents and the planning of care. Nurse assistants have the responsibility for their daily work.

\section{Ethical considerations}

Nurses and nurse assistants participated on a voluntary basis and data provided were kept anonymous. The Ethics Committee's president of the municipal nursing homes of Zürich approved the research.

\section{Data collection}

Nurses and nurse assistants who work in one of the ten municipal nursing homes of Zurich were invited to participate in the survey on a voluntary basis after permission was obtained from the head of the nursing homes and the nurse managers. The clinical nurse specialists were asked to act as contact persons. In a personal instruction, the clinical nurse specialists were familiarized with the aims of the research project and data collection. The clinical nurse specialists of the ten nursing homes organized the measurement in a school room for all nurses and nurse assistants, who participated on a voluntary basis in the project. Each participant received the questionnaires, an envelope and an accompanying letter that explained the complete research project, the instructions for filling out the questionnaire and the written assurance that participation was voluntary and anonymous. After the participants had filled out the questionnaires, they put them in an envelope, sealed the envelope, and gave it to the clinical nurse specialists. The latter sent the questionnaires to the researchers.

\section{Data Analysis}

The statistical analysis was carried out in SPSS 13.0. For the attitude and beliefs scale, an exploratory factor analysis was employed with principal varimax rotated component analysis. Reliability estimates were based on Cronbach's Alpha with Interclass Correlation Coefficients. Descriptive data were provided where applicable. The ANOVA was performed to test the association between demographic data (age, education, experience in the field) with attitude and beliefs. The variable 'age' was divided into three similarly large groups: < 33 years, 33 - 43 years and > 43years, the variable 'education' identifies two groups: nurses with diploma and nurse 
assistants and the variable 'experience in the field' distinguished between three groups: $<3$ years, $3-10$ years and $>10$ years.

Possible answers on the six-point Likert scale ranged from 1-6 (strongly agree to strongly disagree). Negatively stated items were recoded.

\section{RESULTS}

Registered nurses and nurse assistants were between 18 and 63 years old, with a mean of 28 years. $40 \%$ were younger than 33 years, $28 \%$ were 33 to 43 years and $32 \%$ were older than 43 years. $39 \%$ of the participants had more than 10 years experience in the care of old people, $40 \%$ between 3 and 10 years, $21 \%$ less than 3 years.

\section{Validity and reliability}

Construct validity of the scale was examined by conducting a principal component analyses. According to the screeplot three factors were important. The three-factor model yielded an explained variance of $34.8 \%$ : factor $1: 16.6 \%$, factor $2: 9.3 \%$ and factor $3: 8.9 \%$. The first factor contains twenty-two items, and has been labelled 'beliefs'. It concerns nurses' beliefs about urinary incontinence in general. The second factor contains nine items, and has been labelled 'behavioural attitude', reflecting a perspective that influences the behaviour towards care of incontinent residents. The third factor contains eleven items, and has been labelled 'emotional attitude', reflecting a perspective that influences thought, feeling and perception towards incontinent residents. Item 32 loaded less than 0.2 and has therefore been deleted. The loadings of the items of these three factors are shown in table 2 . The reliability for each subscale was calculated with Cronbach's Alpha. Reliability for the first factor (beliefs) was 0.88 , for the second factor (behavioural attitude) 0.71 and for the third factor (emotional attitude) 0.71 .

\section{The beliefs and attitude of nurses and nurse assistants about urinary incontinence}

As a result of the factor analysis, the German version of the urinary incontinence attitude and beliefs scale consists of 42 items and contains three subscales. Table 3 shows the possible scores of each subscale and their interpretations. 
Table 2: Loadings of the factor analysis

\begin{tabular}{|c|c|c|c|}
\hline Item Numbers * & beliefs & behavioural attitude & emotional attitude \\
\hline 1. & .38 & \multirow[t]{11}{*}{.37} & \\
\hline 3. & .42 & & \\
\hline 5. & .31 & & \\
\hline 8. & .52 & & \\
\hline 9. & .41 & & \\
\hline 10. & .66 & & \\
\hline 11. & .67 & & \\
\hline 12. & .72 & & \\
\hline 14. & .68 & & \\
\hline 15. & .64 & & \\
\hline 16. & .46 & & \\
\hline 17. & .46 & \multirow[t]{6}{*}{-.42} & \\
\hline 19. & .44 & & \\
\hline 20. & .46 & & \\
\hline 25. & .65 & & \\
\hline 27. & .40 & & \\
\hline 29. & .48 & & \\
\hline 30. & .47 & \multirow[t]{4}{*}{-.35} & \\
\hline 31. & .55 & & \\
\hline 34. & .32 & & \\
\hline 39. & .60 & & \\
\hline$\frac{43 .}{2 .}$ & \multirow{9}{*}{-.36} & .45 & \\
\hline 4. & & .54 & \\
\hline 22. & & .35 & \\
\hline 23. & & .65 & \\
\hline 35. & & .33 & \\
\hline 36. & & .45 & \\
\hline 37. & & .43 & \\
\hline 40. & & .63 & \\
\hline 41. & & .63 & \\
\hline 6. & \multirow{3}{*}{$\begin{array}{l}.30 \\
.30\end{array}$} & \multirow{5}{*}{-.43} & .39 \\
\hline 7. & & & .68 \\
\hline 13. & & & .56 \\
\hline 18. & \multirow[t]{7}{*}{.40} & & .50 \\
\hline 21. & & & .51 \\
\hline 24. & & & .30 \\
\hline $\begin{array}{l}26 . \\
28 .\end{array}$ & & -.47 & $\begin{array}{l}.58 \\
.50\end{array}$ \\
\hline 33. & & .30 & .37 \\
\hline 38. & & & .55 \\
\hline 42. & & & .63 \\
\hline
\end{tabular}

Tab. 3: Scores of the three subscales

\begin{tabular}{|l|l|l|l|l|l|l|}
\hline Subscales 1-3 & $\begin{array}{l}\text { Strongly } \\
\text { positive } \\
\text { beliefs or } \\
\text { attitude }\end{array}$ & $\begin{array}{l}\text { Moderately } \\
\text { positive } \\
\text { beliefs or } \\
\text { attitude }\end{array}$ & $\begin{array}{l}\text { Positive } \\
\text { beliefs } \\
\text { or } \\
\text { attitude }\end{array}$ & $\begin{array}{l}\text { Negative } \\
\text { beliefs or } \\
\text { attitude }\end{array}$ & $\begin{array}{l}\text { Moderately } \\
\text { negative } \\
\text { beliefs or } \\
\text { attitude }\end{array}$ & $\begin{array}{l}\text { Strongly } \\
\text { negative } \\
\text { beliefs or } \\
\text { attitude }\end{array}$ \\
\hline Beliefs & 132 points & $110-131$ & $88-109$ & $66-87$ & $44-65$ & $22-43$ \\
\hline Behavioural Attitude & 54 points & $45-53$ & $36-44$ & $27-35$ & $16-26$ & $5-15$ \\
\hline Emotional Attitude & 66 points & $55-65$ & $44-54$ & $33-43$ & $22-32$ & $11-21$ \\
\hline
\end{tabular}




\section{The beliefs of nurses with diploma and nurse assistants (subscale 1)}

Nurses: The scores ranged from 42 to 112 points with a mean of 81.9 points (table 5 ), implying that nurses' beliefs about urinary incontinence are negative (table 3 ). The items 3 and 8 show highest scores and the items 17 and 30 lowest (table 4).

Nurse assistants: The scores ranged from 46 to 123 points with a mean of 85.7 points (table 5), showing that nurse assistants' beliefs about urinary incontinence are also negative (table 3 ). The items 3 and 8 show also highest scores for nurse assistants and the items 17 and 30 lowest (table 4).

Tab. 4: Highest and lowest means of single items in the subscale, beliefs, behavioural attitude

\begin{tabular}{|l|c|c|}
\hline Beliefs: Items & $\begin{array}{c}\text { Nurses with diploma: } \\
\text { Mean }\end{array}$ & $\begin{array}{c}\text { Nurse assistants: } \\
\text { Mean }\end{array}$ \\
\hline 3. Urinary incontinence is an annoying thing to have. & 5.4 & 5.4 \\
\hline 8. Having urinary incontinence is a big problem. & 5.3 & 5.3 \\
\hline $\begin{array}{l}\text { 17. A person can feel comfortable with urinary } \\
\text { incontinence }\end{array}$ & 2.1 & 2.6 \\
\hline $\begin{array}{l}\text { 30. Urinary incontinence in women is a hopeless } \\
\text { situation }\end{array}$ & 2.3 & \\
\hline Behavioural attitude: items & & 5.5 \\
\hline $\begin{array}{l}\text { 2. Nursing practice should offer many opportunities to } \\
\text { help people with urinary incontinence }\end{array}$ & 5.7 & 5.4 \\
\hline $\begin{array}{l}\text { 4. Nurses should be knowledgeable enough to care } \\
\text { for clients with urinary incontinence }\end{array}$ & 5.7 & 4.2 \\
\hline $\begin{array}{l}\text { 35. Nurses should ask patients if they have urinary } \\
\text { incontinence }\end{array}$ & 4.6 & 4.4 \\
\hline $\begin{array}{l}\text { Emotional attitude: items } \\
\text { 7. Having urinary incontinence does not decrease } \\
\text { self-esteem in women }\end{array}$ & 5.1 & 4.6 \\
\hline $\begin{array}{l}\text { 33. There is little help a nurse can give a patient with } \\
\text { urinary incontinence }\end{array}$ & 4.9 & 3.0 \\
\hline $\begin{array}{l}\text { 26. Working with women who have urinary } \\
\text { incontinence is rewarding }\end{array}$ & 3.1 & \\
\hline
\end{tabular}

The behavioural attitude of nurses with diploma and nurse assistants (subscale 2)

Nurses: The scores ranged from 30 to 54 points with a mean of 47.2 points (table 5), showing that nurses' behavioural attitude toward urinary incontinent residents is moderately positive (table 3). In this subscale, items 2 and 4 scored highest and item 35 lowest (table 4). 
Nurse assistants: The scores ranged from 23 to 54 points with a mean of 44.1 points (table 5), implying that nurse assistants' behavioural attitude toward urinary incontinent residents is positive (table 3). In this subscale, items 2 and 4 scored also highest in nurse assistants and item 35 lowest (table 4).

\section{The emotional attitude of nurses with diploma and nurse assistants (subscale}

\section{3)}

Nurses: The scores ranged from 28 to 65 points with a mean of 47.5 points (table 5), reflecting that nurses' emotional attitude toward urinary incontinent residents is positive (table 3). In this subscale, items 7 and 33 scored highest (table 4) and item 26 lowest (table 4).

Nurse assistants: The scores ranged from 21 to 65 points with a mean of 42.7 points (table 5), implying that nurse assistants' emotional attitude toward urinary incontinent residents is negative (table 3). In this subscale, items 7 and 33 scored also highest in nursing assistants and the item 26 lowest (table 4).

Table 5: Attitude and Beliefs: Means of the scores

\begin{tabular}{|l|c|c|}
\hline Subscales 1-4 & $\begin{array}{c}\text { Nurses with diploma: } \\
\text { Mean (n: 199) }\end{array}$ & $\begin{array}{c}\text { Nurse assistants: } \\
\text { Mean (n: 116) }\end{array}$ \\
\hline 1. Beliefs (max. 132) & 81.9 & 85.7 \\
\hline 2. Behavioural attitude (max.54) & 47.2 & 44.1 \\
\hline 3. Emotional attitude (max. 66) & 47.5 & 42.7 \\
\hline
\end{tabular}

\section{Association between demographic data and beliefs and attitude}

Association between the demographic data (age, education and experience in the field) and each of the subscales 'beliefs, behavioural and emotional attitude' was performed. The choice of the model was based on the criteria $\mathrm{R}^{2}$.

Behavioural attitude: 'Age, education and experience in the field' are strongly associated with 'behavioural attitude' $\left(F=12.6 ; p=0.000 ; R^{2}=0.17\right)$.

Emotional attitude: 'Education' is strongly associated with 'emotional attitude' ( $F=$ 36.6; $p=0.000 ; R^{2}=0.10$ ). The demographic data 'age and experience in the field' are unimportant.

Beliefs: No association was found between the demographic data 'age, education and experience in the field' and 'beliefs'. 


\section{DISCUSSION AND CONCLUSION}

This article pursues two goals: the translation and testing of Henderson's Urinary Incontinence Attitude and Beliefs Scale (1996) as well as reporting on the results on nurses' and nurse assistants' attitude and beliefs about urinary incontinence. The German version of Hendersons' attitude and beliefs scale consists of three subscales: beliefs, behavioural attitude and emotional attitude. Nurses and nurse assistants' beliefs are negative. The behavioural attitude in both groups can be labelled as positive, while the emotional attitude is positive for nurses and negative for nurse assistants.

The noted negative beliefs can be caused because nurses find care for urinary incontinent patients often difficult and frustrating (Colling et al. 1992, Vinsnes et al. 2001). These results did not coincide with the result of Henderson and Kashka (2000). However, Vinsnes et al. (2001) also found more negative than positive reactions towards patients, and more positive feelings of nurse assistants than of registered nurses (Vinsnes et al. 2001), as in the present study. The reason for the differences can be the different sample of the studies and/or the country where the studies took place. Hendersons and Kashka (2000) investigate American nurses in different nursing fields and Vinsnes et al. (2001) Norwegian nurses and nurse assistants in nursing homes, home and acute care, and the present study Swiss nurses and nurse assistants in nursing homes.

Interestingly, nurses and nurse assistants scored the same items as highest and lowest. They both strongly agree that 'Urinary incontinence is an annoying thing to have' and 'Having urinary incontinence is a big problem'. These results could show that nurses and nurse assistants are willing to take steps to relieve the urinary incontinence of the residents. The low scores on items 17 and 30 (A person can feel comfortable with urinary incontinence. Urinary incontinence in women is a hopeless situation) support these results. The higher scores of the items 17 and 30 of the nurse assistants are interesting, but difficult to explain. One probable explanation is the fact that nurse assistants often deal more directly with residents' care than registered nurses.

However, for nursing care it is important that nurses and nurse assistants have positive beliefs towards urinary incontinent residents. Since education does not seem to be associated with beliefs; (improving) education does not seem to be the right 
way to change the beliefs of nurses and nurse assistants. On-the-job-training and/or motivational training could be a way to support nurses and nurse assistants.

In the subscale 'behavioural attitude' the mean score of nurses indicates a moderately positive attitude towards nursing home residents, and the mean score of nurse assistants indicates a positive attitude. These differences of nurses and nurse assistants could be because of the difference in education. Henderson and Kashka (2000) found a positive attitude among nurses. In the present study the attitude is moderately positive: Swiss nurses yielded a higher score than American nurses. But the comparison with Henderson and Kashkas' work should be done with caution, because they had one subscale 'attitude', and the present study two, and a different study sample.

Nurses and nurse assistants scored the same items as highest and lowest. Item 35 (Nurses should ask patients if they have urinary incontinence) scores lowest. Since it is important to ask residents this question, nurses and nurse assistants should be educated in this case.

Age, education and experience in the field are strongly associated with behavioural attitude. Age and experience in the field is difficult to influence, but education could be influenced. Because of the lower score of nurse assistants, better education should have a positive influence on the nurse assistants' behavioural attitude. The positive and moderately positive attitude of nurse assistants and nurses should positively influence the care of incontinent residents, because it concerns 'attitude, which influences the behaviour'.

In the subscale 'emotional attitude' the mean score of nurses indicates a positive attitude towards nursing home residents, and the mean score of nurse assistants indicates a negative attitude. The difference in scores might reflect the fact of better education. Also Henderson and Kashka (2000) found a positive attitude among nurses, in correspondence with the present study. The low score of item 26 (Working with women who have urinary incontinence is rewarding) of nurses and nurse assistants confirm the fact, that 'Nurses find care for urinary incontinent patients often difficult and frustrating' (Colling et al. 1992, Vinsnes at al. 2001). Item 13 is the same statement, but in men. These scores are also low (nurses: 3.6, nurse assistants 3.5). 
Education is strongly associated with emotional attitude. Because of the negative 'emotional attitude' of nurse assistants, they should receive better education, especially in the area of emotional attitude. Despite the more positive result among nurses, it is important that both groups receive better education. However, the education has to be adapted specifically to the two groups. Since nurses and nurse assistants find care for urinary incontinent patient often difficult and frustrating (Colling et al. 1992, Vinsnes et al. 2001), it is important to support nurse assistants and nurses and give them on-the-job-training and/or motivation training.

The German version of Henderson's Urinary incontinence Attitude and Beliefs Scale (1996) has been carefully translated and adapted. This German Scale consists of three subscales compared to the English version, which consists of two subscales. Henderson's Beliefs subscale consists of 23 items, the German version of 22 items. Items 6, 7, 18 and 28 are in the original beliefs scale, whereas these items in the German version are in the subscale 'Emotional Attitude'. Items 9, 16, and 19 are in the German version in the belief scale, whereas these items in the original version are in the attitude scale. Henderson's attitude scale consists of 20 items and the German version consists of two subscales. Behavioural attitude consists of nine items; these items are the same as in Henderson's version. Emotional Attitude consists of eleven items, seven items are the same as in Henderson's attitude scale and four items are in Henderson's beliefs scale. These small differences may be caused by the translation, cultural differences and by the different samples of the two studies. Henderson's sample consists of nurses from all nursing fields and in this study the sample consists of nurses and nurse assistants in geriatrics. A further reason can be the larger sample of the present research.

According to the screeplot three factors were important. The assignment of the majority of variables to the first, second and third factor is clear. Some variables load in two components, but the highest loadings are unequivocal in the factor one, two or three, with an exception. Item one is loading on two factors, in factor one and two almost equally. Because the highest loading is on factor one, this item is assigned to factor one. The reliability for the three subscales was acceptable.

For future studies, understanding the relationship of beliefs, attitude and knowledge with practice of nurses and nurse assistants would be advantageous. In addition, 
experimental research about the effect of training and education in incontinence care should be explored. The German version of the attitude and belief scale should be further evaluated.

These results about nurses' and nurse assistants' beliefs, behavioural and emotional attitude serve a basis for re-educating, supporting, and training in incontinence care. The use of more vivid and creative teaching methods about urinary incontinence and incontinent residents should be considered, such as role playing, case studies and situation-specific discussions. Also close cooperation with incontinence advisers could be a way to more positive beliefs and attitude toward incontinent residents.

A lot of residents in nursing homes are urinary incontinent and they have the right to excellent care; therefore support for nurses and nurse assistants in incontinence care is of utmost importance. 


\section{References}

Adelmann, PK. (2004). Prevalence and detection of urinary incontinence among older medicaid recipients. Journal of Health Care for Poor and Underserved, 15, 99-112.

Aggazzotti, G., Pesce, F., Grassi, D., Fantuzzi, G., Righi, E., De Vita, D., SantaCroce, S., Artibani, W. (2000). Prevalence of urinary incontinence among institutionalized patients: A cross-sectional epidemiological study in a midsized city in northern Italy. Urology, 56, 245249.

Brandeis, GH., Baumann, MM., Hossain, M., Norris, JN., Resnick, NM. (1997). The prevalence of potentially remediable urinary incontinence in frail older people: A study using the minimum Data set. Journal of the American Geriatrics Society, 45, 179-184.

Campbell, EB., Knight, M., Benson, M., Colling, J. (1991). Effect of an incontinence training program on nursing home staff's knowledge, attitude, and behaviour. The Gerontologist, 31 , 788-794.

Colling, J., Ouslander, J., Hadley, B., Eisch, J., Campbell, E. (1992). The effects of patternd urge-response toileting (PURT) on urinary incontinence among nursing home residents. Journal of the American Geriatrics Society, 40, 135-141.

Cheater, FM. (1991). Elderly people: Attitudes towards incontinence. Nursing Standard, 5, 23-27.

Fantl, JA., Newman, DK., Colling, J., DeLancey, JOL., Keeys, C., Loughery, R., et al. (1996). Urinary Incontinence in Adults: Acute and chronic Management. Cinical Practice Guideline, No. 2, 1996 update. Department of Health and Human Services, Public Health Service, Agency for Halth Care Policy and Research. AHCPR Publication No. 96-0682: Rockville.

Henderson, JS. (1996). Urinary Incontinence Attitude, Belief, Practice and Knowledge Scales. In Nurses' attitude, belief, practice, and knowledge regarding urinary incontinence in adults: LISREL analysis of a model. Unpublished doctoral dissertation, Texas Woman' University, Denton, TX.

Henderson, JS., \& Kashka, MS. (1999). Development and Testing of the Urinary Incontinence Scales. Urologic Nursing, 19, 109-119.

Henderson, JS., \& Kashka, MS. (2000). Effect of knowledge, attitude, and belief on nurses' practice regards urinary incontinence in adults. Urologic Nursing, 20, 291-305.

Palmer, M., Bennett, RG., Marks, J., McCormick, KA., Engel, BT. (1994). Urinary incontinence: a program that works. The Journal of Long-Term Care Administration, 22, 1925.

Roe, B., Watson, NM., Palmer, MH., Mueller, C., Vinsnes, AG., Wils, M. (2004). Translating research on incontinence into practice. Nursing Research 53, (suppl), S56-S60.

Saxer, S., Halfens, RJG., De Bie, R., Dassen, T. (2008). Prevalence and incidence of urinary incontinence of Swiss nursing home residents at admission and after 6, 12 and 24. Journal of Clinical Nursing. doi:10.1111/j.1365-2702.2007.02055.x.

Vinsnes, AG., Harkless, GE., Haltbakk, J., Bohm, J., Hunskaar, S. (2001). Healthcare personnel's attitudes towards patients with urinary incontinence. Journal of Clinical Nursing 10, 455-462. 
Yu, LC., Johnson, K., Kaltreider, DL., Hu, TW., Brannon, D., Ori, M. (1991).Urinary incontinence: nursing home staff reaction toward residents. Journal of Gerontological Nursing, 17, 34-41. 


\section{CHAPTER 6}

Nurses' Knowledge, Beliefs, Attitudes and Self-reported Practice Regarding Urinary Incontinence in Nursing Home Care: A Model

Susi Saxer, Rob A. de Bie, Theo Dassen, Ruud JG. Halfens, (2008) submitted for publication 


\title{
Nurses' knowledge, beliefs, attitudes and aelf-reported practice regarding urinary incontinence in nursing home care: a model
}

\begin{abstract}
Background: $\mathrm{UI}$ is a prevalent problem in aging adults and is associated with significant psychosocial, physical and economic consequences. In order to improve practice when caring for patients with UI, it is important to know whether nurses' knowledge, beliefs and attitudes affect nursing practice. Therefore, this article reports on the relationship between knowledge, beliefs, attitudes and continence-related practice.
\end{abstract}

Methods: A cross-sectional design was used to gather self-reported data of 315 nurses and nursing assistants.

Instrument: Participants completed a questionnaire consisting of three parts: 1.) The Knowledge and Practice Instrument, 2.) The German version of Hendersons' attitude and belief scale, and 3.) Demographic data.

Results: Findings show that knowledge and attitude are related to self-reported practice. In contrast, beliefs showed no relation to practice, or to knowledge, or to attitudes. The practice subscale, which can best be influenced by knowledge and behavioral attitude, is 'assessment and information' and 'drinking habit and excretion'.

Conclusions: It is worth making an effort to increase nurses' knowledge about incontinence-assessment via continuing education. Also, the attitudes should be positively influenced by co-operation with advanced-practice geriatric nurses. In this way, nurses' practice could be improved, especially in the areas 'assessment and information' and 'drinking habit and excretion'. 


\section{Introduction}

Urinary Incontinence $(\mathrm{UI})$ is an increasingly prevalent health problem in aging adults, and is associated with significant adverse psychosocial, physical and economic consequences (Wyman et al. 2004). Some 60\% of nursing home residents suffer from UI (Saxer et al. 2008, Adelmann, 2004, Aggazzotti at al. 2000, Brandeis et al. 1997). Nurses and other health care professionals have a major responsibility in the care of incontinent nursing-home residents. Research shows positive effects of nursing interventions and prevention in $\mathrm{UI}$ in older people (Colling et al. 2003, Schnelle et al. 2002, Fantl et al. 1996, Colling et al. 1992). For example, existing evidence suggests that specific toileting training strategies are an effective treatment for some frail elders (Schnelle et al. 2002, Fantl et al. 1996, Colling et al. 1992). In the long-term care setting, the Minimum Data Set of the RAI/RUG System is used to assess $\mathrm{UI}$. UI is caused by different factors, e.g. deterioration of resident's condition and iatrogenic causes (Fantl et al. 1996, Palese et al. 2007). A planned approach that emphasizes continence, rather than incontinence, and offers an array of assessments and interventions for incontinent individuals should be provided by nurses in long-term care facilities (Palmer, 1995, Roe et al. 2004).

Dingwall and Mclafferty (2006) found that nurses tend to believe that older people accept urinary incontinence as a consequence of aging. Assessment strategies tend to focus on product identification and management of incontinence. Although nurses found it important to promote continence, the problem continues to be contained rather than treated. Lack of knowledge is found as a barrier promoting incontinence (Dingwall et al. 2006). Also Palese and colleagues (2007) found different reasons why nurses decided to use incontinence pads. The most frequent reason were space-time disorientation, followed by limited mobility, incontinence, patient request, nursing shortage and involuntary urine leakage not perceived by patient (Palese et al. 2007).

Various studies investigated the knowledge, attitude and practice of nurses in $\mathrm{UI}$ in different settings (Saxer at al. 2008, Saxer et al. 2007, Vinsnes et al. 2001, Henderson \& Kashka, 2000). When testing about knowledge of UI, Henderson \& Kashka (2000) found that nurses gave on average $72 \%$ correct responses, and they performed continence-related practice behaviours about half the time (Henderson \& Kashka, 2000). In a nursing home setting in Switzerland, the knowledge base of nurses and nurse assistants was somewhat lower (66\% correct among RNs; $56 \%$ 
mean correct responses among nursing assistants). Continence-related actions were performed at best 'sometimes' or 'often' by the nurses and nurse assistants (Saxer et al. 2008). They both carried out actions related to drinking habit and excretion and to assessment and information approximately $70 \%$ of the time. Scheduled toileting and given support was performed according to the nurses and nurse assistants more than $75 \%$ of the time, while documentation was reportedly completed only $35 \%$ of the time (Saxer et al. 2008). Furthermore, it was found that nurses and nurse assistants held negative beliefs towards nursing home residents with UI (Saxer et al. 2007). Nevertheless, nurses' behavioral and emotional attitude towards incontinent nursing home residents was positive. The behavioral attitude of nurse assistants was also positive, but their emotional attitude tended to be negative (Saxer et al. 2007). Vinsnes and colleagues (2001) found more negative than positive reactions in Norwegian nurses and nursing assistants towards people with $\mathrm{UI}$, although nursing assistants showed more positive reactions and feelings than RNs. American nurses in all multiple specialty practices tended to demonstrate positive attitudes and beliefs towards patients with UI (Henderson \& Kashka, 2000). Therefore in order to change the UI management, it is important to know whether nurses' knowledge, beliefs and attitudes affect nursing practice.

According to Rogers' model of the innovation-decision-process (Rogers, 2003), behavioural change follows a well-known sequence: Knowledge, Persuasion, Decision to Implementation, Implementation and Confirmation (Rogers, 2003). This is in line with the findings of Henderson \& Kashka (2000) that knowledge and beliefs were related to attitude, and attitude was related to practice (fig. 1). Since the sample in Henderson's research (Henderson \& Kashka, 2000, 1999) was small and the respondents worked in different settings and positions, the relationship between knowledge, beliefs, attitude and continence-related practice is investigated in the present study in a nursing home setting using the model of Henderson \& Kashka (2000) (Figure 1).

\section{Method}

We used a cross-sectional design to gather self-reported data of nurses and nurse assistants in ten nursing homes. The convenience sample consisted of 199 registered nurses and 116 nursing assistants who work in one of the ten municipal nursing homes of Zurich. It represents approximately one-third of the nurses and 
nurse assistants at those nursing homes. The nursing homes are similar with respect to the residents, staff and management.

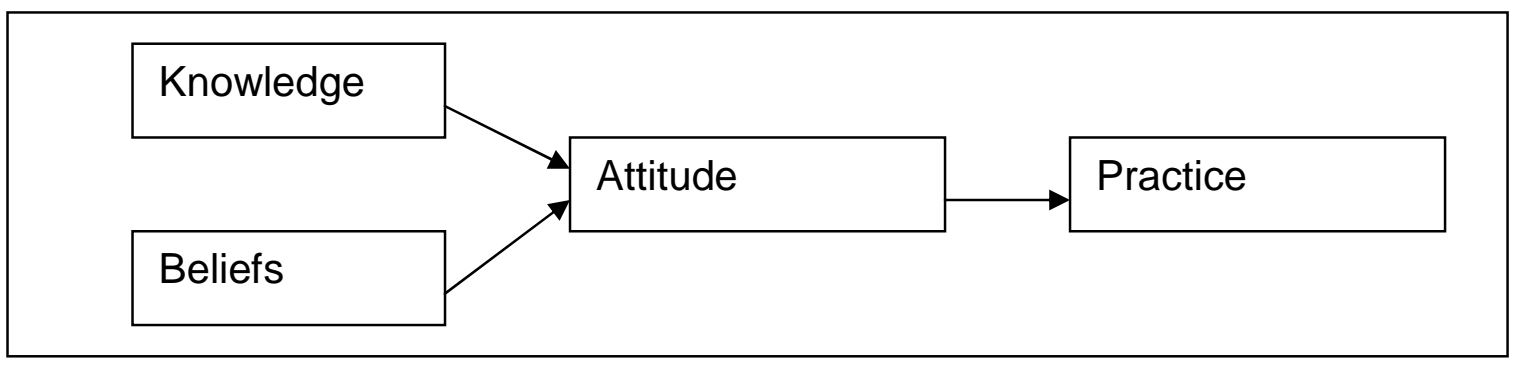

Fig. 1: Henderson and Kashkas' model (Henderson \& Kashka, 2000)

\section{Instrument}

The questionnaire consists of 3 parts: 1) The Knowledge and Practice Instrument (Saxer at al. 2008), 2) The German language version of Henderson's attitude and belief scale (Saxer et al. 2007, Henderson, 1996), and 3) demographic data. The Knowledge and Practice Instrument (KPI) was developed by Saxer and associates (2008) and is based on research findings, clinical practice guidelines for UI management (Fantl et al. 1996) and Henderson's questionnaire (1996). The KPI distinguishes between a knowledge and a practice scale. The knowledge scale comprises 18 items with dichotomous answer categories. Items query facts and statements about UI in elderly persons. The practice scale focuses on actions performed by nurses and nurse assistants when managing nursing home residents with UI; it contains four subscales with four-point Likert response categories. The first subscale labelled 'drinking habits and excretion' contains ten items. The second and third subscales, 'assessment and information' and 'documentation', contain six items each and the fourth subscale (support) contains eight items. Examples of questions are described in table 1. Cronbach's Alpha of these subscales varies from 0.69 and 0.81. The development of the KPI and statistical validation is described elsewhere (Saxer et al. 2008).

The German version of Henderson's attitude and belief scale consists of three subscales with a six-point Likert scale as answer categories (Table 1). The first subscale queries nurses' beliefs about UI. The second subscale (behavioural attitude) contains nine items reflecting a perspective that influences behaviour towards care of incontinent residents. The third subscale labelled 'emotional attitude' 
contains eleven items reflecting a perspective that influences thought, feeling and perception towards incontinent residents. Examples of questions are described in table 1. Cronbach's Alpha of these subscales lies between 0.71 and 0.88 . The translation and validation process is described elsewhere (Saxer et al. 2007). Finally, relevant demographic characteristics of participating nurses and nurse assistants are measured.

Table 1: Examples of questions about knowledge, practice, beliefs and attitude

\begin{tabular}{|c|c|}
\hline $\begin{array}{l}\text { Urinary incontinence knowledge scale: } \\
\text { Residents with dementia are more frequently } \\
\text { incontinent than residents without dementia. }\end{array}$ & $\begin{array}{l}\text { Urinary incontinence belief scale: } \\
\text { Urinary incontinence is an annoying thing to } \\
\text { have. }\end{array}$ \\
\hline $\begin{array}{l}\text { Urinary incontinence practice scales: } \\
\text { Drinking habit and excretion: I know whether the } \\
\text { resident wears a pad or other protection aid. } \\
\text { Assessment and information: I ask the residents } \\
\text { if they lose urine on sneezing, laughing or } \\
\text { coughing. } \\
\text { Documentation: I note the time of incontinence } \\
\text { occurrence of the resident in the documentation. } \\
\text { Support: If incontinent residents wish to go to the } \\
\text { toilet, I help them, if it is necessary. }\end{array}$ & $\begin{array}{l}\text { Urinary incontinence attitude scales: } \\
\text { Behavioural attitude: Nurses should ask patients } \\
\text { if they have urinary incontinence. } \\
\text { Emotional attitude: Having urinary incontinence } \\
\text { does not decrease self-esteem in women. }\end{array}$ \\
\hline
\end{tabular}

\section{Ethical considerations}

Nurses and nurse assistants participated on a voluntary basis and anonymity of data was maintained. Research procedures were approved by the Ethics Committee's president of the municipal nursing homes of Zürich.

\section{Study Procedures}

After permission was obtained from the head of the nursing homes and the nurse managers, we asked clinical nurse specialists to act as contact persons. During a 
personal instruction session, the clinical nurse specialists of each nursing home were familiarized with the aims of the research project, study procedures, and provided with data collection instruments. The clinical nurse specialists organized the measurement in a school room for both nurses and nursing assistants. Each participant received the questionnaire, an envelope and an accompanying letter that explained the complete research project, instructions for completing the questionnaire and written assurance that participation was on a voluntary basis and that anonymity was ensured. Participants completed the questionnaire, and placed it in an envelope, sealed the envelope, and gave it to the clinical nurse specialists. The latter sent the questionnaires to the researchers.

\section{Data Analysis}

Statistical analyses were carried out in SPSS 13.0. A univariate analysis of variance (ANOVA) was performed to test relations between the explained variables (age, education, knowledge, beliefs and behavioural and emotional attitude) and selfreported nursing practice regarding to UI. Additional ANOVA were completed to evaluate associations between the concepts 'knowledge, attitude and beliefs'. The variable age was categorized into three equal-sized groups: 1) < 33 years, 2) 33 - 43 years, and 3) > 43 years. Education was categorized as registered nurses and nursing assistants.

\section{Results}

Statistical analysis was done to test the relation between knowledge, behavioural and emotional attitude and beliefs, between knowledge and behavioural and emotional attitude, and between behavioural and emotional attitude. A significant association was found between knowledge and behavioural attitude $\left(F=14.485, P=<0.001, R^{2}\right.$ 0.21). A further relation was identified between emotional and behavioural attitude $(F$ $=12.596, p=<0.001, R^{2}$ 0.21), (Figure 2). However, no relationship was found between beliefs and knowledge, or beliefs and behavioral or emotional attitude (Figure. 2).

ANOVA was performed to determine if a relationship exists between the self-reported practice subscale 'drinking habit and excretion' and the variables 'age, education, 
knowledge, beliefs, behavioural and emotional attitudes'. Analysis revealed that age, knowledge, behavioural and emotional attitude are related to 'drinking habit and excretion' (Table 2 and Figure 2).

ANOVA was also performed to determine if a relationship exists between the selfreported practice scale 'assessment and information' and 'age, education, knowledge, beliefs, behavioural and emotional attitudes'. Results show that age, education, knowledge and behavioural attitude are related to 'assessment and information' (Table 2 and Figure 2).

Tab. 2: Relations between knowledge, beliefs, attitude and the practice scales 'drinking habit and excretion' and 'assessment and information'

\begin{tabular}{lcc|cc}
\hline Variables & \multicolumn{3}{c}{ Significance levels of association on: } \\
& Drinking habit and excretion & assessment and information \\
\hline & F-value & p-values & F-value & p-values \\
\hline Age & 4.076 & 0.018 & 4.898 & 0.008 \\
Education & 0.400 & 0.527 & 63.164 & 0.000 \\
Knowledge & 5.636 & 0.018 & 21.353 & 0.000 \\
Beliefs & 1.380 & 0.241 & 0.039 & 0.843 \\
Behavioural attitude & 7.244 & 0.007 & 14.688 & 0.000 \\
Emotional attitude & 6.434 & 0.012 & 2.907 & 0.089 \\
\hline $\mathrm{R}^{2}$ & \multicolumn{3}{c}{0.086.}
\end{tabular}

ANOVA was also completed to determine an association between the self-reported practice scale 'documentation' and 'age, education, knowledge, beliefs, behavioral and emotional attitudes'. Results show that only 'emotional attitude' is related to 'documentation' (Table 3, Figure 2).

A final ANOVA was performed with the self-reported practice scale 'support' and 'age, education, knowledge, beliefs, behavioral and emotional attitudes'. Results show that only 'behavioral attitude' was related to 'support' (Table 3 and Figure 2).

Tab. 3: Relations between knowledge, beliefs, attitude and the practice scales 'documentation' and 'support'

\begin{tabular}{|c|c|c|c|c|}
\hline \multirow[t]{3}{*}{ Variables } & \multicolumn{4}{|c|}{ Significance levels of association on: } \\
\hline & \multicolumn{2}{|c|}{ Documentation } & \multicolumn{2}{|c|}{ Support } \\
\hline & F-value & p-values & F-value & p-values \\
\hline Age & 0.497 & 0.609 & 0.456 & 0.634 \\
\hline Education & 0.272 & 0.602 & 4.397 & 0.037 \\
\hline Knowledge & 3.086 & 0.080 & 1.654 & 0.199 \\
\hline Beliefs & 0.176 & 0.675 & 0.879 & 0.349 \\
\hline Behavioural attitude & 2.410 & 0.122 & 9.410 & 0.002 \\
\hline Emotional attitude & 17.657 & 0.000 & 0.017 & 0.896 \\
\hline
\end{tabular}




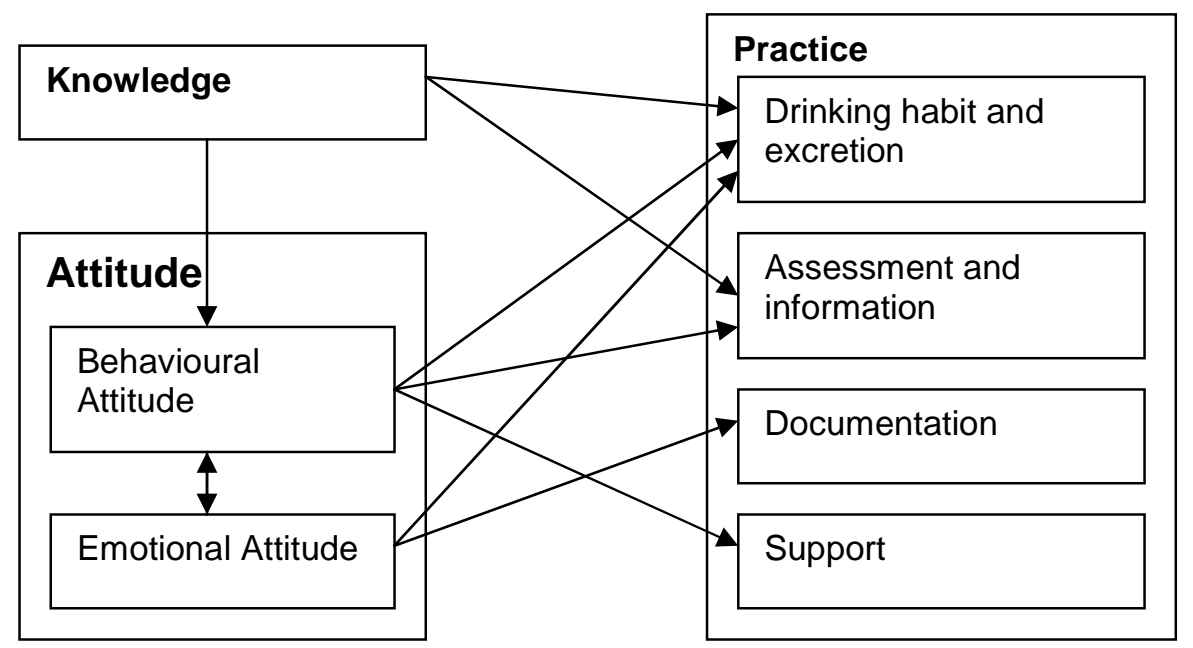

Fig. 2: Newly-developed model: Relations between 'Knowledge, Attitude and Practice

\section{Discussion}

In order to change the practice of $\mathrm{UI}$ care, it is important to know whether nurses' knowledge, beliefs and attitude affect nurses' practice. Our study demonstrates that knowledge and attitude are related to self-reported practice.

The preliminary model (fig. 2) shows relationships between knowledge and the selfreported practice scales 'drinking habit and excretion' and 'assessment and information'. Behavioural attitude is related to the self-reported practice scales 'drinking habit and excretion' and 'assessment and information', but also to the selfreported practice scale 'support', whereas emotional attitude has relationships to the self-reported practice scale 'documentation' and 'drinking habit and excretion'. No significant association was found between beliefs and practice. The results suggest that self-reported practice could change with better knowledge and a positive attitude. For example in the care of urinary incontinent residents, assessment is important because it helps to find the appropriate intervention to address. Without good assessment, good care is almost impossible (Centers for Medicare and Services). A complete assessment includes history of UI, voiding patterns, patterns of fluid intake, functional and cognitive abilities, assistance, environmental factors, physical examination, medication, pertinent diagnosis (Centers for Medicare and Services). Therefore, it is worth making the effort to increase the knowledge of nurses about incontinence-assessment, e.g. with re-education and on-the-job- 
training. The attitudes should also be positively influenced by co-operation with incontinence advisers or advanced-practice geriatric nurses in situation-specific discussions and training for nurses.

The self-reported subscale 'drinking habit and excretion' contains mainly questions about 'how much patients drink and excrete'. Knowledge, behavioural and emotional attitude are related to 'drinking habit and excretion'. The result suggest that selfreported practice about the area 'drinking habit and excretion' could change with e.g. a positive role model or co-operation with clinical nurse specialists, who can work with nurses and advise them. Because 'education' is not associated with 'drinking habit and excretion', re-education would not bring the desired effect. In this way nurses' practice could be improved; especially 'drinking habit and excretion'. The US Government's guidance about UI (Centers for Medicare and Services) gives detailed information for the care of incontinent residents. However, guidelines alone do not improve care; nurses must have knowledge of these guidelines, and integrate this knowledge into their clinical practice.

Beliefs were not related to either self-reported practice or knowledge or attitude. Questions in the beliefs scale concern UI in general and apparently these have no importance in the relationship to knowledge, practice and attitude. This finding differs from Henderson \& Kashka (2000) who reported that beliefs are indirectly associated with practice. These differences may be attributed to variability in sample size, or possibly to cultural differences. Henderson \& Kashka, 2000 reported on a sample of 126 registered nurses, who worked in the US and practiced in a variety of settings. In contrast, we report on a more homogenous sample of 315 registered nurses and nurse assistants, all of whom are employed in municipal nursing homes in Zurich.

Henderson's \& Kashka's model (2000) shows relationships between knowledge and attitude and between attitude and practice. In our study, we also found a relationship between knowledge and attitude and between attitude and self-reported practice. Contrary to the results published by Henderson \& Kashka (2000), we also found that knowledge is associated with self-reported practice. The difference may be for the reasons described above and because Henderson \& Kashka (2000) did not differentiate self-reported practice and attitude into subscales.

On one hand, Henderson's \& Kashka's model (2000) is confirmed by our study, e.g. the relationships between attitude and self-reported practice or between knowledge and attitude; on the other hand, we found no relationship between beliefs and 
attitude, but additional relationships between knowledge and the self-reported practice scales 'drinking habit and excretion' and assessment and information'. These relationships confirm the view that education has to focus on increasing knowledge while presuming a positive effect on practice, however the relationship between attitude and self-reported practice brings additional findings, which can be used in further education and on-the-job training.

\section{Limitations}

The study suffers from some limitations. The relatively small sample does not allow generalization of these results. However, it offers important result for practice, education and future research. In addition, while this study measures nurses' selfreported practice habits, it does not measure the real behaviour of nurses in the clinical field. Additional investigation is necessary to directly observe and measure nurses' practice with urinary incontinent residents. Another limitation of this study is that we had to develop a new instrument. Therefore, the questionnaires may benefit from further validation and clarification of any unclear items. It is possible that others factors exist, apart from those tested, that influence self-reported practice-subscales such as organizational factors, team-co-operation, no time for care. Therefore, the inclusion of additional organizational factors in future studies may provide further insights into these complex relationships.

\section{Implications for future research}

Future research is needed. Experimental studies should evaluate the influence of higher knowledge and positive attitude on practice. Future research should also address the limitations discussed in this article, such as direct observation of nurses' practice and further validation of the questionnaire.

\section{Conclusion}

The study demonstrates that knowledge and attitude are related to self-reported practice, whereas beliefs showed no relation to practice, or to knowledge or to attitudes. This suggests that further education and professional training has to focus on increasing knowledge and positive attitude. The self-reported practice subscales which can best be influenced by knowledge and attitude are 'assessment and 
information' and 'drinking habit and excretion'. Both are important aspects in the care of incontinent residents.

\section{Key points}

UI; nurses' knowledge, practice, attitudes and beliefs; nursing home 


\section{References}

Wyman, JF., Bliss, DZ., Dougherty, MC., et al. (2004). Shaping future directions for incontinence research in aging adults: Executive Summary. Nurs Res, 53 (suppl), S1-S10.

Saxer, S., Halfens, RJG., de Bie, RA., Dassen, T. (2008). Prevalence and incidence of UI of Swiss nursing home residents at admission and after 6, 12 and 24 months. $J$ Clin Nurs. doi:10.1111/j.1365-2702.2007.02055.x.

Adelmann, PK. (2004). Prevalence and detection of UI among older medicaid recipients. $J$ Health Care Poor Underserved, 15, 99-112.

Aggazzotti, G., Pesce, F., Grassi, D., et al. (2000). Prevalence of Ul among institutionalized patients: A cross-sectional epidemiological study in a midsized city in northern Italy. Urology, 56, 245-249.

Brandeis, GH., Baumann, MM., Hossain, M., Norris, JN., Resnick, NM. (1997). The prevalence of potentially remediable UI in frail older people: A study using the minimum Data set. J Am Geriatr Soc, 45, 179-184.

Colling, J., Owen, T., McCreedy, M., Newman, D. (2003). The effects of a continence program of frail community-dwelling elderly persons. Urol Nurs, 29, 117-131.

Schnelle, JF., Alessi, CA., Simmons, SF., Al-Sammarai, NR., Beck, JC., Ouslander, JG. (2002). Translating clinical research into practice: A randomized controlled trial on exercise and incontinence care with nursing home residents. J Am Geriatr Soc, 50, 1476-1483.

Fantl, JA., Newman, DK., Colling, J., et al. UI in Adults: Acute and chronic Management. Cinical Practice Guideline, No. 2, 1996 update. Department of Health and Human Services, Public Health Service, Agency for Health Care Policy and Research. AHCPR Publication No. 96-0682: Rockville.

Colling, J., Ouslander, J., Hadley, B., Eisch, J., Campbell, E. (1992). The effects of patternd urge-response toileting (PURT) on UI among nursing home residents. J Am Geriatr Soc, 40, 135-141.

Palese, A., Regattin, L., Venuti, F., Innocento, A., Banaglio, C. (2007). Incontinence pad use in patients admitted to medical wards: An Itlian multicentre prospective cohort study. JWOCN, 34, 649-654.

Palmer, MH. (1995). Nurses' knowledge and beliefs about continence interventions in longterm care. J Adv Nurs, 21, 1065-1072.

Roe, B., Watson, NM., Palmer, MH., Mueller, C., Vinsnes, AG., Wils, M. (2004). Translating research on incontinence into practice. Nurs Res, 53 (suppl), S56-S60.

Dingwall, L., Mclafferty, E. (2006). Do nurses promote urinary continence in hospitalized older people? an exploratory study. J Clin Nurs, 15, 1276-1286.

Saxer, S., de Bie, RA., Dassen, T., Halfens, RJG. (2008). Nurses' knowledge and practice about UI in nursing home care. Nurse Educ. Today. doi:10.1016/j.nedt.2008.05.009.

Saxer, S., Halfens, RJG., Dassen, T., de Bie, RA. (2007). Nurses' attitude and beliefs about $\mathrm{UI}$ in nursing home care. submitted. 
Vinsnes, AG., Harkless, GE., Haltbakk, J., Bohm, J., Hunskaar, S. (2001). Healthcare personnel's attitudes towards patients with UI. J Clin Nurs, 10, 455-462.

Henderson, JS., \& Kashka, MS. (2000). Effect of knowledge, attitude, and belief on nurses'practice regards UI in adults. Urol Nurs, 20, 291-305.

Rogers, EM. (2003). Diffusion of Innovations. $5^{\text {th }}$ ed. New York: The Free Press.

Henderson, JS., \& Kashka, MS. (1999). Development and testing of the UI scales. Urol Nurs, 19, 109-119.

Henderson, JS. UI Attitude, Belief, Practice and Knowledge Scales. In Nurses' attitude, belief, practice, and knowledge regarding UI in adults: LISREL analysis of a model. Unpublished doctoral dissertation: Texas Woman' University,1996; Denton, TX.

Centers for Medicare and Services. Urinary Incontinence. F 315. http://www.cms.hhs.gov/SurveyCertificationGenlnfo/downloads/SCLetter05-23.pdf

Ryden, MB., Snyder, M., Gross, CR., at al. (2000). Value-added outcomes: The use of advanced practice nurses in long-term care facilities. The Gerontologist, 40, 654-662. 


\section{CHAPTER 7}

General Discussion 


\section{General discussion}

This chapter summarises the main findings and critically reflects on methodological and theoretical aspects of the studies on prevalence, incidence and risk factors of urinary incontinent residents in Swiss nursing homes and on nurses' knowledge, practice, beliefs and attitude about urinary incontinent residents. The chapter ends with recommendations for practice and further research.

\subsection{Prevalence and risk factors of urinary incontinent residents}

\subsubsection{Major findings}

The results of the prevalence study show a point prevalence of urinary incontinence of $51 \%$ in Swiss nursing home residents, whereas the prevalence at the time of admission to a nursing home was only $37 \%$. At admission, men are more affected by urinary incontinence than women (men $43 \%$, women $34 \%$ ). Prevalence in both groups increases during their stay in a nursing home (Chapter 2).

The most important risk factor for incontinence at admission and over time was not being able to move in bed. The odds for urinary incontinence at the time of admission were two times higher for patients with 'difficulties moving in bed' than for persons without. Six months after admission, the odds were 5.9 times higher and 12 months after admission even 7.7 times higher for patients with 'difficulties moving in bed' than for persons without.

The second important factor was 'deficits in long-term memory', but only at admission and six months after admission. At the time of admission, the odds for incontinence were 1.4 times higher and six months after admission 5.3 times higher for patients with these difficulties than for persons without (Chapter 3). As demonstrated also in the prevalence study, gender is an important predictive factor too, but only at admission. A possible reason could be that care-dependent men are cared for longer at home than women and therefore men enter the nursing home in poorer condition and as a result are also more urinary incontinent than women.

Our survey about prevalence, incidence and risk factors in Northwestern Switzerland was the first study on this topic in the German-speaking part of Switzerland. The study shows results about the extent of urinary incontinence and risk factors. The results are comparable to results of other international studies. However, a newlypublished study (Boyington et al. 2007) from the U.S. showed a much higher 
prevalence rate at admission than our prevalence study. No gender differences were found at admission, but post-admission they found a higher prevalence rate in women than in men. At admission and post-admission, we found a higher prevalence rate in men in the group for whom data were available for the first year. Because the data from Boyington et al. (2007) and our data were secondary data of the MDS, and the data of both studies were collected around approximately the same time, the difference in prevalence could be because the residents in the U.S. nursing homes were in much worse health condition than residents in our study.

\subsubsection{Methodological reflection}

\subsubsection{Secondary Analyses of MDS (RAI 2.0)}

For this study we used data from the Minimum Data Set (MDS) of the Residential Assessment Instrument (RAl) in a cross-sectional as well as a longitudinal approach. The use of secondary data has both advantages and disadvantages. A large advantage is "that secondary analyses are efficient and economical because data collection is typically the most time-consuming and expensive part of a research project" (Polit \& Beck, 2003, p. 236). In our study, the data were routinely gathered for quality management, financing and resource management and care planning. This could influence the validity of our findings, because there was no extensive control of data gathering. Nevertheless, some safeguards were in place to guarantee the best-possible data set. Data collection was done by nurses, who were specially trained for assessment with the MDS for $1 \frac{1}{2}$ days. Only observations were included when nurses had at least one year practical experience with the instrument. Additionally, only registered nurses performed the assessment, and assessments with the MDS is routine - but important - work for registered nurses. Moreover, the assessment-data were important for nurses in practice for residents' care-planning they therefore had to rely on these data for daily practice. Since we had to rely on secondary analysis of data, it was impossible to have control or to do reassessments of the same patients. Crooks et al. (1995), who examined correlations between Minimum Data Set (MDS) ratings and physical checks for wetness performed by nursing home staff and performed independently by research staff in nine nursing homes in lowa (USA), found statistically significant correlation between research staff wet checks and the MDS rating, but wetness checks performed by 
nursing home staff had an insignificant correlation with MDS ratings. This could support the thesis that nurses' assessment of urinary incontinence could be incorrect. On the other hand, Sgadari et al. (1997) tested the inter-rater reliability of core items of the MDS in different countries. In each country, two trained nurses independently evaluated the same residents. The inter-rater reliability of the items about bowel and bladder incontinence achieved an adequate to excellent level of reliability $(0.58$ to 0.95). An inter-rater reliability of 0.93 was achieved in Switzerland. In cognitive skills, the inter-rater reliability was 0.88 (all countries: 0.47-0.88), in ADL (activity of daily living) self-performance 0.87 (all countries: 0.61- 0.92), in ADL support provided 0.85 (all countries: 0.57- 0.87). Self-performance and support items about mobility are included in the ADL. These results confirm the probability of correct data collection. Therefore, the assessment of the data sets in terms of their appropriateness for answering the research questions and the relatively large sample, especially the number of observations for the cross-sectional part of the study, lead to the conclusion that this sample could be used for this study.

\subsubsection{Definition of urinary incontinence}

Urinary incontinence is defined as having at least two episodes of involuntary loss of urine within one week. This definition or the definition by the International Continence Society, which defines "urinary incontinence as the complaint of any involuntary leakage of urine" (Abrams et al. 2002) does not cite the cause of incontinence. Urinary incontinence could be due to a lot of reasons, not only physiological but also if the residents simply forget to go to the toilet, or the residents are not able to go to the toilet alone. Some incontinence can be prevented with good quality of care, for instance by bringing residents to the toilet every two hours, others forms of incontinence can not be prevented. Although it would be very interesting to calculate the prevalence rate for both forms, no data were available to make this distinction.

The question for assessing urinary incontinence aims at the numbers of incontinence episodes. Therefore we could assume that nurses assess actual incontinence and not whether residents wear pads.

\subsubsection{Sample}

During the time period from January 1999 (January 2000) to June 2002, 2722 residents entered the nursing homes, and 2610 residents were living in 42 nursing 
homes at the time of the cross-sectional analysis. All residents of these 42 nursing homes were included in the analyses (chapter 2 and 3). The size of nursing homes was different; the smallest had 20, and the largest more than 150 residents. There is no reason to assume that the size of a nursing home impacts on residents' urinary incontinence or risk factors for urinary incontinence. Other institutional factors like adequate staffing (Ryden et al. 2000, Schnelle, 2002), quality of care (Ryden et al. 2000, Schnelle, 2002), limited resources and time (Schnelle, 2002) and use of clinical practice guidelines (Ryden et al. 2000) will have an influence on prevalence, incidence and risk factors of urinary incontinence, but these factors were not incorporated in our database.

\section{Table 1: Observations}

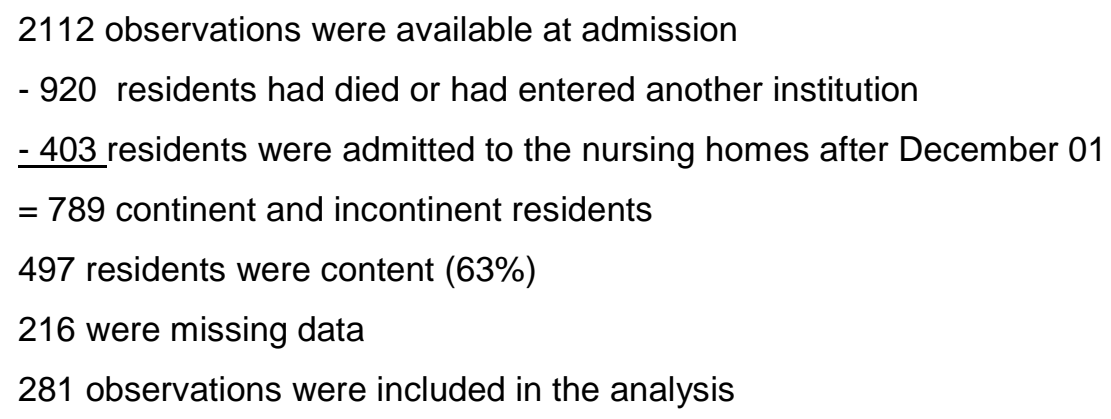

2112 observations were available to assess the risk factors for urinary incontinence at admission (logistic regression 1). 610 (22\%) observations could not be used because the assessments were incomplete. Incomplete assessments were those in which one of the 11 items about urinary incontinence, mobility and cognitive abilities was missing. Although approximately $80 \%$ of the residents were included in the sample, it was supposed that the missing observations were produced by chance.

281 observations could be included in logistic regression 2 (chapter 3). However, not all residents could be used for this analysis. Excluded were residents who died during the first six months of their stay in the nursing homes, or who were transferred to another institution $(=920)$, and residents who entered the nursing home after December 2001 (=403), because the data gathering was finished in June 2002. Only those residents $(=497)$, who were continent at the time of admission were included in the analysis. 216 data sets were incomplete. This resulted in a net sample of 281 residents (table 1), which seems to be an enormous reduction of the total 
observations. However, the reduction due to residents who died or left the nursing home, and the reduction due to admission after December 2001 do not influence the results since they do not belong to the target group: residents who stay at least 6 months in the nursing home. The same holds for the reduction due to the fact that the residents were continent at admission because only these belong to the target group. However, the reduction due to the missing values may have influenced the results. Therefore the results of this analysis must be interpreted with some caution.

\subsection{Nurses' knowledge, practice, beliefs and attitude about urinary incontinent residents \\ 7.2.1 Major findings}

In the second part of the thesis, nurses' and nurse assistants' knowledge, practice, beliefs and attitudes towards patients with urinary incontinence are investigated, and whether nurses' and nurse assistants' knowledge, beliefs and attitude affect nursing practice. Two new scales were developed and validated to measure nurses' knowledge and practice (chapter 4). To measure nurses' beliefs and attitudes, Hendersons' Urinary Incontinence Scales $\odot$ (Henderson, 1996) about attitude and beliefs were translated from English to German and tested (chapter 5).

This study shows that nurses have a mediocre knowledge base in relation to urinary incontinence. The level of knowledge of the nurse assistants is even lower than that of nurses (chapter 4). Continence-related actions were performed at best 'sometimes' or 'often' by the nurses and nurse assistants. They both carried out actions related to drinking habits and excretion and to assessment and information approximately $70 \%$ of the time. Scheduled toileting and given support was performed according to the nurses and nurse assistants more than $80 \%$ of the time, while documentation was done only $35 \%$ of the time (chapter 4 ). Furthermore, it was found that nurses and nurse assistants had negative beliefs towards urinary incontinent nursing home residents (chapter 5). However, nurses' behavioural and emotional attitude towards incontinent nursing home residents was positive. The behavioural attitude of nurse assistants was also positive, but their emotional attitude tended to be negative (chapter 5).

Henderson's model was not confirmed by our study. In contrast to Henderson's model (Henderson and Kashka, 2000), our proposed model (fig. 1) shows that knowledge and attitude are associated with practice. This holds true especially for 
nurses' and nurse assistants' actions related to assessment and information. An association exists between knowledge and behavioural attitude and between emotional and behavioural attitude (fig. 1). 'Beliefs' did not associate to either practice or knowledge or attitude (chapter 6).

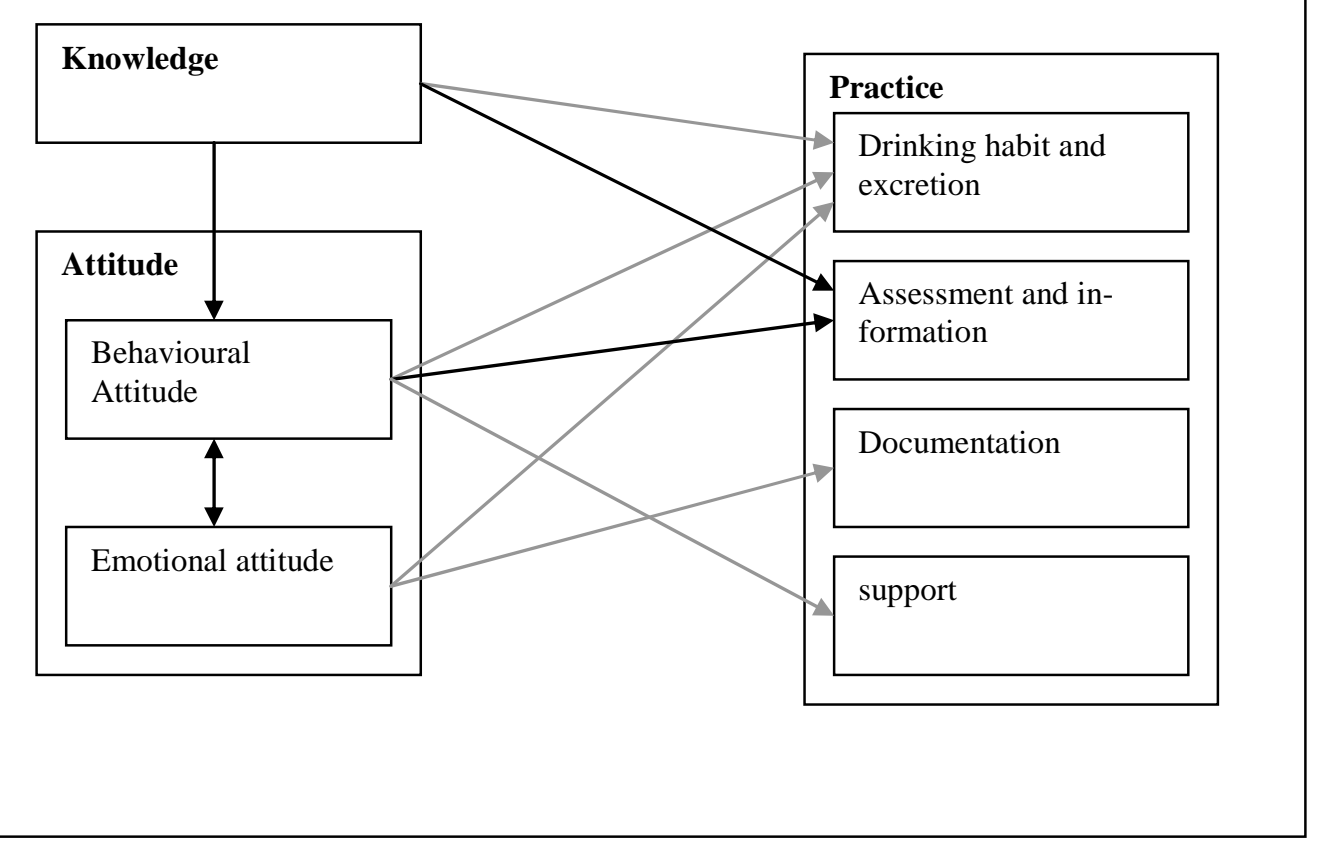

Fig. 1: Model: Postulated association between 'Knowledge, Attitude and Practice'

\subsubsection{Methodological reflection}

Some methodological aspects in the development and use of the questionnaires about knowledge, practice, beliefs and attitude should be discussed to clarify the results.

\subsubsection{Validity and reliability of the questionnaires}

Figure 1 shows a number of direct associations with low explained variances. Apart from organisational factors which could have an impact on the practice-subscales, there are other explanations, e.g. the development and validation of the questionnaires.

Internal consistency was evaluated with Cronbach's Alpha in the newly-developed and translated questionnaires (Chapter 4 and 5). Test-retest reliability was not measured, because concepts like attitudes, behaviours and knowledge can be 
modified by experience between testings. Moreover the subject could be influenced by memory (recall-bias) (Polit \& Beck, 2004).

A panel of experts evaluated the content-validity of the newly-developed instrument (Chapter 4). These experts were involved in the development of the 'Nationale Expertenstandard zur Kontinenzförderung' in Germany (DNQP, 2007). All of the experts worked with urinary incontinent patients, some worked as researchers in this field and the others worked as nurses and advisers and were involved in the daily care of incontinent patients. The criterion-related validity was not measured, because a gold standard was lacking with which the instrument can be compared. We assessed validity with a factor analysis. In general, the first evaluation of reliability and validity was done with quite good results. Further evaluation is needed, according to Waltz et al. (1991, p. 23): "The reliability and validity of the measurements process itself is increased, when multiple measures of the same thing are employed; that is, more than one type of instrumentation is used to answer a given question".

Practice scale: Although this scale reflects the practice of nurses, there are some questions which did not apply to the actual work of nurse assistants, e.g. 'At admission or if the health condition changes, I ask the resident how long she or he has been incontinent' or 'I note in the documentation how much urine the resident loses in each incontinence episode'. To maintain the comparability of the results from nurses and nurse assistants, we used the same questionnaire for both groups. According to the factor analyses, all questions could easily be assigned to the four factors, but some loadings were low. It is possible that if the questions with low loadings $(<0.45)$ were deleted, this would have a positive impact on the clearness of the factors and also on the variance. They were not deleted, because these items present a part of the concept which we measured. Due to the fact that these practice scales were used the first time, no comparative data are available to assist in the interpretation of the results.

Knowledge Scale: The knowledge scale contains 18 items on general and specific knowledge about urinary incontinence and urinary incontinent residents. Items on general knowledge concern symptoms or interventions of different kinds of urinary incontinence, and items about specific knowledge concern knowledge, which was 
more likely on an abstract level, e.g. prevalence of urinary incontinence in definite groups of residents, such as cognitive impaired residents. It could be that the questions on a more abstract level were appropriate for nurses but not for nurse assistants. Because nurses have the responsibilities for the residents' care and care planning, it is important to have specific knowledge about urinary incontinent residents. An example is the following statement 'More than $80 \%$ of nursing home residents are incontinent'. This statement was not true. Often nurses think that urinary incontinence is common in old age (Department of Health, 2000). But this is not true, either. If nurses think this way, they would answer the statement incorrectly. Nurses who do not know the right answer are less attentive to the continent residents; however these residents need attention in order to prevent urinary incontinence. Another example is the statement 'at admission in nursing homes, more women are incontinent than men.' This statement is also not true. When we look at the population in general, more women are incontinent than men, but in the nursing home population, this is not the case. This question is difficult to answer, but it would be good for prevention and care of urinary incontinent residents if nurses know the right answer for such questions. Such theoretical questions could increase nurses' awareness of the problem.

The abstract statements were probably difficult to answer for nurse assistants. Additional questions which are nearer to the work of nurse assistants, e.g. 'how many litres should an old person drink', or 'should old persons wear pads only for security', should be included in subsequent studies. These would be also fitting questions for nurses.

Attitude and belief scale: The URINARY INCONTINENCE SCALESC) (Henderson, 1996) about attitude and beliefs were translated from English to German and tested. The initial attitude and beliefs scale by Henderson (2000) consists of two subscales, while the German version consists of three. These three subscales were based on the results of the factor analyses (chapter 5). The differences may be caused by the cultural differences and by the different and larger samples in our studies. Henderson's sample consisted of nurses from all nursing fields, while the sample in our study consists of nurses and nurse assistants in nursing homes. In our study, the sample is not only more homogeneous but also two-and-one-half times larger than in Henderson's study. Probably the clearness of the factors would be better if the 
questions with low loadings (eight questions with loadings $<0.4$ or 13 questions with loadings <0.45) in the factor analyses were deleted. But they were not deleted, because these items present a part of the concept which we measured. Some results of our study (chapter 5) are difficult to compare with Henderson's results because we used three subscales (factors) in our study and Henderson two.

\subsubsection{The postulated model}

In chapter six, we looked at the associations between knowledge, beliefs, attitude and continence-related practice. We wanted to evaluate whether Henderson's and Kashka's model (2000) is tenable in another population. The results are also discussed with other similar theories: Theories of reasoned action and planned behaviour (Ajzen and Fishbein, 1980, Ajzen, 1985), the ASE -and I-Change model (De Vries et al. 1988, 2003), and the innovation-decision-process (Rogers, 2003).

The newly-developed model (fig. 1) can be regarded as a preliminary model. It shows that knowledge and attitude are associated with practice. Based on our study, it is not possible to conclude that practice influences knowledge and attitude. Since different elaborate theories and models show the direction from knowledge to actions (Rogers, 2003), or from attitude to behaviour (Ajzen and Fishbein, 1980, Ajzen, 1985, De Vries et al. 1988, 2003), it is supposed that the relationships go from knowledge or attitude to practice and not in the other direction in the case of nurses' care of urinary incontinent residents.

In the newly-developed model (chapter six), we found no relationship between beliefs and practice, attitude or knowledge, although in Henderson's model a relationship is given between beliefs and attitude. Also in the elaborate theories of planned behaviour (Ajzen, 1985) there are relationships between beliefs and attitude toward the behaviour, subjective norm, and perceived behavioural control. According to Ajzen "beliefs play a central role in the theory of planned behaviour" [W001]. In the ASE - and I-change model 'self-efficacy' can be seen as a person's belief (De Vries et al. 1988) and it leads to intention and behaviour. Self-efficacy has also a relationship to behaviour via intention. Because 'beliefs' is defined differently in the different models and theories, and also 'practice' and 'behaviour' do not mean the same thing, a direct comparison could not be made. 
In Henderson's model beliefs are associated with attitude and in our preliminary model not, therefore it is important to evaluate the concept 'beliefs'. The reason for this difference could be the different samples and cultural influences. We conclude that it is important to further develop and confirm the model, especially the relationship from belief to attitude and/or to behaviour. Other variables like organizational, cultural or ward-specific variables have to be incorporated in the model.

Henderson's and our newly-developed model (fig. 1) lack the concept 'intention' which is in Ajzen's model of planned behaviour, and in the ASE - and I-change model. Intention has to do with "person's readiness to perform a given behaviour" [W001]. We assume that nurses' practice with urinary incontinent residents needs a lot of readiness and motivation for the actions, and since 'intention' is an important concept in Aizen's and De Vries' theories, we could conclude that 'intention' has to be incorporated in further development of our model.

In additional to intention, the l-change model incorporates barriers and abilities, and Ajzen's theory of planned behaviour includes 'actual behavioural control', which could influence behaviour. We assume that in case of urinary incontinence care, barriers and abilities or actual behavioural control are important too, and therefore they have to be incorporated in our model.

The concept 'knowledge' is not incorporated in Ajzen's theories, as in Henderson's and our model, but it is included in the l-change model of De Vries et al. (2003). In this model 'social influences' is determined by awareness factors especially knowledge, but also by predisposing and information factors. In Henderson's model attitude is determined by knowledge (and beliefs). In our model, practice (drinking habit and excretion, and assessment and information) is determined by knowledge, but (behavioural) attitude is also determined by knowledge. Because the definition of 'Knowledge' in the l-change model is broader than in Henderson's and our model, a direct comparison could not be made.

In Rogers' innovation-decision process (2003), knowledge leads to implementation via persuasion and decision. According to Rogers (2003), in the persuasion stage "the individual forms a favourable or unfavourable attitude towards the innovation". 
This is in line with Henderson's and Kashka's model, and the association between knowledge and behavioural attitude of our model.

Our proposed model showed low $\mathrm{R}^{2}$ values. These could point to other factors, apart from those tested, and might have impact on practice or attitude. De Vries et al. (2003) include predisposing, awareness and information factors and barriers in their l-change model. It is possible that these factors would be important in the case of nurses' care of incontinent residents. Moreover, we could assume that also other factors, which are more in line with the organisation and staffing, would affect nurses' practice.

It seems that the idea of proposing one simple model (Henderson and Kashka, 2000) does not work. Comparison of our preliminary model with the more elaborate theories shows that other factors have to be included in the model. Important factors are barriers and abilities, but 'intention' could also be important.

\subsection{Recommendations for future research}

Considering the results of the studies discussed above, the following recommendations for further research are made:

\subsubsection{Nurses' knowledge, attitude, belief and practice}

Our preliminary model has to be refined, evaluated and completed. First of all, additional factors must be identified (barriers and abilities and/or predisposing, awareness and information factors) which influence nurses' practice. The questionnaires about knowledge, practice, attitude and beliefs need further evaluation. It must be considered whether nurse assistants need a separate questionnaire about knowledge incorporating questions which are more in line with their daily work. Different theories show association between beliefs and other concepts; however our newly-developed model does not. Therefore we suggest a concept analysis of 'beliefs', because it has to be evaluated whether the correct items are incorporated in the questionnaire and if additional items are needed. Further studies are needed in order to understand the association between the newly- 
identified factors and knowledge, attitude, belief and practice. The discussed theories and models give references for this.

Next, experimental studies are needed to evaluate the influence of higher knowledge, positive attitude and belief, and the newly-identified factors on nurses' practice.

\subsubsection{Prevalence and risk factors}

An important finding was the increase of prevalence in urinary incontinence in the first 12 months after admission to a nursing home. A cohort study in which newlyadmitted residents are followed for one year could evaluate the prevalence and incidence of urinary incontinence at different time points. Especially important will be the exact time-point at which residents become incontinent. Part of the study must be the intensity of urinary incontinence, care-dependency, cognition and mobility during the initial time period in a nursing home. The results about the risk factors (chapter 3 ) can be also confirmed. Such a cohort study could also demonstrate whether the increase in incidence is also an increase in care-dependency, a decline in the health status and/or low quality of care.

\subsection{Recommendations for practice}

Urinary incontinence is a significant problem in nursing home residents especially for residents with limitations in 'moving in bed' and 'long-term memory'. Urinary incontinence increases also during the time of stay in a nursing home. Knowledge and practice of nurses and nurse assistants are not sufficient. Therefore it is important to start programmes to enhance quality of urinary incontinence care.

It is important to perform a detailed urinary incontinence assessment at admission and any time when the health condition changes. The following topics have to be included in the assessment: frequency and extent of urinary incontinence episodes, duration of urinary incontinence, conditions (e.g. how far is it from resident's room to the bathroom), risk factors, amount of drinking (Getliffe and Dolman, 2003, Deutsches Netzwerk für Qualitätsentwicklung in der Pflege, 2007). This information leads to diagnoses, and then appropriate interventions have to be introduced. Limitations in moving in bed could improve with therapeutic exercises. 
A way to enhance knowledge is to promote further education, support and experience with urinary incontinent residents. The low score in documentation indicates the importance of support in this domain e.g. on-the-job-training. The scores in the other three subscales are higher than in documentation, nevertheless support in these domains would also improve these scores and thereby the care of urinary incontinent residents. The noted negative beliefs concerning urinary incontinence can be because nurses often find caring for urinary incontinent patients difficult and frustrating (Colling et al. 1992, Vinsnes et al. 2001). Motivational training could be a way to support nurses and nurse assistants. As with knowledge, education is one way to enhance attitude because behavioural and emotional attitudes are associated with education.

It has to be noted that deficits in knowledge and practice are not only a problem of individuals, they can also be a problem of organisation or management, e.g. less time for incontinence care or problems with transfer of evidence-based research findings. Research groups who concern themselves with the transfer of research findings to practice mention several barriers. Beside the characteristics of nurses, e.g. education and clinical experience of nurses (Estabrooks et al. 2003), important factors are the organizational systems and methods and style of communication (Roe et al. 2004). Translating research into practice is a challenging process. Multifaceted interventions have been shown to be effective in inducing change in general practice (Wensing et al. 1998). Lekan-Rutledge (2000) reported that a prompted voiding program was effectively introduced with Rogers' diffusion-of-innovation-model. Apart from the planning and program development, the procedures included educational workshops and on-the-job competency trainings. After six months of implementation, the program showed evidence that new strategies were successfully adopted by nursing staff (Lekan-Rutledge, 2000). Successful practice change requires not only educational strategies but also change agent or facilitators, such as continence advisers (Abbott \& Hotchkiss, 2001, Roe et al. 2004).

In conclusion, good care of nursing home residents needs detailed assessment of urinary incontinence and appropriate interventions. To improve practice with urinary incontinent residents, nurses and nurse assistants need on-the-job training, motivational training and an organisation in which good care is possible, e.g. sufficient time for this care. 


\section{References}

Abbott, S., \& Hotchkiss, J. (2001). It takes more than clinical effectiveness to change nursing practice: An unsuccessful project in the nurse promotion of urinary incontinence. Clinical effectiveness in Nursing, 5, 81-87.

Abrams, P., Cardozo, L., Fall, M., Griffiths, D., Rosier, P., Ulmsten, U., van Kerrebroeck, P., Victor, A., Wein, A. (2002). The standardisation of terminology of lower urinary tract function: Report from the standardisation sub-committee of the International Continence Society. Neurourology and Urodynamics, 21, 167-178.

Ajzen, I., \& Fishbein, M. (1980). Understanding Attitudes and Predicting Social Behavior. NJ: Prentice-Hall.

Ajzen, I. (1985). From intentions to actions: a theory of planned behaviour. In Kuhl, J., \& Beckmann, J. (Eds). Action control: Form cognition to behaviour. Berlin: Springer.

Boyington, JEA., Howard, DL., Carter-Edwards, L., Gooden, KM., Erdem, N., Jallah, Y., Busby-Whitehead, J. (2007). Differences in resident characteristics and prevalence of urinary incontinence in nursing homes in Southeastern United States. Nursing Research, 56, 97107.

Colling, J., Ouslander, J., Hadley, B., Eisch, J., Campbell, E. (1992). The effects of patterned urge-response toileting (PURT) on urinary incontinence among nursing home residents. Journal of the American Geriatrics Society, 40, 135-141.

Crooks, VC., Schnelle, JF., Ouslander, JP., McNees, MP. (1995).Use the minimum data set to rate incontinence severity. JAGS, 43, 1363-69.

Deparment of Health (2000). Good practice in continence services. DoH, London.

http://www.dh.gov.uk/en/Publicationsandstatistics/Publications/PublicationsPolicyAndGuidan ce/DH 4005851

DNQP Deutsches Netzwerk für Qualitätsentwicklung in der Pflege (Hrsg.) (2007). Expertenstandard Förderung der Harnkontinenz in der Pflege. Osnabrück: Schriftenreihe des Deutschen Netzwerks für Qualitätsentwicklung in der Pflege.

De Vries, H., Dijkstra, M., Kuhlmann, P. (1988). Self-efficacy the third factor besides attitude and subjective norm as a predictor of behavioural intention. Health Education Research, 3, 273-282.

De Vries, H., Mudde, A., Leijs. I., Charlton, A., Vartiainen, E., Buijs, G., et al. (2003). The European Smoking Prevention Framework Approach (EFSA). An example of integral prevention. Health Education Research, 18, 611-626.

Estabrooks, CA., Floyd, JA., Scott-Findlay, S., O'Leary, KA., Gushta, M. (2003). Individual determinants of research utilization: A systematic review. Journal of Advanced Nursing, 43, 506- 520.

Getliffe, K., \& Dolman, M. (2003). Promoting continence: A clinical and research resource. $2^{\text {nd }}$ ed. Ballière Tindall.

Henderson, JS. Urinary Incontinence Attitude, Belief, Practice and Knowledge Scales. In Nurses' attitude, belief, practice, and knowledge regarding urinary incontinence in adults: LISREL analysis of a model. Unpublished doctoral dissertation, Texas Woman' University, Denton, TX, 1996. 
Henderson, JS., \& Kashka, MS. (2000). Effect of knowledge, attitude, and belief on nurses' practice regards urinary incontinence in adults. Urologic Nursing, 20, 291-305.

Lekan-Rutledge, D. (2000). Diffusion of innovation: A model for implementation of prompted voiding in long-term care setting. Journal of Gerontological Nursing, 26, 25-33.

Polit, DE., \& Beck, CT. (2004). Nursing Research: Principles and methods. 7. ed. Philadelphia: Lippincott Williams \& Wilkins.

Roe, B., Watson, NM., Palmer, MH., Mueller, C., Vinsnes, AG., Wils, M. (2004). Translating research on incontinence into practice. Nursing Research (Supplement,) 53, S56-S60.

Rogers, E.M. (2003). Diffusion of Innovations. $5^{\text {th }}$ ed. New York: The Free Press.

Ryden, MB., Snyder, M., Gross, CR., Savik, K., Pearson, V., Krichbaum, K., et al. (2000). Value-added outcomes: The use of advanced practice nurses in long-term care facilities. The Gerontologist, 40, 654-662.

Saxer, S., Halfens, RJG., De Bie, R., Dassen, T., (2008). Prevalence and incidence of urinary incontinence of Swiss nursing home residents at admission and after 6, 12 and 24. Journal of Clinical Nursing. doi:10.1111/j.1365-2702.2007.02055.x

Segaar, D., Willemsen, MC., Bolman, C., de Vries, H. (2007). Nurse adherence to a minimalcontact smoking cessation intervention on cardiac wards. Research in Nursing \& Health, 30, 429-444.

Schnelle, JF., Alessi, CA., Simmons SF., Al-Sammarai, NR., Beck, JC., Ouslander, JG. (2002). Translating clinical research into practice: A randomized controlled trial of exercise and incontinence care with nursing home residents. Journal of the American Geriatrics Society, 50, 1476-1483.

Sgadari, A., Morris, JN., Fries, BE., Ljunggren, G., Jonsson, PV., DuPaquier, J, et al.(1997). Efforts to establish the reliability of the resident assessment instrument. Age Ageing, 26, 2730 .

Vinsnes, AG., Harkless, GE., Haltbakk, J., Bohm, J., Hunskaar, S. (2001). Healthcare personnel's attitudes towards patients with urinary incontinence. Journal of clinical Nursing, 10, 455-462.

Waltz, CF., Strickland, OL., Lenz, ER. (1991). Measurement in Nursing Research. 2. ed. Philadelphia: F. A. Davis Company.

Welz-Barth, A., Garcia-Schürmann, C., Füsgen, I. (1998). Incontinence, dementia and comorbidity: Predictive factors for need of care and admission to nursing homes. Wiener Medizinische Wochenschrift, 13, 305-308.

Wensing, M., Van der Weijden, T., Grol, R. (1998). Implementing guidelines and innovations in general practice: which interventions are effective? British Journal of General Practice 48, 991-997.

[W001]: http://people.umass.edu/aizen/pdf/tpb.measurement.pdf (10.3.08) 
Summary 


\section{Urinary Incontinence in Nursing Home Care}

Urinary incontinence is defined by the International Continence Society (ICS) as the complaint of any involuntary leakage of urine and is usually subdivided into different types. Involuntary loss of urine is a high prevalent problem, especially in aging adults. Amongst elderly residents of long-term facilities, the prevalence rate of $\mathrm{UI}$ ranges between 49 and $77 \%$. Urinary incontinence is a burden for nursing home residents. It has a negative effect on quality of life and the costs associated with incontinence are considerable. Urinary incontinence substantially increases the risk of hospitalization and the risk of admission to a nursing home. These consequences of urinary incontinence in nursing home residents underscore the necessity of research in this area.

This dissertation project consists of two parts. In the near future, the proportion of the population aged 65 and older will increase in Switzerland, as in other European countries. An increase in handicaps and chronic diseases, and also urinary incontinence is expected. Since data on prevalence rates in Swiss nursing home populations are missing, the first part of the thesis focuses on incontinent nursing home residents, the second part aims at nurses' knowledge, practices, beliefs and attitudes regarding urinary incontinence.

Chapter 2 describes prevalence and incidence of urinary incontinence of Swiss nursing home residents at admission. Special focus was placed on sex- and agerelated differences. With a point prevalence rate of $51.5 \%$, women and men were equally affected by urinary incontinence. Urinary incontinence increased with increasing age (65 - over 95 years). At admission, 36.8\% of residents were incontinent, $33.6 \%$ in the group of women and $43.3 \%$ in the group of men $(p<$ 0.0001 ). No significant difference was found between age groups. The incidence rate of urinary incontinence increased by $15 \%$ over 12 and $26 \%$ over 24 months in both women and men.

Chapter 3 illustrates the risk factors for urinary incontinence in nursing home residents at the time of admission and over time. It was established that the variables 'moving in bed' and 'long term memory' were the most important factors predicting for incontinence at admission and at different time points during the stay in a nursing home. At admission, the odds for urinary incontinence were approximately two times 
higher for somebody who needed assistance moving in bed than for persons without. Six months after admission, the odds were 5.9 times higher and 12 months after admission even 7.7 times higher for residents with 'difficulties in moving in bed' than for persons without. The second important factor was 'deficits in long term memory'. At admission, the odds for incontinence were 1.4 times higher and six months after admission 5.3 times higher for patients with these difficulties than for persons without.

Chapter 4 presents the development and validation of two scales and explored nurses' and nurses assistants' knowledge about urinary incontinence and practice with urinary incontinent residents. The nurses had a mediocre knowledge base and, as expected, the level of knowledge of nurse assistants is even lower than that of nurses. The practice scale was divided in 4 subscales: Drinking habit and excretion, assessment and information, documentation and support. Nurses and nurse assistants performed continence-related actions only 'sometimes' or 'often' at best. Both groups had best results in the subscale 'support' and they had most deficits in 'documentation'. The association between demographic data and knowledge and practice were demonstrated.

Chapter 5 illustrates the translation and validation of Henderson's Urinary Incontinence Attitude and Belief Scales and explored nurses' and nurse assistants' attitude and beliefs. It could be demonstrated that nurses had a positive behavioural and emotional attitude towards urinary incontinence residents. Nurse assistants' behavioural attitude was also positive, but their emotional attitude tended to be negative. Also nurses' and nurse assistants' beliefs were negative. 'Age, education and experience in the field' were strongly associated with behavioural attitude, and only 'education' was strongly associated with emotional attitude. No association was found between 'age, education and experience in the field' and 'beliefs'.

Chapter 6 describes the relationship between knowledge, beliefs, attitude and continence-related practice in a nursing home setting. Findings showed that knowledge and attitude were related to self-reported practice. In contrast, beliefs showed no relation to practice, or to knowledge, or to attitudes. The practice 
subscale, which could best be influenced by knowledge and behavioural attitude, was 'assessment and information' and 'drinking habit and excretion'.

Chapter 7 presents the summary of the main findings and the methodological reflections of the study about prevalence and risk factors as well as a summary of the main findings of the study about nurses' and nurse assistants' knowledge, attitude, beliefs and self-reported practice. The methodological reflection of this study includes mainly the validity and reliability of the questionnaires and the postulated model. This chapter concludes with recommendations for future research and practice. For practice, it is important to start programmes to enhance quality of urinary incontinence care. Important is a detailed urinary incontinence assessment, in order that appropriate interventions can be introduced. For research, additional factors which influenced nurses' practice with urinary incontinent residents had to be identified. Further studies are needed in order to understand the association between the newly-identified factors and practice of urinary incontinence care. A cohort study in which newly-admitted residents are followed for one year could evaluate the prevalence and incidence of urinary incontinence at different time points. Especially important will be the exact time-point at which residents become incontinent. 
Samenvatting 


\section{Urine-incontinentie in de verpleeghuiszorg}

Urine-incontinentie (UI) wordt door de International Continence Society (ICS) gedefinieerd als objectief aantoonbaar ongewild urineverlies, dat een sociaal en/of hygiënisch probleem vormt.

Ongewild urineverlies is een veel voorkomend probleem, in het bijzonder bij oudere volwassenen. Onder oudere bewoners van verpleeghuizen en inrichtingen, ligt de prevalentie van UI tussen de 49 en $77 \%$. Urine-incontinentie heeft een negatief effect op de levenskwaliteit en de ermee gepaard gaande kosten zijn aanzienlijk. Bovendien vergroot $\mathrm{UI}$ het opnamerisico in een verpleeghuis wezenlijk. Derhalve is nader onderzoek naar de invloed van factoren bewoners van verpleeghuizen die lijden aan UI noodzakelijkheid.

Deze dissertatie bestaat uit twee delen.

In de nabije toekomst zal de proportie van mensen ouder dan 65 in Zwitserland en ook in andere Europese landen toenemen. Bij deze populatie wordt een toename van handicaps, chronische ziekten en ook urine-incontinentie verwacht. Omdat exacte gegevens over de preventie van UI in Zwitserse verpleeghuizen ontbreken, ligt de focus van het eerste deel op incontinente bewoners van verpleeghuizen. Het doel van het tweede deel bestaat uit het vergaren van kennis en inzicht over het de kennis en kunde van het verplegend personeel ten aanzien van UI, de dagelijkse uitvoering van hun werkzaamheden, alsmede de attitude en houding van verplegend personeel ten aanzien van personen die lijden aan urine-incontinentie.

Hoofdstuk 2 beschrijft de prevalentie en incidentie van urine-incontinentie bij bewoners van verpleeghuizen ten tijde van de opname, en de daarbij optredende verschillen naar geslacht en leeftijd. De puntprevalentie van UI is voor mannen en vrouwen precies gelijk, namelijk 51.5\%. De prevalentie van UI stijgt met het toenemen van de leeftijd. Bij de opname waren $36.8 \%$ van de bewoners incontinent, $33.6 \%$ van de vrouwen en $43.3 \%$ van de mannen $(p<0.0001)$. Leeftijdsverschillen hadden geen significante invloed. Gedurende 12 maanden en 24 maanden na opname steeg het aantal nieuwe gevallen met $15 \%$ resp. $26 \%$ procent, in gelijke mate voor vrouwen en mannen. 
Hoofdstuk 3 rapporteert omrent de risicofactoren voor urine-incontinentie van bewoners in verpleeghuizen bij opname en in het verloop van de tijd. Er werd vastgesteld dat de variabelen "zich in bed bewegen" en "lange termijn geheugen" de belangrijkste factoren voor het voorspellen van incontinentie bij de opname en bij verschillende tijdpunten gedurende het verblijf in het verpleeghuis waren. Bij opname was de kans voor urine-incontinentie ongeveer dubbel zo hoog bij een persoon die hulp bij het bewegen in bed nodig had als bij een persoon zonder behoefte aan hulp. Zes maanden na de opname was de kans 5.9 hoger en 12 maanden na de opname 7.7 hoger bij bewoners met moeilijkheden "zich in bed te bewegen" als voor personen zonder deze problemen.

Hoofdstuk 4 presenteert de ontwikkeling en validatie van twee schalen en onderzocht de vakkennis van verpleegkundigen en verpleegkundig assistenten met betrekking tot urine-incontinentie en hun dagelijks handelen tegenover incontinente bewoners. De verpleegkundigen hadden een middelmatig kennisniveau; het kennisniveau van de verpleegkundig assistenten was nog lager. De schaal die het dagelijks handelen in kaart bracht bestond uit vier subschalen: Vocht inname en uitscheiding, beoordeling van verkregen informatie, verslaglegging en ondersteuning. De verpleegkundigen en de verpleegkundig assistenten voerden de relevante acties met betrekking tot UI veelal "soms" of in het beste geval "vaak" uit. Beide groepen scoorden het beste op de subschaal "ondersteuning" en schoten het meest tekort in het onderdeel "verslaglegging". Er bestond een duidelijke samenhang tussen demografische gegevens en kennisniveau van het verplegend personeel

Hoofdstuk 5 gaat in op de vertaling en validatie van de schalen die urineincontinentie attitude en overtuiging vastleggen (volgens Henderson). Vervolgens zijn hiermee de attitudes en overtuigingen van de verpleegkundigen en van de verpleegkundig assistenten onderzocht. Verpleegkundigen vertoonden positief gedrag en een positieve emotionele houding tegenover de urine incontinente bewoners. Het gedrag van de verpleegkundig assistenten was óók positief, maar hun emotionele houding tendeerde naar negatief. Overtuigingen van de verpleegkundigen en de verpleegkundig assistenten ten aanzien van $\mathrm{UI}$ waren negatief. "Leeftijd, opleiding en relevante beroepservaring in het UI domein" toonden een sterke samenhang met de houding. De factor "opleiding" vertoonde een sterk 
verband met de emotionele houding. Er kon geen verband tussen "leeftijd, opleiding en relevante beroepservaring in het UI domein" en "overtuigingen" gevonden worden.

Hoofdstuk 6 beschrijt de relatie tussen kennisniveau, overtuigingen, attitude en de voor incontinentie relevante praktijk in het domein van verpleeghuizen. De resultaten laten zien dat kennisniveau en attitude relaties tot de zelf gerapporteerde praktijk hebben. Attitude beïnvloedde kennisniveau en emotionele houding niet. De subschaal die door kennisniveau en attitude het best beïnvloed kon worden was "beoordeling van verkregen informatie" en "vocht inname en uitscheiding".

Hoofdstuk 7 vat de belangrijkste resultaten samen en geeft een methodologische reflectie op het onderzoek. Besproken worden gesignaleerde prevalenties en risicofactoren, evenals een samenvatting van het onderzoek over het kennisniveau, de attitudes, de overtuigingen en de zelf gerapporteerde praktijk van de verpleegkundigen en de verpleegkundig assistenten. De methodologische reflectie van dit onderzoek gaat met name in op de geldigheid en betrouwbaarheid van de vragenlijst en het gehanteerde model. Hoofdstuk zeven sluit af met aanbevelingen voor toekomstig onderzoek en praktijk.

Voor de praktijk is het belangrijk gerichte programma's ter verbetering van de incontinentie zorg op te zetten. Van belang hierbij zijn het aanleren van een nauwkeurige inschatting van de mate urine-incontinentie, om daarna passende interventies aan te kunnen bieden. Aanvullende factoren die een invloed op verpleegkundige zorg van bewoners met urine-incontinentie hebben moeten in nieuw onderzoek vastgesteld worden. Tevens is aanvullend onderzoek nodig om de samenhang tussen de nieuw vastgestelde factoren en de praktijk van de incontinentie te kunnen interpreteren. Een cohort onderzoek waarin prevalentie en incidentie van de urine-incontinentie bij nieuw opgenomen bewoners gedurende één jaar worden gevolgd zou meer inzicht in de precieze ontwikkeling van UI en de daarbij van belang zijnde factoren kunnen opleveren. 
Zusammenfassung 


\section{Urininkontinenz im Pflegeheim}

Die internationale Continence Society (ICS) definiert Urininkontinenz als unfreiwilligen Urinverlust. Vor allem bei alten Menschen kommt Urininkontinenz häufig vor, Prävalenzraten von $49-77 \%$ wurden festgestellt. Urininkontinenz ist eine belastende Situation für die Betroffenen. Die Lebensqualität wird negativ beeinflusst, und die durch Urininkontinenz entstandenen Kosten sind gross. Urininkontinenz erhöht auch das Risiko für eine Spitaleinweisung oder einen Pflegeheimeintritt. Die häufig vorkommende Urininkontinenz und deren Folgen unterstreichen die Wichtigkeit von Forschung in diesem Gebiet.

Das Dissertationsprojekt beinhaltet zwei Forschungsprojekte. Im ersten Projekt stehen die Prävalenz und Inzidenz von Urininkontinenz der Pflegeheimbewohnerinnen und -bewohner im Fokus, denn in der Schweiz fehlen Prävalenz- und Inzidenzraten von Urininkontinenz. Im zweiten Forschungsprojekt wird das Wissen, die Praxis sowie die Meinung und Haltung der Pflegenden gegenüber urininkontinenten PflegeheimbewohnerInnen untersucht.

Das 2. Kapitel beschreibt die Prävalenz und Inzidenz der Urininkontinenz von Pflegeheimbewohnerinnen und -bewohnern. Ein spezieller Fokus lag bei den verschiedenen Altersgruppen und dem Geschlecht. Die Punkte-Prävalenz lag bei $51.5 \%$, Frauen und Männer waren gleich häufig von Urininkontinenz betroffen. Beim Eintritt waren $36.8 \%$ der Pflegeheimbewohnerinnen und -bewohner (Frauen: 33.6\%, Männer: 43.3\%) von Urininkontinenz betroffen. Beim Eintritt konnten keine signifikanten Unterschiede zwischen den Altersgruppen gefunden werden. Die Inzidenzrate nimmt um 26\% während den ersten zwei Jahren nach dem Pflegeheimeintritt zu, 15\% alleine schon im ersten Jahr.

Das 3. Kapitel zeigt die Risikofaktoren der Urininkontinenz bezüglich Mobilität und kognitiven Fähigkeiten bei PflegeheimbewohnerInnen zum Zeitpunkt des Eintrittes und im Verlaufe der Zeit auf. Als wichtigste Faktoren wurden ,Bewegen im Bett' und ,Langzeitgedächtnis' identifiziert. Beim Eintritt war die Odds für Inkontinenz ungefähr 2 Mal, sechs Monate später 5.9 Mal und 12 Monate später 7.7 Mal höher bei Bewohnerlnnen mit Einschränkungen beim Bewegen im Bett als bei solchen ohne. Der zweitwichtigste Faktor war ,Langzeitgedächtnis'. Beim Eintritt war die Odds für 
Inkontinenz 1.4 Mal und sechs Monate später 5.3 Mal höher bei PatientInnen mit Schwierigkeiten mit dem Langzeitgedächtnis als bei solchen ohne.

Das 4. Kapitel präsentiert die Entwicklung und Validierung von zwei Messinstrumenten über das Wissen und die Praxis der Pflegefachpersonen und PflegeassistentInnen mit urininkontinenten Pflegeheimbewohnerlnnen. Die Pflegefachpersonen haben ein mittelmässiges Wissen über Urininkontinenz; das Wissen der PflegeassistentInnen ist erwartungsgemäss tiefer. Das Messinstrument der Praxis wurde eingeteilt in vier Unterskalen: Drinkgewohnheiten und Ausscheidung, Assessment und Information, Dokumentation und Unterstützung. Pflegefachpersonen und PflegeassistentInnen führten Pflegehandlungen mit urininkontinenten Bewohnerlnnen ,manchmal' oder ,oft' durch. Die Pflegefachpersonen und PflegeassistentInnen erzielten innerhalb der Subskala ,Unterstützung' die besten Resultate; die meisten Defizite wurden bei der Subskala ,Dokumentation' festgestellt. Assoziationen zwischen den demografischen Daten und dem Wissen und der Praxis der Pflegenden wurden dargestellt.

Das 5. Kapitel zeigt die Übersetzung und Validierung von Henderson's Urinary Incontinence Attitude and Belief Scale und exploriert die Meinung (beliefs) und die Haltung (attitude) der Pflegefachpersonen und PflegeassistentInnen. Es konnte gezeigt werden, dass die Pflegefachpersonen eine positive Haltung (behavioural und emotional) gegenüber urininkontinenten Pflegeheimbewohnerlnnen haben. Die PflegeassistentInnen zeigten ebenfalls eine positive behaviourale Haltung gegenüber urininkontinenten PflegeheimbewohnerInnen, jedoch eine negative emotionale Haltung. Die Meinung (belief) der Pflegefachpersonen und PflegeassistentInnen gegenüber urininkontinenten Heimbewohnerlnnen war negativ. Das Alter, die Ausbildung und die Erfahrung zeigten einen signifikanten Zusammenhang mit der behaviouralen Haltung, jedoch ausschliesslich die Ausbildung zeigte einen signifikanten Zusammenhang mit der emotionalen Haltung. Keine Zusammenhänge konnten festgestellt werden zwischen der Meinung der Pflegenden und ihrem Alter, ihrer Ausbildung und ihrer Erfahrung.

Das 6. Kapitel beschreibt die Zusammenhänge zwischen dem Wissen, der Meinung und der Haltung mit der Praxis der Pflegenden. Die Resultate zeigten signifikante 
Zusammenhänge zwischen dem Wissen und der Haltung mit der Praxis. Im Unterschied dazu ist die Meinung der Pflegenden nicht assoziiert mit der Praxis der Pflegenden bei urininkontinenten Pflegeheimbewohnerlnnen. Die Subskalen ,Assessment und Information' und ,Drinkgewohnheiten und Ausscheidung' können mit ,Wissen' und ,behaviouraler Haltung' beeinflusst werden.

Das 7. Kapitel präsentiert die wichtigsten Resultate und eine methodologische Reflektion der Untersuchung über Prävalenz, Inzidenz und Risikofaktoren. Anschliessend folgen die wichtigsten Ergebnisse der zweiten Studie über das Wissen, die Praxis, die Haltung und Meinung der Pflegefachpersonen und PflegeassistentInnen. Die methodologische Reflektion dieser Studie beinhaltet vor allem die Reflektion über Validität und Reliabilität der Fragebogen und über das Modell. Das Kapitel schliesst mit Empfehlungen für weitere Forschungsprojekte und für die Praxis ab. In der Praxis ist es wichtig, dass die Qualität der Pflege von urininkontinenten Menschen verbessert wird. Wichtig dabei sind detaillierte Assessments, um dann gezielte Interventionen einleiten zu können. In der Forschung sollen weitere Faktoren, welche die Praxis der Pflegenden mit urininkontinenten BewohnerInnen beeinflussen, erfasst werden. Weitere Untersuchungen sind notwendig, um die Assoziationen zwischen den neu identifizierten Faktoren und der Praxis mit urininkontinenten BewohnerInnen zu identifizieren. Eine Kohortenstudie mit neu eintretenden PflegeheimbewohnerInnen, die über mindestens ein Jahr beobachtet werden können, sollte die Prävalenz und Inzidenz der Urininkontinenz an verschiedenen Zeitpunkten untersuchen. Wichtig ist dabei, den exakten Zeitpunkt festzustellen, wann die kontinenten BewohnerInnen inkontinent werden. 


\section{Acknowledgements}

I wish to express my thanks to numerous persons and institutions for their help and support during this project. I would like to thank my supervisors, Professor Dr. Rob A. de Bie (Universiteit Maastricht), Professor Dr. Theo Dassen (Humboldt University of Berlin) and Associate Professor Ruud JG. Halfens (Universiteit Maastricht) for their expertise, support, constructive criticism and their patience.

Furthermore, I thank Professor Dr. Marianne Müller (University of Applied Science Winterthur, Switzerland) for the statistical support and Dr. Joanne Eysell (Freiburg, Germany) for the English correction.

Great thanks also go to Sivia Schmid, Horst Rettke und Harry Hulskers. Discussions with them were great support and help.

Many thanks go also to numerous nursing homes, nurses and nurse assistants who participated in the study and care daily for the incontinent residents.

Finally, I am greatly indebted to my partner Mado for her support and encouragement during all stages of this endeavour. This thesis would never have been completed without her. 


\section{Curriculum vitae}

Susanne Saxer was born in Sargans, Switzerland, on $7^{\text {th }}$ May 1953. In 1980 , she completed her professional training in nursing care at the nursing school in Winterthur, Switzerland. In the following years, she worked as a nurse in different units and as a head of a medical ward at the Kantonsspital in Winterthur. In 1987 she achieved her diploma as a teacher at the post-graduate school in Aarau. From 1987 till 1990, she was a teacher at the Nursing School, Zurich. After that she worked as a tutor and nurse in the surgical and rehabilitation units of the University Hospital Zurich (Aussenstation Hegibach). From 1993, after her training as a clinical nursing expert in WE'G Institute for Post Diploma Education in Health Professions, Aarau, Switzerland, she worked as a tutor and project leader and as a head of the HöFa II program in the Institute for Post Diploma Education in Health Professions, Aarau.

From 1996 to 1999, she completed her Master's degree in Nursing Science at the Universiteit Maastricht, The Netherlands and the University of Applied Sciences in Aarau, Switzerland.

Since 2006, she has worked as a project leader responsible for the development of a Master of Advanced Studies in Geriatric Nursing, as teacher for nursing science and as a researcher at the WE'G, University of Applied Sciences, Aarau.

She started the studies described in this thesis in 2002. 